\title{
Proanthocyanidins and Where to Find Them: A Meta-Analytic Approach to Investigate Their Chemistry, Biosynthesis, Distribution, and Effect on Human Health
}

\author{
Giuseppe Mannino $^{1}\left(\mathbb{D}\right.$, Giorgia Chinigò ${ }^{2,+}{ }^{\text {, Graziella Serio }}{ }^{3,+}{ }^{\text {, Tullio Genova }}{ }^{2} \mathbb{D}$, Carla Gentile ${ }^{3, * \mathbb{D}}$, \\ Luca Munaron ${ }^{2, \ddagger(\mathbb{D})}$ and Cinzia Margherita Bertea ${ }^{1, \ddagger(\mathbb{D})}$
}

1 Plant Physiology Unit, Department of Life Sciences and Systems Biology, University of Turin, Via Quarello 15/A, 10135 Turin, Italy; giuseppe.mannino@unito.it (G.M.); cinzia.bertea@unito.it (C.M.B.)

2 Department of Life Sciences and Systems Biology, University of Torino, Via Accademia Albertina 13, 10123 Turin, Italy; giorgia.chinigo@unito.it (G.C.); tullio.genova@unito.it (T.G.); luca.munaron@unito.it (L.M.)

3 Department of Biological, Chemical and Pharmaceutical Sciences and Technologies (STEBICEF), University of Palermo, Viale delle Scienze, 90128 Palermo, Italy; graziella.serio01@unipa.it

* Correspondence: carla.gentile@unipa.it

+ These authors contributed equally to this work.

$\ddagger$ These authors are both last-authors.

\section{check for} updates

Citation: Mannino, G.; Chinigò, G.; Serio, G.; Genova, T.; Gentile, C.; Munaron, L.; Bertea, C.M. Proanthocyanidins and Where to Find Them: A Meta-Analytic Approach to Investigate Their Chemistry, Biosynthesis, Distribution, and Effect on Human Health. Antioxidants 2021, 10, 1229. https:// doi.org/10.3390/antiox10081229

Academic Editor: Stefania D'Angelo

Received: 25 June 2021

Accepted: 27 July 2021

Published: 30 July 2021

Publisher's Note: MDPI stays neutral with regard to jurisdictional claims in published maps and institutional affiliations.

Copyright: (c) 2021 by the authors. Licensee MDPI, Basel, Switzerland. This article is an open access article distributed under the terms and conditions of the Creative Commons Attribution (CC BY) license (https:// creativecommons.org/licenses/by/ $4.0 /)$.
Abstract: Proanthocyanidins (PACs) are a class of polyphenolic compounds that are attracting considerable interest in the nutraceutical field due to their potential health benefits. However, knowledge about the chemistry, biosynthesis, and distribution of PACs is limited. This review summarizes the main chemical characteristics and biosynthetic pathways and the main analytical methods aimed at their identification and quantification in raw plant matrices. Furthermore, metaanalytic approaches were used to identify the main plant sources in which PACs were contained and to investigate their potential effect on human health. In particular, a cluster analysis identified PACs in 35 different plant families and 60 different plant parts normally consumed in the human diet. On the other hand, a literature search, coupled with forest plot analyses, highlighted how PACs can be actively involved in both local and systemic effects. Finally, the potential mechanisms of action through which PACs may impact human health were investigated, focusing on their systemic hypoglycemic and lipid-lowering effects and their local anti-inflammatory actions on the intestinal epithelium. Overall, this review may be considered a complete report in which chemical, biosynthetic, ecological, and pharmacological aspects of PACs are discussed.

Keywords: polyphenols; proanthocyanidins; cluster analysis; forest plot; ecology; hyperglycemia; hyperlipidemia; cholesterol; inflammation; metabolic disorders

\section{Introduction}

It has repeatedly been shown that diet and physical/psychological well-being are closely linked. Moreover, the World Health Organization (WHO) states that nutrition and health are two fundamental and interconnected human rights [1]. Having a healthy and balanced diet not only provides energy and essential nutrients for growth and sustenance, but it is the main factor that actively influences and improves individual health status [2]. In this context, scientific evidence has shown that the intake of plant foods is closely related to the decrease of "civilization disease" incidences, such as neoplasms, diabetes, and several forms of dyslipidemia [3-5]. The potential beneficial effects derived from plant food consumption against these pathologies is related to the nutritional aspects of food as well as to the phytochemical profiles. Indeed, plants are the main sources of biologically active compounds that may exert a wide range of potential pharmacological activities [6,7].

The bioactive phytocomponents constitute a heterogeneous family of compounds, mainly without a nutritional role, but with high beneficial effects on human health. Al- 
though characterized by a high structural diversity, all of the phytochemical compounds peculiar to the plant kingdom generally have a low molecular weight, and as products of the plant secondary metabolism, they are not essential for the survival of the producer organism. Plants biosynthesize secondary metabolites to fulfil some physiological needs, such as the defense against herbivorous predators, pathogens, or insects, an interspecific competition with other plants, or to facilitate reproductive processes [8].

Although many plant bioactive compounds have been extensively investigated in the past, and are almost fully understood, others are still partially unknown from the functional point of view. In particular, proanthocyanidins (PACs) are still under investigation because many aspects related to their chemistry, biosynthesis, distribution, and role in plants and animals is still unknown. In particular, despite the fact that PACs derive from the condensation of at least two flavan-3-ol subunits, it is still unclear how the qualitative selection of the single monomers occurs. Moreover, to date, the mechanisms and reasons why plants preferably condense two flavan-3-ols through a single (B-type) or a double (B-type) bond, to form PACs, are not completely elucidated. From a biosynthetic point of view, although the pathways for PAC production is partly superimposable to that of other polyphenols, some aspects still remain only hypothesized, including the process of polymerization as well as the transport in plant vacuole. In addition, a detailed distribution of PACs in the plant kingdom has not been reported in the literature to date. Finally, many potential bioactivities of PACs in both plants and animals remain unknown, and those already investigated have been exclusively associated with their active redox properties $[9,10]$. However, not all of the demonstrated pharmacological activities can be explained through this action mechanism.

The aims of this review are to (i) elucidate the chemical structure of PACs; (ii) describe the biosynthetic pathways of PACs, highlighting what is currently unknown; (iii) use a meta-analytic approach to study the distribution of PACs in the plant kingdom; (iv) describe the ecological and physiological role of PACs in plants; (v) investigate the potential implications for human health due to the consumption of foods rich in PACs; (vi) use a meta-analytic approach to investigate a new potential action of PACs as glucose and cholesterol lowering agents.

\section{Chemistry}

From a chemical point of view, PACs are oligomers or polymers resulting from the condensation of two or more 2-phenyl-3,4-dihydro-2H-chromen-3-ol (flavan-3-ol) units, which are composed of two aromatic benzyl rings joined by three carbon atoms that form an oxygenated heterocyclic ring (C6-C3-C6) (Figure 1A). In this context, oligomers derive from the condensation of 2-5 flavan-3-ol units, meanwhile polymers are much larger and derived by the condensation of 6-60 units [11-13]. Unlike other flavonoids, flavan-3-ols and, consequently PACs, have saturated A-ring and, hence, are non-planar molecules [14].

Structurally, PACs may differ from each other in regard to (i) the number and position of hydroxyl groups linked to the aromatic rings (or B-ring); (ii) the stereochemistry of flavonol heterocycle (or C-ring); (iii) the type of linkage among the different units. According to the number and position of hydroxyl groups, three main PACs may be identified: propelagordins (having a hydroxyl group alone); procyanidins (having two hydroxyl groups), and prodelphinidins (having three hydroxyl groups) (Figure 1B). The reason why these molecules have these names is due to the fact that, in an acid environment, they may be hydrolyzed, following the formation of the corresponding anthocyanins [15]. The generated compounds, differently from the original oligomers or polymers, have a characteristic color ranging between red and blue [15]. Concerning the flavan-3-ol ring, since three carbons $\left(\mathrm{C}_{2}, \mathrm{C}_{3}\right.$, and $\left.\mathrm{C}_{4}\right)$ of the heterocycle are asymmetric, they may present different configurations. At the beginning, it was assumed that the $\mathrm{C}_{2}$ configuration could be exclusively in R. However, although this configuration is certainly the most common in nature, other PACs composed of flavan-3-ols having $C_{2}$ in $S$, have been detected $[16,17]$. When $C_{2}$ presents a configuration in $R$, the prefix "ent-" is added to the nomenclature 
of the molecules. Additionally, the stereochemistry of $C_{3}$ may exist both as $3 R$ or 3S. Consequently, four different conformations are possible (2R,3R, 2R,3S, 2S,3R, and 2S,3S). When $C_{2}$ and $C_{3}$ have substituents spatially oriented in the same direction (2R, 3R or $2 S, 3 S$ ), the suffix "-epi" is added to the nomenclature. Moreover, because the orientation of $\mathrm{C}_{3}$ influences the optical rotation, the suffix " $(+)$ "is assigned to flavan-3-ols with $3 S$ configuration, meanwhile " $(-)$ " is assigned to those having $3 R$ configuration. Consequently, the (+)-epi-flavan-3-ols, (-)-epi-flavan-3-ols, (+)-flavan-3-ols, (-)-flavan-3-ols of a same molecule can exist (Figure 1C). Finally, the bond at $\mathrm{C}_{4}$ is always trans, with respect to the hydroxy group at $C_{3}$ and, fortunately, this does not further complicate the nomenclature of these molecules $[11,18]$. The most famous example of this condition is represented by the catechin, which has been detected and identified in all four different forms (Figure 1C). In order to form a PAC, each flavan-3-ol unit is linked to another unit through $\mathrm{C}-\mathrm{C}$ and/or $\mathrm{C}-\mathrm{O}$ bonds $[12,17,19]$. The most usual linkages are $\mathrm{C}-\mathrm{C}$ bonds established between the $\mathrm{C}_{4}$ of one flavan-3-ol unit and $\mathrm{C}_{8}$ or $\mathrm{C}_{6}$ of another (Figure $2 \mathrm{~A}$ ).

A

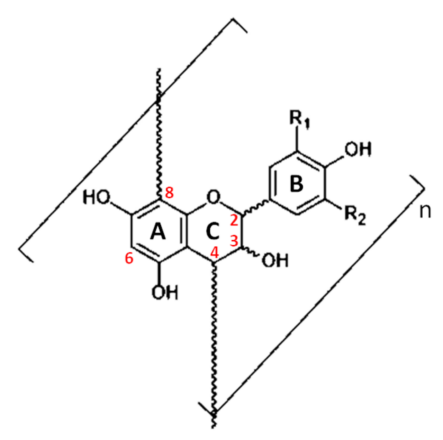

B

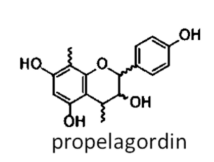

C
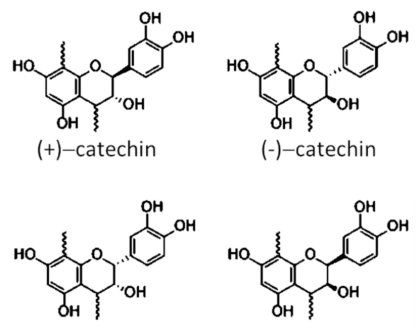

(+)-epicatechin
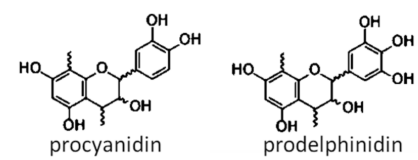

Figure 1. Chemical structures of some PAC monomers. Panel (A) shows the general chemical structure of flavan-3-ol monomers; Panel (B) shows a monomer of propelagordin, procyanidin, and prodelphinidin, which differ from each other in regard to the number and/or position of hydroxyl groups on the B-ring; Panel (C) shows the chemical structure of catechin and epicatechin, along with the respective enantiomers, which are different from each other in regard to the stereochemistry of flavonol heterocycle.

A

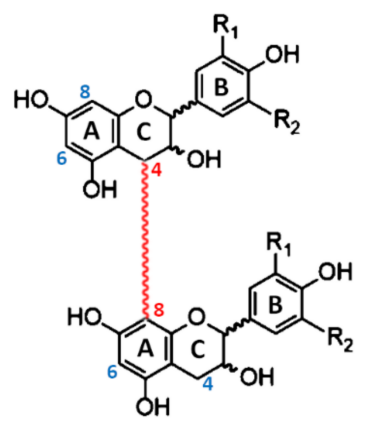

B-type PACs

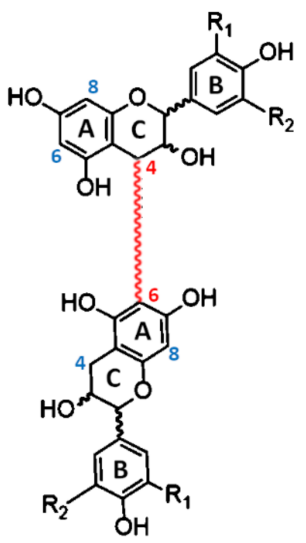

B A-type PACs

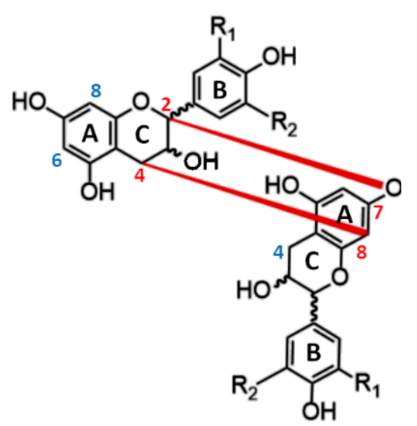

Figure 2. Linkage (red) that allows the polymerization of two monomers of flavan-3-ols, leading to the formation of B-type (A) or A-type (B) PACs. 
In this case, proanthocyanidins take the name of B-type. However, when the linkage between two units occurs, the hydroxyl group linked to the C-ring of each flavan-3-ol can be in either $\mathrm{S}$ or in R. Consequently, four different B-type PACs can be formed from $\mathrm{C}_{4}-\mathrm{C}_{8}$ linkages (B1-B4), and another four from $\mathrm{C}_{4}-\mathrm{C}_{6}$ (B1-B8) (Figure 3). Moreover, $\mathrm{C}-\mathrm{O}$ bounds between $\mathrm{O}_{7}$ of one flavan-3-ol unit and $\mathrm{C}_{2}$ of another one can be established [20]. In this case, the PAC is named A-type (Figure 2B). For the same reasons previously described, in this case, four typologies of A-type PACs can be formed (Figure 4).
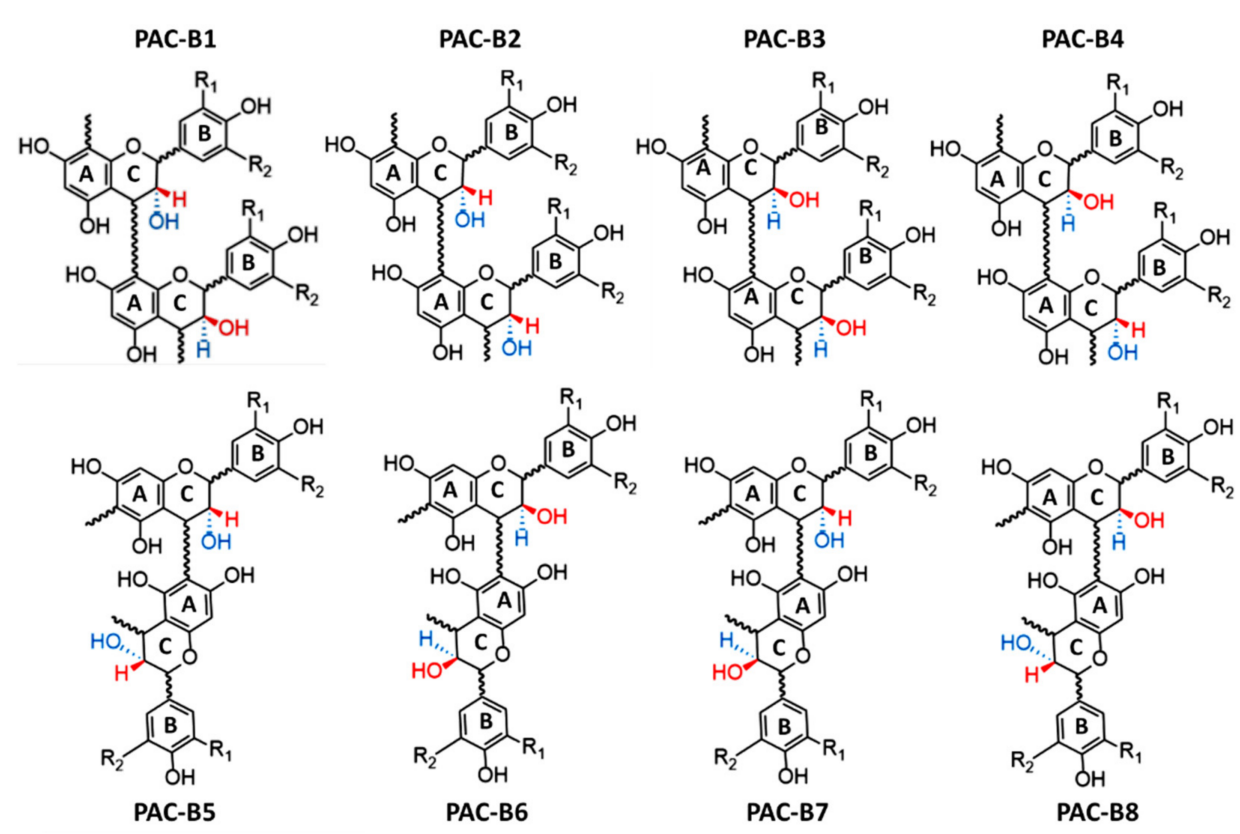

Figure 3. Chemical structures of the different B-type PACs, depending on the stereochemistry of substituents. The blue dashed line represents bonds that "sink" below the plane of the sheet, while the red wedged line indicates a chemical bond that is directed towards the observer.

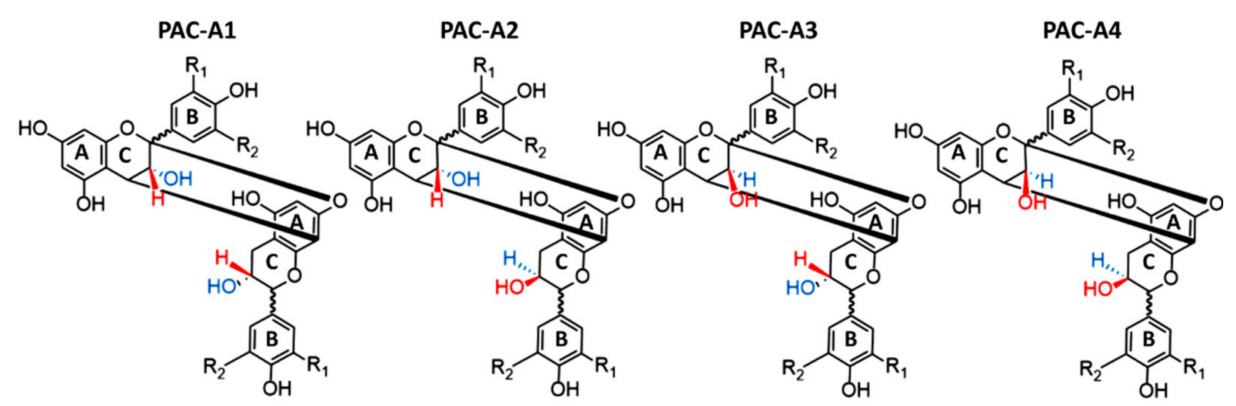

Figure 4. Chemical structures of the different A-type PACs depending on the stereochemistry of substituents. The blue dashed line represents bonds that "sink" below the plane of the sheet, while the red wedged line indicates a chemical bond that is directed towards the observer.

\section{Biosynthesis, Transport, and Polymerization}

\subsection{Biosynthesis of Proanthocyanidins}

The biosynthesis of flavan-3-ols, the PAC precursors, is a long and complicate process involving three different pathways (shikimate, phenylpropanoid, and flavonoid pathways) and about 20 different enzyme-catalyzed reactions (Figures 5 and 6) that occur on the cytosolic face of the endoplasmic reticulum (ER) of plant cells [21,22]. Therefore, the precursor units are transported into the vacuole where polymerization process probably takes place, leading to the formation of PACs $[23,24]$. 


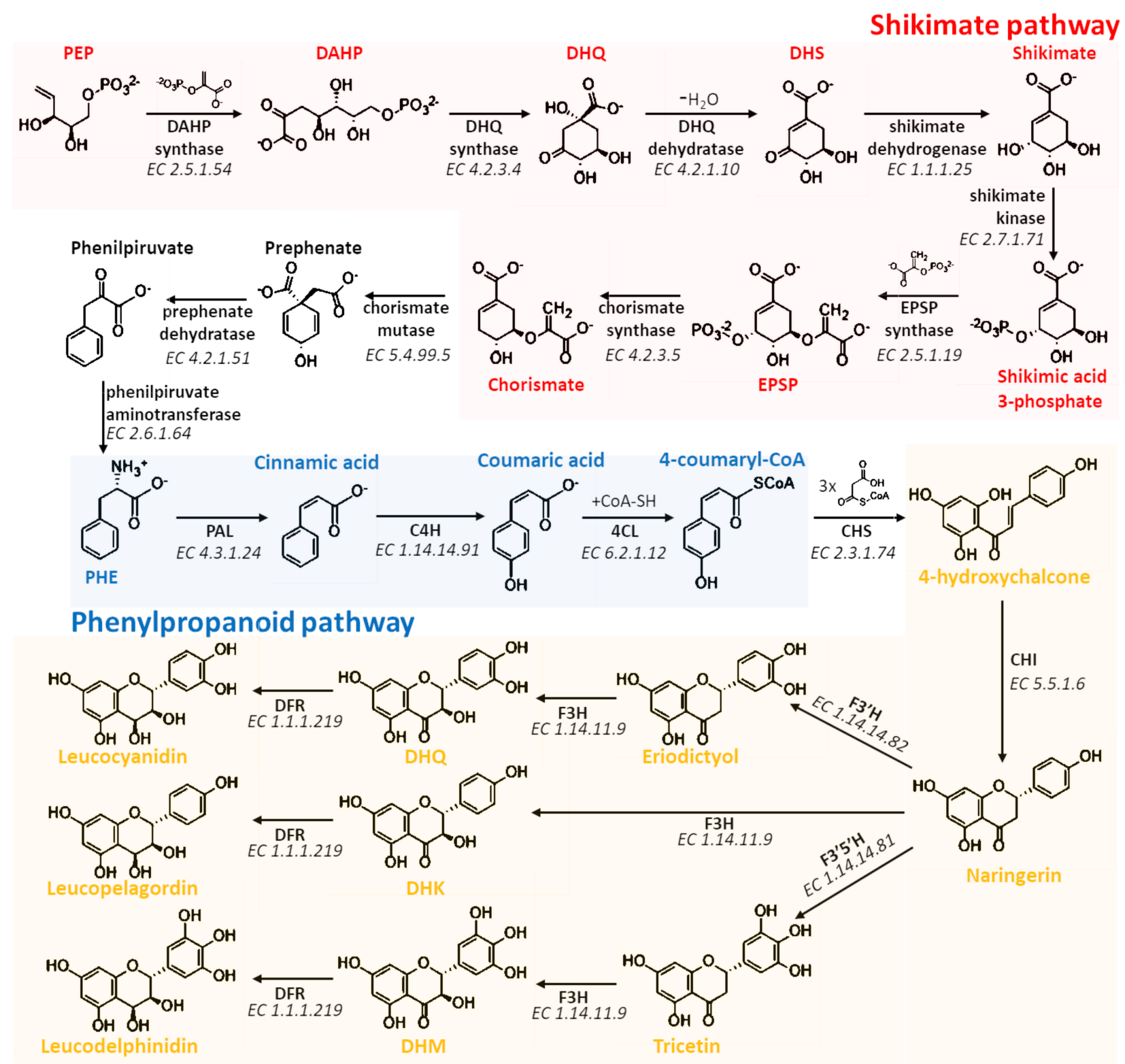

\section{Flavonoid pathway}

Figure 5. Biosynthetic pathway involved in the synthesis of leucoanthocyanidins, the key precursor compounds of flavan-3-ols. The pathway involves the shikimate (Red), phenylpropanoid (Blue), and flavonoid (Yellow) pathways.

The shikimic acid pathway consists of seven different metabolic steps that allow the biosynthesis of folates and aromatic amino acids, such as phenylalanine, tyrosine, and tryptophan $[22,25]$. The first reaction of this pathway is catalyzed by the 3-deoxy-Darabinoheptulosonate 7-phosphate (DAHP) synthase (EC 2.5.1.54), which, starting from phosphoenolpyruvate (PEP) and erythrose-4-phosphate, leads to the formation of DAHP. DAHP is then converted into 3-dehydroquinate (DHQ) in a reaction catalyzed by the DHQ synthase (EC 4.2.3.4) that uses an NAD molecule as a cofactor. The subsequent two reactions involve the removal of a water molecule via the DHQ dehydratase (EC 4.2.1.10) using NADPH as a cofactor and forming 3-dehydroshikimate (DHS), and the reduction of the carbonyl group to the hydroxyl group by the activity of the shikimate dehydrogenase (EC 1.1.1.25) that allows the formation of shikimate. Therefore, shikimate is phosphorylated in position three by the shikimate kinase (EC 2.7.1.71), and condensed with 5-enolpyruvylshikimate-3-phosphate (EPSP) by the EPSP synthase (EC 2.5.1.19). The last reaction of the shikimate pathway, catalyzed by the chorismate synthase (EC 4.2.3.5), con- 
verts EPSP in chorismate that is the fundamental intermediate for the production, not only of all aromatic amino acids, but also of other non-amino acid aromatic compounds. However, in order to achieve the biosynthesis of PACs, it is necessary that chorismate is transformed into phenylalanine. Consequently, chorismate mutase (EC 5.4.99.5) catalyzes a Claisen rearrangement forming prephenate, which in turn is both decarboxylated in phenylpyruvate by the prephenate dehydratase (EC 4.2.1.51) and transaminated in phenylalanine (PHE) by the phenylpyruvate aminotransferase (EC 2.6.1.64) that transfers the amino group from a molecule of glutamic acid [25].

2R,3S-flavan-3-ols

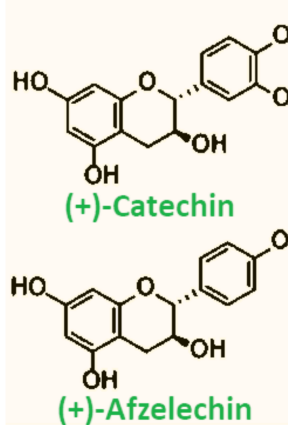

$\mathrm{OH}$

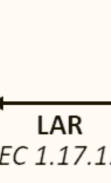

\section{H}

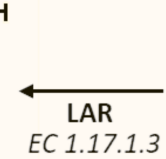
EC 1.17.1.3

(+)-Afzelechin<smiles>CCOc1cc(O)cc2c1CC(O)CCO2</smiles>

(+)-Gallocatechin
EC 1.17.1.3

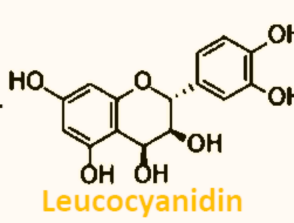<smiles>CC(Oc1ccc(O)cc1)c1ccc(O)cc1</smiles>

$\mathrm{OH}$

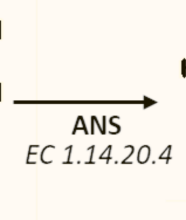<smiles>Oc1cc(O)c(-c2ccc(O)c(O)c2)c(O)c1</smiles>

2R,3R-flavan-3-ols<smiles>Oc1cc(O)c2c(c1)OC(c1ccc(O)c(O)c1)C(O)C2</smiles>

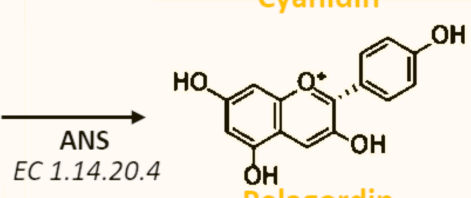

Pelagordin

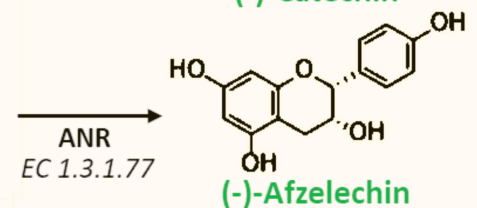

\section{Flavonoid pathway}
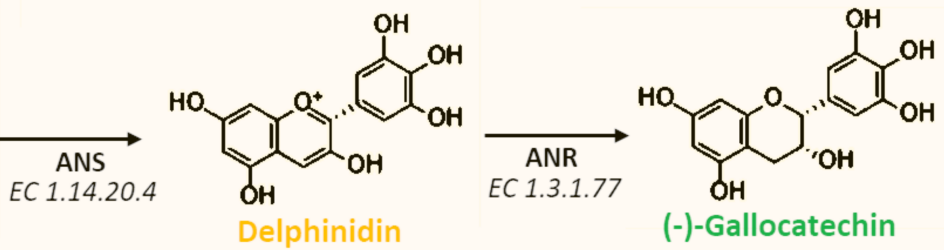

Figure 6. Biosynthetic reactions leading to the formation of 2R,3S-flavan3-ols or 2R,3R-flavan3-ols from the respective leucoanthocyanidin.

The four subsequent reactions are part of the phenylpropanoid pathway and allow the transformation of PHE into 4-hydroxychalcone, the key molecule at the beginning of the flavonoid pathway. This series of chemical reactions is made possible thanks to the activity of four cytosolic enzymes associated in a single multi-enzymatic complex anchored to the cellular RE through a N-terminal domain of one of these enzymes [26]. In particular, phenylalanine ammonia-lyase (PAL) (EC 4.3.1.24) cleaves the carbon-nitrogen bond of PHE using 4-methylideneimidazole-5-one (MIO) as a cofactor, and then converts it into trans-cinnamic acid. The previously formed cinnamic acid is then processed by the trans-cinnamate 4-monooxygenase $(\mathrm{C} 4 \mathrm{H})(\mathrm{EC}$ 1.14.14.91), which is an enzyme belonging to the family of oxidoreductases, and able to add a hydroxyl group in para position of the ring. The last two reactions involve the combined action of 4-coumarate-CoA ligase (4CL) (EC 6.2.1.12) and chalcone synthase (CHS) (EC 2.3.1.74) that condensate and cyclize three malonyl-CoA molecules with 4-coumaroyl-CoA, leading to the formation of 4-hydroxychalcone (or naringenin chalcone) and, thus, starting the flavonoid pathway.

The flavonoid pathway is well known to be highly branched and complex. Indeed, through this pathway, the flavonoid scaffold can be largely modified, leading to the biosynthesis of almost all of the phenolic compounds thus far identified $[27,28]$. Below, the reactions involved in the synthesis of leucoanthocyanidins, the key PAC precursor compounds, will be described. The first step that characterizes this pathway is the isomerization of naringenin chalcone to naringenin, through the action of a ubiquitous enzyme named chalcone isomerase (CHI) (EC 5.5.1.6). Moreover, the isomerization of naringenin chalcone is a spontaneous reaction that could occur without the intervention of any enzyme. However, $\mathrm{CHI}$ stereospecifically directs and highly accelerates the cyclization of naringenin chalcone, thus facilitating and increasing the production yield of this intermediate fundamental for all subsequent biosyntheses [29]. Consequently, since the reaction catalyzed by $\mathrm{CHI}$ is highly 
stereoselective, the production of 2R-naringerin, which might occur from spontaneous isomerization, is drastically reduced [29]. Different enzymes can modify the naringenin, but only flavanone 3-dioxygenase ( $\mathrm{F} 3 \mathrm{H})\left(\mathrm{EC}\right.$ 1.14.11.9), flavonoid $3^{\prime}$-monooxygenase $\left(\mathrm{F}^{\prime} \mathrm{H}\right)$ (EC 1.14.14.82), and flavonoid $3^{\prime}, 5^{\prime}$-hydroxylase $\left(\mathrm{F}^{\prime} 5^{\prime} \mathrm{H}\right)(\mathrm{EC}$ 1.14.14.81) lead to the synthesis of flava-3-ol compounds. These three enzymes are oxidoreductases that selectively add one or two hydroxyl groups to naringenin. In particular, $\mathrm{F}^{\prime} \mathrm{H}$ and $\mathrm{F}^{\prime} 5^{\prime} \mathrm{H}$ add one or two hydroxyl groups to the B-ring of the flavanone scaffold leading to the formation of eriodictyol or tricetin, respectively. On the other hand, $\mathrm{F} 3 \mathrm{H}$ adds a hydroxyl group to the C-ring of eriodictyol, tricetin, or naringenin leading to the biosynthesis of dihydroquercetin (DHQ), dihydromyricetin (DHM), or dihydrokaempferol (DHK), respectively. Moreover, since the reaction catalyzed by $\mathrm{F} 3 \mathrm{H}$ is highly stereoselective, in this case, the formation of 3R-flavonols is limited [8,30]. If from a biosynthetic point of view F3H is fundamental for the formation of flavan-3-ols, F3' $\mathrm{H}$ and F3'5' $\mathrm{H}$ are two very important enzymes for the variability of PACs within plants. Indeed, the presence or absence of the gene sequences coding for these two enzymes strongly influence the hydroxylation pattern of B-rings of flavan-3-ols that will constitute the PACs as monomers [31-33].

The last step before the formation of leucoanthocyanidins involves the reduction of dihydroflavonols (DHQ, DHM, and DHK) by the action of the dihydroflavonol 4-reductase (DFR) (EC 1.1.1.219). This enzyme also belongs to the oxidoreductase family, but, unlike the previous ones, it simply reduces the ketone group in $\mathrm{C}_{4}$ of the $\mathrm{C}$-ring to hydroxyl group. For this reason, leucoanthocyanidins are also known as flavan-3,4-diols.

At this point, leucocyanidin, leucopelargonidin, and leucodelphinidin can be converted into their respective anthocyanins by the anthocyanidin synthase (ANS) (EC 1.14.20.4) (Figure 6). This reaction allows the formation of the key compounds that may alternatively enter into biosynthetic pathway of anthocyanins, in which the anthocyanin scaffold may be further modified through different enzymatic modifications, including methylation, acetylation, and glycosylation $[15,33]$. However, anthocyanins may be converted into the respective colorless $2 \mathrm{R}, 3 \mathrm{R}$-flavan-3-ols by the double reduction operated by the anthocyanidin reductase (ANR) (EC 1.3.1.77). Moreover, since this enzyme is able to saturate the cationic C-ring of the anthocyanin scaffold, it strongly stabilizes the molecules from a chemical point of view. In another pathway branch, leucoanthocyanidins can alternatively be converted into 2R,3S-flavan-3-ols by the leucoanthocyanidin reductase (LAR) (EC 1.17.1.3) without going through the anthocyanidin intermediate (Figure 6). Moreover, this last reaction is very important as it explains the occurrence of PACs and anthocyanins in plants from a phylogenetic point of view. Indeed, plants lacking ANS and ANR are able to produce PACs, but not anthocyanins; plants lacking LAR and ANR are able to produce anthocyanins, but not PACs; meanwhile plants having all the previously reported enzymes are able to produce both PACs and anthocyanins. Moreover, in this latter case, PACs may be composed by both 2R,3S and 2R,3R flavan-3-ols [33].

\subsection{Transport of Proanthocyanidins}

As previously mentioned, once the precursor units are formed, they are transported into the vacuole where the polymerization process probably takes place, leading to the formation of PACs $[19,34]$. Several studies have been performed with the aim to identify and describe the mechanism related to the transport of PAC precursors from the RE cytosolic face to plant vacuole, but until now, a precise transport mechanism of individual flavan-3-ol monomers has not been well identified [19,35-37]. However, several hypotheses have been proposed. (i) Since the RE surface is actively involved in the synthesis of PAC precursors, it has been proposed that vesicles budded from rough RE (RER) may be involved [36-39]. In this case, the vesicles may transport the flavan-3-ols to the cis-face of the Golgi apparatus, where their contents could be released into lumen. Here, the molecules may be transported across the trans-face of the Golgi, chemically marked and consequently sent to the vacuole. This process, known as the trans-Golgi network, is typical of both animal and plant cells for the intracellular transport, not only of primary, but also of secondary metabolites [36,37]. 
(ii) A second potential transport mechanism of flavan-3-ols involves glutathione $\mathrm{S}$ transferase (GST) mediated transport (GST-mT). GSTs are enzymes known to be associated with detoxification and antioxidant processes in both animals and plants [40,41]. In this context, they are able to conjugate the glutathione (GSH) to electrophilic and lipophilic compounds increasing their hydrophilicity and, consequently, facilitating their elimination. Nevertheless, other functions for GSTs have been suggested, such as their contribution to sequestration and intracellular transport of secondary metabolites, including anthocyanins [36,37]. However, despite that direct contribution of GST in transport to the vacuole of many flavonoids has been proven, no experimental evidences of transport of flavan-3-ols have been reported. However, given the structural similarity of flavan-3-ols to anthocyanins, this transport mechanism has not only been proposed, but also the putative amino acids involved in the interaction GST-flavan-3-ols have been theoretically identified, albeit molecular docking analysis were not performed [36,37]. Recently, Ricardo Pérez-Díaz and colleagues (2016) combined molecular docking with gene expression analysis, giving, for the first time, experimental insights of the transport of PAC precursors mediated by GSTs in grapevine [34]. (iii) Finally, the last potential mechanism for the transport of flavan-3-ols from cytosol to vacuole may be related to ATP binding cassette (ABC), multidrug, and toxic compound extrusion (MATE), and mammalian bilitranslocase (BLT) transporters [24]. These proteins are membrane transporters and, although scientific evidences on their direct involvement for flavan-3-ol transport has not been reported, some experimental results demonstrate that they are actively implicated in the intracellular trafficking of many other active metabolites [24].

\subsection{Polymerization of Proanthocyanidins}

If the transport mechanism from plant cytosol to vacuole has only been theorized, the process by which the flavan-3-ols polymerize is even more ambiguous. Indeed, it is not yet clear whether a specific enzyme is involved in the regulation of the polymerization or if it may occur completely in a spontaneous way [19]. Recently, it was theorized that LAR could have a central role in the extension process of PACs. In particular, Liu and colleagues, studying the effects derived from the knockdown of $L A R$ on the model legume Medicago truncatula, observed (i) a loss of low molecular weight PACs; (ii) a concomitant increase of PACs with high polymerization degree; (iii) a strong accumulation of $4 \beta$-(Scysteinyl)-epicatechin. Consequently, the authors hypothesized that LAR may convert $4 \beta$ (S-cysteinyl)-epicatechin into epicatechin, the starter unit for PAC elongation [42]. Another crucial point for the polymerization of PACs concerns the possibility that the carbocationform of flavan-3-ols can be synthesized in some way [43]. The presence of a carbocation species of flavan-3-ols would increase the reactivity of the reaction intermediates, and could explain the polymerization of PACs through non-enzymatic mechanisms. However, this is only another hypothesis and, in order to better understand this process, more biochemical and genetic evidences are needed.

\section{Role in Plants}

The main role of PACs in plants is represented by the first biochemical defense to external injuries (Table 1). Indeed, since plants are sessile organisms, they are subjected to a series of menaces derived not only from adverse environmental conditions, but also from animals, insects, fungi, bacteria, or other plants. Generally, these phenomena lead to the overproduction of reactive oxygen (ROS) and nitrogen (RNS) species, and then in oxidative stress [44]. ROS and RNS are very dangerous molecules for both animal and plant cells, as they are highly reactive and capable of compromising the normal function of a large class of biomolecules, including proteins, lipids, and nucleic acids $[15,44]$. In order to counteract the overproduction of ROS and RNS, during both biotic and abiotic stresses, the normal physiological functions of plants are alternated, and in particular, specific metabolic pathways are activated, resulting in the biosynthesis of both non-enzymatic antioxidants, such as ascorbic acid, flavonols, glutathione and various pigments, and/or enzymatic 
defenses [15]. Plant cells, unlike animal ones, are characterized by the presence of a large central vacuole where antioxidant flavonoids are accumulated, including PACs [45]. Moreover, as already described in the previous paragraphs, it is reasonable thinking that the elongation of PACs takes place inside this cellular organelle, despite that the polymerization mechanism is still unknown. The elongation of flavan-3-ol monomers into more complex molecules, such as PACs, is likely a strategy adopted by plants to increase the antioxidant properties of these molecules. This hypothesis is supported by experimental data through which the lower antioxidant capacity of monomers with respect to PACs have been demonstrated [45].

Table 1. Documented plant physiological processes and plant responses to abiotic and biotic stresses that involve proanthocyanidins.

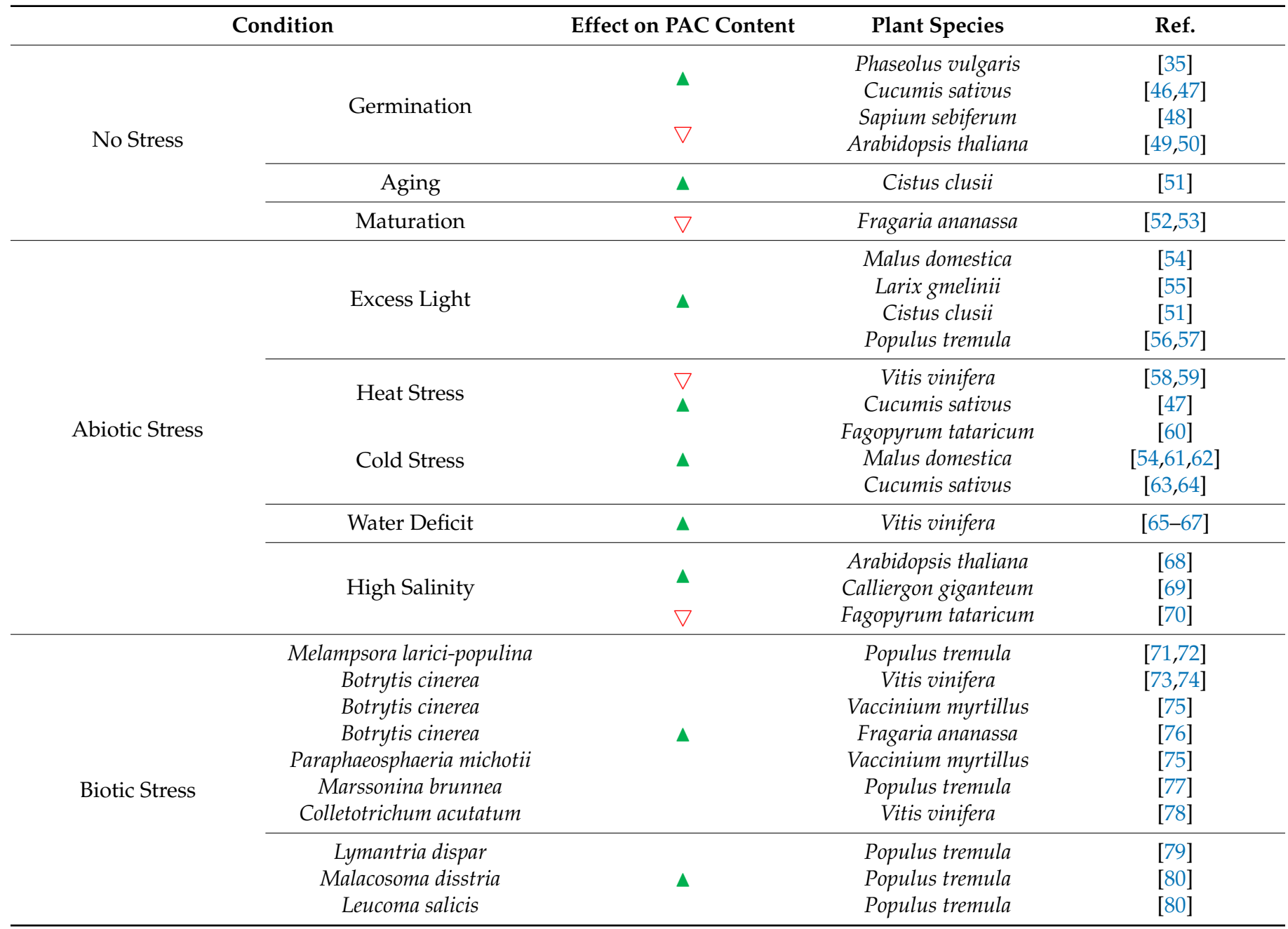

PACs: proanthocyanidins; $\Lambda$ : increase of PAC content; $\nabla:$ decrease of PAC content.

From a histological point of view, PACs are almost exclusively stored in the endothelial layer of the seed coats and in the epidermis and vascular bundles of plant leaves, thus constituting a protective barrier. Indeed, from these localizations, they can easily counteract both abiotic and biotic injuries [81]. The changes in PAC content under abiotic stress are more studied than those derived from biotic stresses (Table 1). However, while biotic stresses always result in an increasing of PACs, for abiotic stresses, the situation is more complicated. Indeed PAC biosynthesis and/or degradation seems to be dependent on both the type of stress and the plant species. Concerning biotic stresses, the astringent flavor determined by PACs is certainly one of the most common plant defenses against attacks by herbivores [82]. However, PACs have also been shown effective against fungi infection. Indeed, several experimental studies have reported that after the inoculation of different 
fungal strains, the plants increased the biosynthesis of PACs, causing a reduction, and in some cases the complete eradication, of the infection [71-78]. Similar phenomena were also observed during insect attack $[79,80]$.

\section{Analytical Methods for the Identification and Quantification of Proanthocyanidins}

Despite the importance of PACs, an accurate and standardized method for their quantification is missed. Numerous analytical procedures, including colorimetric, gravimetric, chromatographic, and mass-spectrometric methodologies, are employed in order to detect, identify, or quantify PACs in plant samples. However, their extreme complexity and structural heterogeneity result in highly variable results. Below, the most employed methodologies will be discussed, describing experimental protocols and focusing on the main advantages and limitations.

\subsection{Gravimetric Methods}

Gravimetry is an old-fashioned method based on the selective separation of the compounds compound via precipitation or chromatographic separation. Despite gravimetric methods providing accurate data on the total content, they do not provide reliable qualitative information. Furthermore, although not expansive, gravimetric procedures are very long and complex. Consequently, their industrial applications are not appreciated [83-85].

Gravimetric methods consist of a number of purification steps by which the plant extract is fractionated using chromatographic columns and/or resins. Finally, the eluate is dried and the solid residue is weighed. For PAC quantification, the plant raw material is normally extracted until exhaustiveness using a variable extraction ratio, ranging from 1:10 $(w / v)$ to $1: 100(w / v)$. The obtained extract is then fractionated via reverse chromatographic resins and finally weighted.

Experimentally, in order to remove sugars and organic acids that may be present in the aqueous extract, the sample containing PACs is loaded into a reverse phase C18silica column. At the beginning, water is flushed into the column alone, and then with $15 \%(v / v)$ methanol. After the hydroalcoholic solution is completely eluted, $99 \%(v / v)$ methanol acidified with $1 \%(v / v)$ acetic acid is added to detach polyphenol compounds from the column. The fraction containing polyphenol compounds is then dried at $40{ }^{\circ} \mathrm{C}$ and 350 mbar using a rotary evaporator. The obtained dried extract is resuspended in 50\% ethanol $(v / v)$ and again loaded into a chromatographic column packed with an adsorption resin (Sephadex LH-20). In order to remove polyphenolic glycosides without eluting PACs, $50 \%(v / v)$ ethanol is added to the column. PACs are therefore detached from the column by adding $70 \%(v / v)$ acetone. The organic solvent of this last fraction is completely removed via a rotary evaporator set up at $40{ }^{\circ} \mathrm{C}$ and $560 \mathrm{mbar}$, meanwhile the residual water content is freeze-dried. The obtained dried extract is weighed and compared to the starting sample weight (Figure 7) [85].

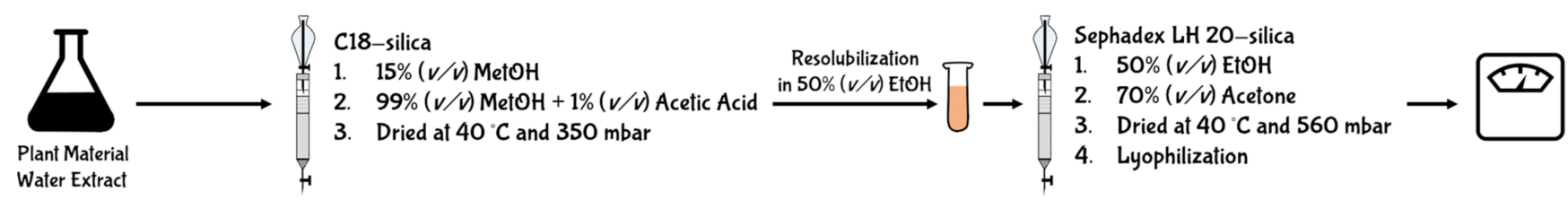

Figure 7. Schematic representation of the gravimetric method for the quantification of PACs.

\subsection{Colorimetric Methods}

Unlike gravimetric methodologies, colorimetric assays are not only easy to perform, they are low-cost procedures. These methodologies are mainly divided into two groups: (i) spectrophotometric methods based on PAC hydrolysis into anthocyanins; and (ii) complexation reactions with chemical reagents. In the first case, the measurement of the absorbance is performed at the typical wavelength of anthocyanidin compounds 
$(\lambda=510-520 \mathrm{~nm})$, whereas the complexation reactions typically produce a bathochromic shift into wavelengths in which few, or none, interferences are recorded. Consequently, the methodologies based on PAC hydrolysis can be highly influenced by the basal content of anthocyanin compounds present in the raw material, resulting in unreliable measurements. On the contrary, the methodologies based on the bathochromic shift allow to drastically reduce this interference.

\subsubsection{Acid Butanol Assay}

One of the main characteristics of PACs is related to their peculiar ability to depolymerize in both acid and strong oxidizing environments leading to the formation of the respective anthocyanin compounds [86]. Consequently, the uncolored mixture containing PACs assumes a very intense red coloration. This unusual property of PACs was then exploited for the development of analytical methods aimed at their quantification. In this context, the Acidic Butanol Assay (also known as Porter's method or Bate-Smith Assay) is a spectrophotometric assay experimentally designed to quantify PACs using the absorbance produced by anthocyanins derived from their depolymerization process [86]. This methodology consists of the preparation of a reaction mixture, composed of $95 \%(v / v)$ butanol acidified with $5 \%(v / v) \mathrm{HCl}$ (Reagent $\mathrm{A}$ ), and of a catalytic mixture containing $2 \%(w / v)$ $\mathrm{FeNH}_{4}\left(\mathrm{SO}_{4}\right)_{2}$ dissolved in water acidified with $17 \%(v / v) \mathrm{HCl}$ (Reagent B). Concerning the experimental protocol, the plant raw material is normally extracted in $80 \%(v / v)$ methanol using a ratio ranging from 1:5 (w/v) to 1:20 (w/v). Then, to $1 \mathrm{~mL}$ of plant extract are added $6 \mathrm{~mL}$ of Reagent A and $200 \mu \mathrm{L}$ of Reagent B. Therefore, the mixture is centrifuged $(8000 \times g$, at room temperature) and incubated at $80^{\circ} \mathrm{C}$ for $50 \mathrm{~min}$. During the incubation time, the interflavan bonds are cleaved, forming highly unstable intermediates named carbocations. Since these compounds are very unstable, they spontaneously and quickly arrange in the respective anthocyanins [86]. Once the anthocyanins are formed, the mixture is cooled for $25 \mathrm{~min}$ at room temperature, and the absorbance is read at $550 \mathrm{~nm}$ (Figure 8).

A

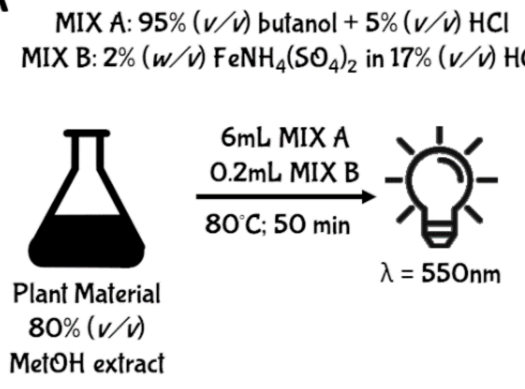

B

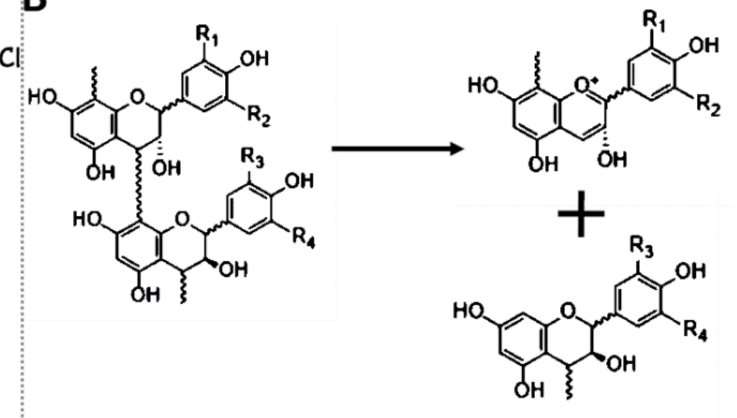

Figure 8. Schematic representation of Acid Butanol Assay for the quantification of PACs. Panel (A) displays the experimental protocol; Panel (B) displays the chemical reaction that allows the formation of the carbocation that spontaneously and quickly arrange in the respective anthocyanin.

However, several limitations were reported for this assay: (i) since the depolymerization of PACs generate different typologies of anthocyanins with specific maximum wavelength of absorbance, the qualitative composition of PACs strongly affect the spectrophotometric assay [87]; (ii) increased concentrations of transition metal ions catalyzing the color formation decrease the color development and the depolymerization process [88]; (iii) the formation of anthocyanin compounds interferes in PAC quantification for plant extracts that simultaneously contain both PACs and other red colored pigments, like anthocyanins or betalains. Consequently, the acid butanol assay should be used with caution if quantitative results must be provided [89,90]. On the other hand, despite that quantitative results cannot be accurately provided using this method, it is useful to provide information regarding the presence or absence of PACs in plant extracts [89]. 


\subsubsection{Pharmacopoeia Method}

In the second volume of the European Pharmacopoeia, an analytical assay for the quantification of PACs from extracts of Crataegus fruits is described [91]. Since the aim of the European Pharmacopoeia chapter is to provide a quality code, no indication regarding therapeutic activity, toxicity, or dosage is reported for PACs. Despite the reliability of Pharmacopoeia for the quality control of pharmaceutical products, some of the assays described for the quantification of phytochemicals are quite dated and approximate. In particular, the assay reported for the quantification of PACs is a long, complex, and expensive method that leads to the collection of unreliable results [92] (Figure 9).

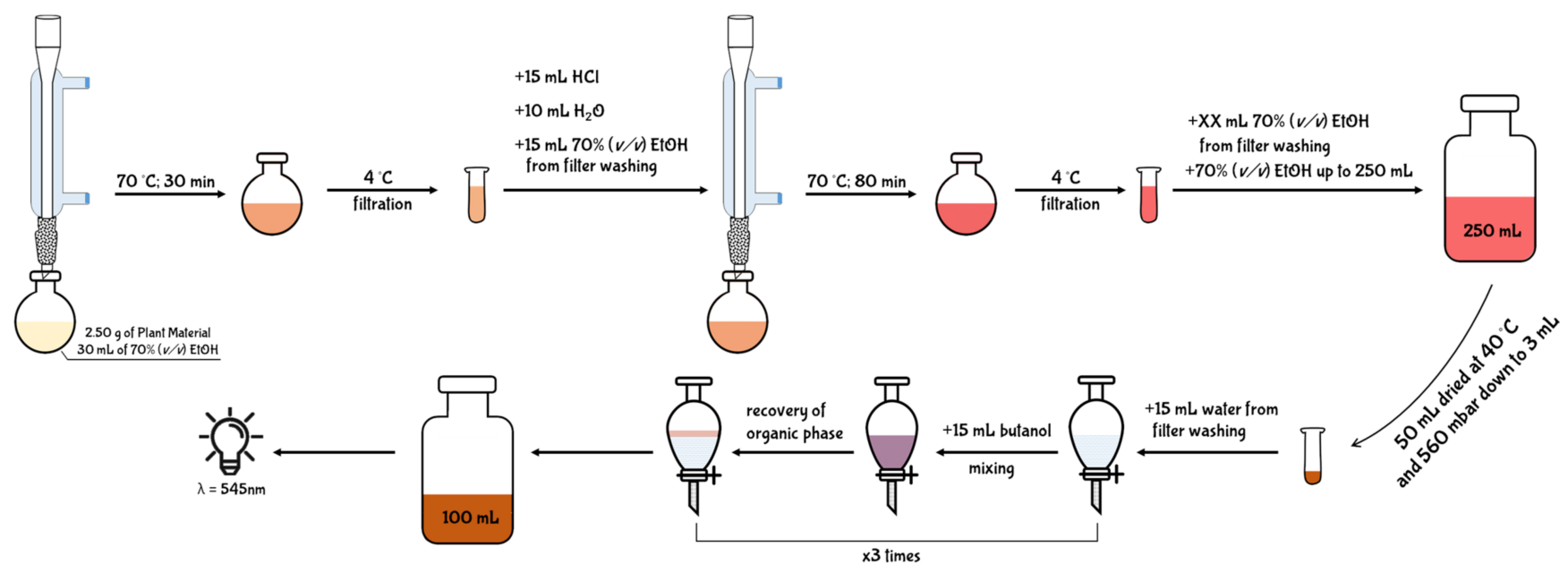

Figure 9. Schematic representation of the Pharmacopoeia Method employed for the quantification of PACs from Crataegus fruits.

The experimental protocol described in the Pharmacopoeia reports that $2.50 \mathrm{~g}$ of plant raw material is weighed and extracted with $30 \mathrm{~mL}$ of $70 \%(v / v)$ ethanol. Consequently, the mixture is heated to $70{ }^{\circ} \mathrm{C}$ under reflux using a round-bottom flask combined with a condenser tube. After $30 \mathrm{~min}$, the extract is cooled on ice and filtered on filter paper. In order to recover any residues from the filter, $10 \mathrm{~mL}$ of $70 \%(v / v)$ ethanol are employed for washing. The washing solvent is then added to the extract, and the mixture is acidified with $15 \mathrm{~mL}$ of $\mathrm{HCl}$ and diluted with $10 \mathrm{~mL}$ of water. The new acidic mixture is again heated to $70^{\circ} \mathrm{C}$ for $80 \mathrm{~min}$ under reflux using a clean round-bottom flask combined with the same condenser tube. After the incubation time, the mixture is again cooled on ice, and filtered with a clean paper filter. Moreover, in this case, the filter is washed with $70 \%(v / v)$ ethanol until it is completely whitened. The filtrate and the washing solvent are again combined and the mixture is diluted with $70 \%(v / v)$ ethanol up to a final volume of $250 \mathrm{~mL}$. Only a $50 \mathrm{~mL}$ aliquot of the diluted mixture is concentrated down to $3 \mathrm{~mL}$ under reduced pressure using an evaporating rotator $\left(40^{\circ} \mathrm{C}, 350 \mathrm{mbar}\right)$. Therefore, the concentrated mixture is transferred into a separatory funnel, and the round-bottom flask is sequentially washed with $10 \mathrm{~mL}$ and $5 \mathrm{~mL}$ of water. The resulting $15 \mathrm{~mL}$ of washing solvent is then combined in the separatory funnel with the mixture previously concentrated. Finally, in order to perform a liquid/liquid separation, $15 \mathrm{~mL}$ of butanol are loaded into the separatory funnel and then vigorously shaken for few seconds. After a rapid decantation, the butanol phase enriched in anthocyanins derived from PAC hydrolysis separates from the aqueous one. The butanol phase is then collected and transferred in a clean glass-cylinder. The separation process with butanol is repeated twice, and the individual organic phases are then combined in the same glass-cylinder. The obtained $45 \mathrm{~mL}$ are then diluted up to $100 \mathrm{~mL}$ with pure butanol, and the absorbance of $1 \mathrm{~mL}$ of the mixture is read at $545 \mathrm{~nm}$. The content of PACs is finally expressed as percentage using Equation (1):

$$
\% \mathrm{PACs}=(\mathrm{A} \times 500) /(75 \times \mathrm{m}),
$$


where: ' $\mathrm{A}$ ' is the absorbance recorded at $545 \mathrm{~nm}$ for one $\mathrm{mL}$ of the mixture, and ' $\mathrm{m}$ ' is the weight of the starting plant material used for extraction and expressed as grams.

\subsubsection{Vanillin Assay}

The first method employed for PAC quantification and not based on their depolymerization is the Vanillin Assay. This assay involves the condensation of vanillin, an aromatic aldehyde, with the hydroxyl group present on $\mathrm{C}_{6}$ of the A-ring of the flavan-3-olic scaffold. The reaction yields the formation of a red colored adduct that is spectrophotometrically measured at $500 \mathrm{~nm}$ [93] (Figure 10A).

A
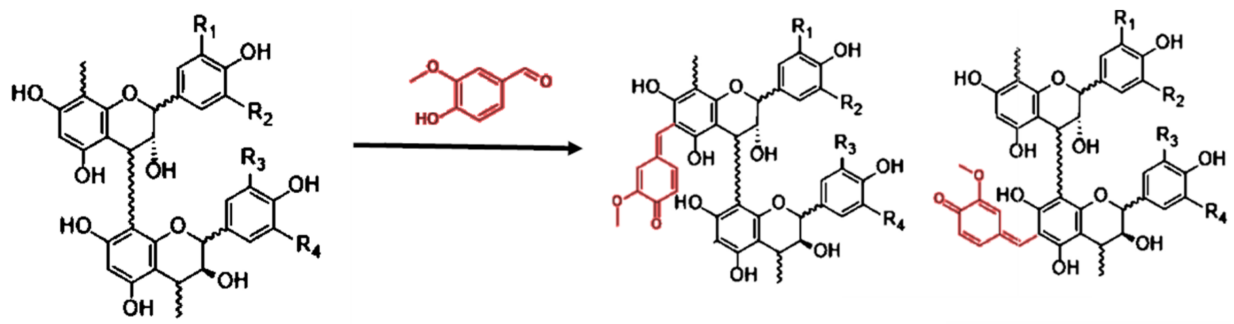

B

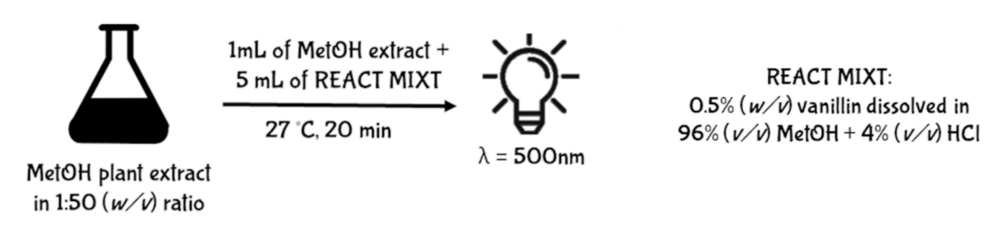

Figure 10. Schematic representation of Vanillin Assay for the quantification of PACs. Panel (A) displays the chemical reaction that allows the formation of red colored adducts, spectrophotometrically measured at $500 \mathrm{~nm}$. Panel (B) displays the experimental protocol.

Experimentally, the plant raw material is extracted with methanol using 1:50 $(w / v)$ ratio. After centrifugation and filtration, $5 \mathrm{~mL}$ of reaction mixture, composed by $0.5(w / v)$ vanillin solubilized in $96 \%(v / v)$ methanol acidified with $4 \%(v / v) \mathrm{HCl}$, are added to $1 \mathrm{~mL}$ of plant extract. Therefore, it is incubated at $27^{\circ} \mathrm{C}$ for $20 \mathrm{~min}$ and the absorbance is read at $500 \mathrm{~nm}$ against a blank not containing the plant extract. The quantification is performed using catechin for the construction of a calibration curve, and the results are expressed as $\mathrm{mg}$ of catechin equivalent (EC) per $100 \mathrm{~g}$ of plant material (Figure 10B).

Despite Vanillin Assay being a fast and inexpensive method, it has several limitations. In particular, (i) it was demonstrated that the condensation reaction is not specific for PACs, since properly substituted compounds including dihydrochalcones, anthocyanins, flavan3-ols and ascorbic acid, can also react with vanillin causing an overestimation of the PAC content [94]; (ii) the formation of a red colored adduct may interfere with PAC quantification in plant extracts that simultaneously contain both PACs and other red colored pigments, like anthocyanins or betalains [94]; (iii) the acidity of the extraction and reaction solvent strongly influences the kinetics of the condensation reaction, resulting in the production of greater color intensities [94,95]; (iv) the presence of water in the plant sample also negatively influences this reaction; (v) excessive concentrations of vanillin in the mixture yields to a self-condensation process causing an error in the PAC quantification [94,95]; (vi) small changes in reaction temperature lead to important variations in absorbance [95].

\subsubsection{Brunswick Laboratories 4-dimethylaminocinnamaldehyde (BL-DMAC) Assay}

BL-DMAC is a colorimetric assay known to be the most accurate method for PAC estimation. Originally, the assay was studied with the aim to detect and quantify PACs from cranberry samples and correlate their content with potential antimicrobial activity against uropathogenic Escherichia coli [83]. However, after several experimental studies, the high reproducibility and analytical precision of BL-DMAC was demonstrated, also using differ- 
ent typologies of plant raw materials [96-102] and their derived products [47,64,103-105]. Since the PAC determination occurs at $640 \mathrm{~nm}$, this assay is less affected by the presence of other phytochemicals, including anthocyanins [83]. However, the chemical reaction that allows the bathochromic shift of PACs from 260 to $640 \mathrm{~nm}$ is not well known. It is hypothesized that in an acidic environment the aldehyde group of the DMAC molecule is protonated, leading to the formation of a highly reactive carbocation. This carbocation specifically reacts with molecules (1) having hydroxyl groups in meta-position of the A-ring of the flavonol scaffold; (2) having a single bond $\mathrm{C}_{2}-\mathrm{C}_{3}$; and (3) not having a carbonyl at $\mathrm{C}_{4}$ [96]. Consequently, in addition to PACs, only flavan-3-ols (such as catechins and epicatechins) and some anthocyanins (such as cyanidins and delphinidins) can react with DMAC reagent, causing a potential interference, which was proven to be really weak [96].

Experimentally, the plant raw material should be extracted with $75 \%(v / v)$ acetone acidified with $0.5 \%(v / v)$ acetic acid and using 1:20-1:100 $(w / v)$ ratio. The mixture is then vortexed for $30 \mathrm{~s}$, sonicated at room temperature for $30 \mathrm{~min}$, and placed on an orbital shaker for $60 \mathrm{~min}$. After centrifugation $(2000 \times g$ at room temperature for $10 \mathrm{~min}), 70 \mu \mathrm{L}$ of a proper dilution of the extract is added to $210 \mu \mathrm{L}$ of DMAC solution containing $0.1 \%(w / v)$ DMAC dissolved in $75 \%$ ethanol $(v / v)$ acidified with $12.5 \%(v / v)$ hydrochloric acid. After $25 \mathrm{~min}$ of incubation, the absorbance is read at $640 \mathrm{~nm}$ and against a blank containing $70 \mu \mathrm{L}$ of extraction solvent and $210 \mu \mathrm{L}$ DMAC solution. PAC content is expressed and mg A-type PAC equivalents per $100 \mathrm{~g}$ of fresh weight using a calibration curve of pure PAC standard ranged between 20 and 100 ppm (Figure 11).

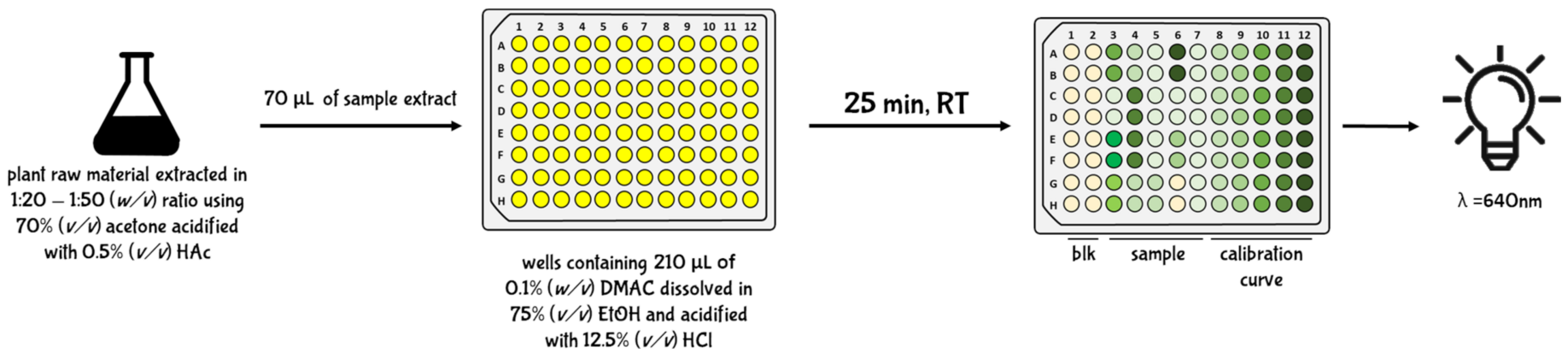

Figure 11. Schematic representation of BL-DMAC assay for the detection and quantification of PACs.

\subsection{Mass Spectrometry (MS) Methods}

Unlike other polyphenolic compounds, the quantification of the punctual PACs through mass-spectrometry (MS) methodologies is still under investigation and currently represents a hard challenge. Indeed, the analytical process is strongly affected from multiple factors, including: (i) the great qualitative heterogeneity of the monomers that constitute PACs; (ii) the variable number of monomeric subunits that can be present in PAC structures (from 2 to 60 units); (iii) the lack of commercially available standards fundamental for their analytical quantification. For these reasons, the UV/Vis methodologies previously described and aimed to the quantification of the total PAC amount are still widely used despite providing data considerably affected by the different experimental conditions used. On the other hand, MS-based methods could give a more precise and standardized information of PAC profile. However, both MS methods coupled with liquid chromatography (LC) or with matrix-assisted laser desorption ionization (MALDI) have severe limitations.

\subsubsection{Chromatographic System}

LC-MS methods for PAC quantification consist in the separation of these molecules using chromatographic columns. However, plant extracts containing PACs are complex mixtures of other phytochemicals and PACs, having several and different polymerization degrees [106]. It was reported that PACs with a polymerization degree ranging between 2 and 10 can be efficiently separated via normal phase chromatography. However, PACs with 
a polymerization degree higher than 10 co-elute all together at the end of chromatographic run [107]. Moreover, an additional problem with the use of normal phase chromatography is the interference caused by the co-elution of other phytochemicals during the chromatographic run. For this reason, chromatographic methods employing the normal phase are currently rare and replaced by reverse phase chromatography [107-109]. However, even if reverse phase columns can easily fractionate monomers, dimers, trimers, and tetramers of PACs and their relative isomers, the order of elution is not in accordance with their molecular size. It has also been reported that the analysis of PACs with polymerization degree higher than tetramers is strongly affected by the co-elution of PAC oligomeric isomers. Indeed, reversed phase columns are able to separate oligomers of equivalent molecular mass into their isomers, but proanthocyanidins bigger than tetramers have a large number of isomers which elute together causing an overlap of the retention time. Consequently, isomers of the same oligomers are recorded in the chromatogram in a single and large unresolved peak that cannot be neither identified and/or quantified [110].

Additionally, UV/Vis detectors are avoided due to the non-specific maximum wavelength of PAC absorbance $(280 \mathrm{~nm})$. On the other hand, fluorescence detectors, although offering increased sensitivity and selectivity for some PAC typologies, show similar problematics. Moreover, fluorescence quantification is also affected by the qualitative composition of PACs that strongly modifies the emission and excitation maximum wavelengths [108]. Consequently, mass spectrometry (MS) detectors seem to be the only ones able to provide a realistic identification and quantification of PACs, although an additional limitation is related to the ionization methodologies. The development of electrospray ionization (ESI) had an enormous impact on the analysis of plant bioactive compounds, including PACs, achieving the simultaneous volatilization and ionization also for non-volatile molecules. However, ESI is not well suited for the analysis of highly variable molecules like PACs, because it generates several charged ions that make impossible spectra interpretation. Finally, the most common MS detectors coupled with LC-ESI instrumentations have a very limited range of molecular weight acquisition. The above mentioned problems explain why in literature no scientific articles reporting the quantification of PACs having polymerization degree higher than 10 are available.

\subsubsection{Matrix-Assisted Laser Desorption/Ionization (MALDI) System}

Analysis of PACs using MS-based methods can alternatively be performed without solving the chromatographic separation problems. In this case, MALDI can be used as ionizing source and chromatographic co-elution problems are avoided [111]. Moreover, MALDI has a greater tolerance for impurities with respect to ESI. This system is able to detect mainly single-charged molecular ions, and is designed to interface with high resolution detectors, such as the time-of-flight (TOF) detector [111,112]. Indeed, unlike LC-MS instrumentations, the analysis performed via MALDI-TOF not only have unlimited mass range, but also higher sensitivity. Consequently, qualitative analyses on plant samples may include PACs with very high polymerization degrees [113,114]. However, quantification by MALDI-TOF is still a great challenge because pure analytical standards are not commercially available. Indeed, similar to other MS detectors, also during TOF analysis the equimolar loading of different compounds results in peaks of different intensity, which cannot be quantified in a semi-quantitative fashion. Moreover, MALDI-TOF spectra generated from the loading of the same sample have a strong variability in ion current, noise level, baseline, and peak intensities. These variations are equally present after consecutive laser shots in the same position or across different locations of the target surface. Finally, competitive ionization/ion suppression is an additional factor that hinders this kind of analysis, especially in complex samples such as plant material [114].

Therefore, although MALDI-TOF allows to obtain a truly representative profile of PACs theoretically including all existing polymerization grades, quantifications through this MS technique is not recommended [114]. 


\section{Distribution in Edible Sources}

PACs are bioactive compounds variously distributed within the plant kingdom [115]. Most of red fruits are well known to contain high contents of PACs; however, their presence has also been detected also in non-red colored roots, leaves and fruits [115]. The simultaneous presence of anthocyanins and PACs in red fruits can be explained by the ability of the plants to regulate the transcription of genes encoding for ANS and ANR, which respectively catalyze the transformation of leucoanthocyanidins into the respective anthocyanins, and their consequent reduction into 2R, 3R-flavan-3-ols. On the contrary, plants having PACs only, lack both ANS and ANR, but express LAR that directly yields to the production of 2R, 3S-flavan-3-ols from leucoanthocyanidins (Figure 6).

In order to investigate the distribution of PACs in the plant kingdom, a database consisting of published articles in which the phytochemical composition of different plant raw materials containing PACs was built. This selection provided 3868 entries, which were individually analyzed to select papers that provided PAC estimation through BL-DMAC assay $(n=41)$. Then, information regarding the species binomial name, plant family, common name, and plant part used for the extraction was extrapolated along with the PAC content. Data reported using different measurement units were homogeneous, fixing for the water content when necessary. Consequently, all data were expressed as mg PAC equivalents per $100 \mathrm{~g}$ of fresh weight.

The total number of selected species was 55, and the estimated average PAC content was $171.80 \mathrm{mg}$ PACs per $100 \mathrm{~g}$ of fresh weight. The 55 species belonged to 35 different families (Figure 12). Among them, the most representative family was Vaccinium, which included 10 different species. Moreover, the Vaccinium family also displayed one of the highest PAC values with respect to the other families. In particular, it recorded a mean value equal to $290.97 \mathrm{mg}$ PAC equivalents per $100 \mathrm{~g}$ of fresh weight, which was lower only to Styrax (497 mg PAC equivalents per $100 \mathrm{~g}$ of fresh weight) and Carya (508 mg PAC equivalents per $100 \mathrm{~g}$ of fresh weight) families. On the other hand, Santalum (10.5 mg PAC equivalents per $100 \mathrm{~g}$ of fresh weight), Vicia (10.2 mg PAC equivalents per $100 \mathrm{~g}$ of fresh weight), and Fagopyrum (2.5 mg PAC equivalents per $100 \mathrm{~g}$ of fresh weight) displayed the lowest ones (Figure 12).

Focusing on the plant raw material, the database contained the PAC estimation from four beans/seeds (Glycine max, Vicia faba, Theobroma cacao, and Oryza sativa), one flower (Rosa damascena), 43 fresh fruits (Annona atemoya, Annona cherimola, Aronia arbutifolia, Aronia melanocarpa, Aronia prunifolia, Campomanesia phaea, Carya illinoinensis, Citrus aurantifolia, Citrus limon, Citrus paradisi, Davidsonia pruriens, Elaeagnus umbellata, Euterpe oleracea, Fragaria ananassa, Geoffroea decorticans, Hippophae rhamnoides, Lepisanthes alata, Litchi chinensis, Malus domestica, Myrciaria dubia, Passiflora setacea, Plinia cauliflora, Prunus cerasus, Prunus domestica, Prunus serotina, Punica granatum, Ribes nigrum, Rubus adenotrichus, Rubus ulmifolius, Santalum acuminatum, Styrax ramirezii, Symphysia poasana, Vaccinium angustifolium, Vaccinium ashei, Vaccinium consanguineum, Vaccinium cyanococcus, Vaccinium floribundum, Vaccinium macrocarpon, Vaccinium oxycoccos, Vaccinium uliginosum, Vaccinium vitis idaea, Vitis labrusca, and Vitis vinifera), four fruit peels/skins (Arachis hypogaea, Pistacia vera, Plinia cauliflora, and Vaccinium macrocarpon), six leaves (Aloe vera, Annona atemoya, Annona cherimola, Fagopyrum tataricum, Ginkgo biloba, and Rosa damascena), and one resin (Aloe perryi) (Figure 13). The large number of samples related to fresh fruits is certainly linked to the importance that PACs have shown in producing beneficial effects on human health through the consumption of foods rich in these bioactive compounds. Indeed, it is well known that plants tend to synthesize and store bioactive compounds, including PACs, not only in fruits, but also in leaves and flowers [16]. However, since most flowers and leaves are not edible, the estimation of PAC content has been almost exclusively limited to fruits. Consequently, the limited availability of data related to the content of PACs in other plant parts is the major limitation of the analysis presented in this section (Figures 12 and 13). 


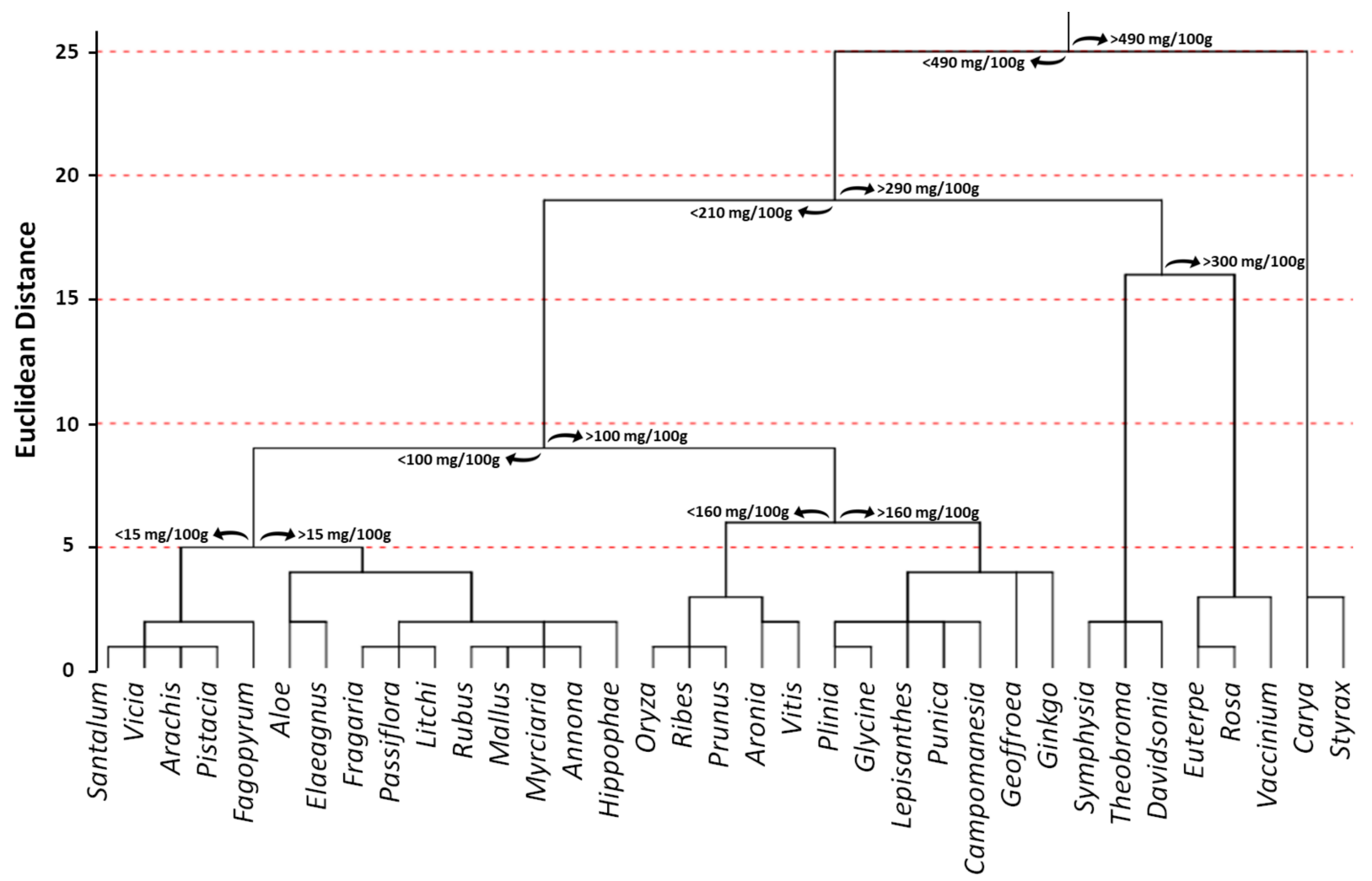

Figure 12. Cluster distribution of proanthocyanidins based on the total proanthocyanidin content within plant families and according to previously published data [96,97,99-102,104,105,116-148]. Euclidean distances were calculated with the average linkage method. Statistical analysis and graphical representation were made using SPSS v. 24 software.

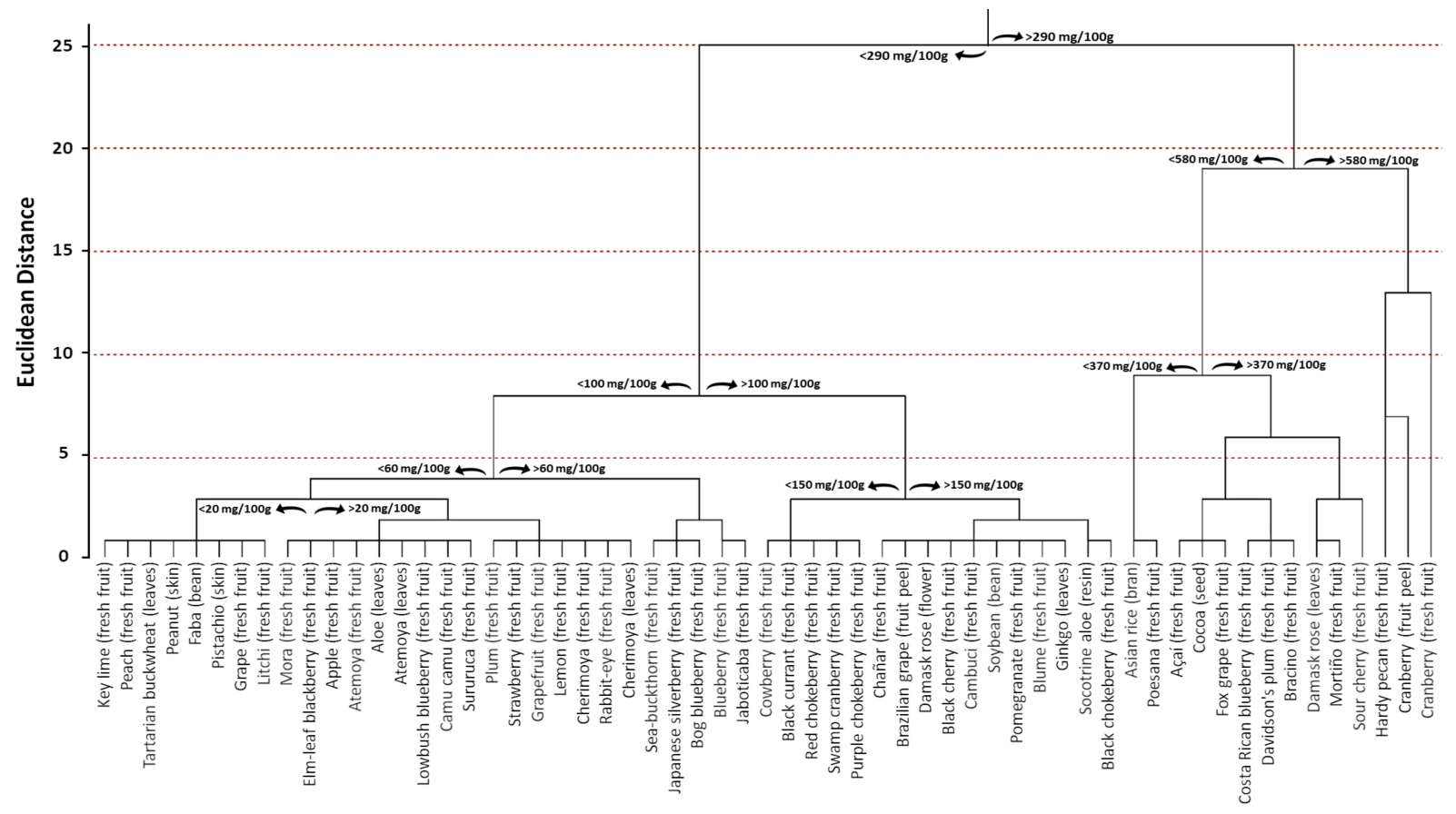

Figure 13. Cluster distribution of proanthocyanidins in plant kingdom based on the total proanthocyanidin content according to previously published data [87,88,90-93,95,96,107-139]. Euclidean distances were calculated with the average linkage method. Statistical analysis and graphical representation were made using SPSS v. 24 software. 7. PAC Availability. 
To assess potential positive effects of dietary phytochemicals on human health, the evaluation of their bioavailability is essential knowledge. Indeed, unless local effects at the bowel level are considered, a dietary compound must be available in the blood to exert biological effects. Therefore, bioactivity of phytochemicals in vivo depend on their release from the food matrix, their stability under digestion conditions, their intestinal absorption, their metabolism, and excretion [149]. On the other hand, potential biological activity of phytochemical metabolites must also be considered [150].

Physiochemical parameters largely influence phytochemical bioavailability [151]. In particular, molecular weight was shown to be a determining factor for intestinal absorption [152]. Moreover, some small polyphenols, such as phenolic acids, are easily absorbed through the gut barrier via paracellular or transcellular transport, eventually involving protein carriers $[153,154]$. On the contrary, for large molecular weight compounds, such as proanthocyanidins and ellagitannins, intestinal absorption is quite limited [149]. The uptake of proanthocyanidins at the proximal intestinal is rather poor, while at the level of the colon, almost exclusively proanthocyanidin dimers and trimers are effectively absorbed. Indeed, it was demonstrated by in vitro models of trans-epithelial transport and intestinal digestion that permeation coefficient across epithelial monolayer is a function of polymerization degree $[155,156]$. Accordingly, Ou et al. evaluating the transport of A-type PAC dimer, trimer and tetramer through in vitro Caco 2 monolayer systems, recorded a transport ratio of $0.6 \%, 0.4 \%$, and $0.2 \%$, respectively [157]. Therefore, the bioavailability of PACs depends on the presence in the food matrix of small bioavailable oligomers or on the degradation of large proanthocyanidins to dimers and trimers during gastrointestinal digestion. Moreover, the low bioavailability of these large polyphenols is also due to their ability to interact with other components in the digestive tract, including food matrix components, intestinal mucosa constituents, and digestive enzymes [158]. The better known property of tannins is their capacity to form complexes with proteins [159]. This property may have nutritional implications. Indeed, PACs affect digestive processes by binding digestive enzymes and dietary proteins. For instance, PACs have been shown to interact with $\alpha$-amylase producing complexes undetectable in plasma samples $[160,161]$. Additionally, it has also been demonstrated that high molecular weight PACs can interact with cell membranes [162,163]. In particular, large proanthocyanidins have been shown to produce a significant increase in the trans-epithelial electrical resistance (TEER) of polarized intestinal epithelium monolayers, which is indicative of their interactions with plasmatic membrane [164,165].

Regarding PAC stability in the stomach after the intake of proanthocyanidin richfoods scientific data are very conflicting. Some in vitro studies showed PAC degradation under the acid conditions of the gastric environment. In particular, it was showed that large polymers produce a precipitate, while oligomers, until hexamers, are hydrolyzed to catechin and PAC dimers, which are able to cross intestine mucosa $[150,166]$. In contrast, Rios et al. demonstrated that in human subjects proanthocyanidins, regardless of the molecular weight, are remarkably stable in the stomach environment reaching high concentration in intact form in the small intestine [167]. Accordingly, Serra et al., using a combination of in vitro and in vivo murine models, showed a significant PACs stability at gastric digestive conditions [168]. Conversely, in a randomized cross-over study in humans, the demonstrated absence of proanthocyanidin monomers and dimers in plasma samples after intake of cocoa beans, which are high in large proanthocyanidins, suggests the lack of proanthocyanidin depolymerization during both gastric and intestinal digestion [169]. In contrast, evaluating bioavailability of proanthocyanidins from Choerospondias axillaris peels in an in vitro model of gastrointestinal digestion, Li et al. showed that the total polyphenol content and the mean degree of polymerization, unchanged during gastric digestion, suffered a strong reduction during intestinal digestion. The authors suggested that pancreatic enzymes, rather than the $\mathrm{pH}$ value of the intestinal milieu, could be involved in proanthocyanidin degradation [170]. However, other studies suggested a significant influence of $\mathrm{pH}$ in the intestinal environment on proanthocyanidin digestion and absorption. Indeed, it was 
assessed in an in vitro model of gastrointestinal digestion that large proanthocyanidins, producing precipitate under gastric conditions, were solubilized at the basic environment of the gut becoming available to subsequent modifications and absorption [156].

The susceptibility of PACs during intestinal digestion also depends on the intestinal microbiome. In particular, in a murine model, it was shown that although epicatechin can be produced by PAC degradation by colonic microflora, it is subsequently rapidly metabolized to low molecular phenolic acids that are the main metabolites of PACs in urine $[152,171]$. Moreover, Tao et al. proposed that proanthocyanidin dimers and trimers are the main substrates of the gut microbiota, while large polymers are less fermented substrates [156].

Based on what is known about digestive stability and absorption of proanthocyanidins, it is therefore likely that the systemic effects of these phytochemicals have to be attributed to the small oligomers (dimers and trimers). On the contrary, high molecular weight proanthocyanidins, rather stable under gastrointestinal digestion conditions and little susceptible to fermentation by the microflora of the colon, as a consequence of the poor ability to cross the intestinal barrier, reach high concentrations in the colon in the native form, potentially useful to carry out local action at the gut level. On the other hand, these effects could be useful in explaining the protective effects of PACs on the physiology of the intestinal tract, including the inverse correlation between the intake of foods rich in proanthocyanidins and the risk of colorectal cancer [172].

\section{PAC Bioactivity}

Through their well-established antioxidant properties discussed above, PACs may exert crucial roles in several pathological conditions, including cancer, inflammatory, cardiovascular and neurodegenerative diseases and metabolic disorders. Indeed, all these pathological processes may take off severe conditions of oxidative stress (OS) and PACs may tone down OS both by acting as free radicals' scavengers and by affecting signaling pathways associated with cellular OS homeostasis. Among them, the best characterized pathways that have been shown to be influenced by PACs in several human, animal, and culture studies are those involving nuclear factor erythroid 2-related factor 2 (Nrf2), mitogen-activated protein kinase (MAPK), nuclear factor-kB (NF- $\mathrm{kB}$ ), and phosphoinositide 3-kinase/protein kinase B (PI3K/Akt).

In recent years, the molecular events and signaling pathways involved in the antioxidant mechanism of specific PACs have been extensively investigated and partly clarified, increasingly emphasizing the potential of these molecules in the clinical setting for the prevention and treatment of various OS-associated diseases. Moreover, PACs have been shown to be safe and to have not apparent side effects, thus making them suitable, promising and powerful candidates in clinical medicine.

Many studies on PAC's benefits on human health have been published and, recently, well summarized, in particular regarding their anti-cancer, cardiovascular, and neurological protective properties [30,43]. Moreover, emerging evidence from clinical studies indicates that higher PAC intake is associated with reduced risk of several metabolic disorders, including metabolic syndrome (MetS), non-alcoholic fatty liver disease (NAFLD), and nonalcoholic steatohepatitis (NASH), type 2 diabetes mellitus (T2DM), and the complications associated with it, such as nephropathy and neuropathy [173-175]. In particular, PACs are emerging to play a key role in modulating glucose- and lipid-lowering effects. In this review, we will mainly focus on the role of PACs in metabolic disorders, delving into the mechanisms through which this class of compounds may affect both glucose and lipid metabolism also thanks to their capability to interact with food-derived proteins, digestive enzymes, and cell membrane proteins along the entire gastrointestinal tract [176].

\subsection{Glucose-Lowering Effect}

In order to understand if PAC supplementation could affect blood glucose levels, we performed a meta-analysis on data collected from articles published in the last 10 years 
and that satisfied the pre-established inclusion criteria. Briefly, the previously published articles $(n=327)$ were obtained by a literature search on PubMed, Scopus, Google Scholar, and ISI Web of Science research tool using the following keywords: ("proanthocyanidin(s)" OR "procyanidin(s)" OR "PAC(s)" AND “blood glucose" OR "glucose" OR "glycaemia"). Then, a manual screening of the articles was performed by reading the title, abstract or full text. Original articles were exclusively included if they met the following inclusion criteria: (i) the language should be English; (ii) articles should be published in peer-review journals; and (iii) after the reviewing by experts; (iv) the study design should be a randomized controlled clinical trials on human; (v) the intervention should be the supplementation of formulation containing PACs only, not in combination with other substances; (vi) only studies where the number of participant has been clearly reported should be included; (vii) the parameter measured should be the blood glucose level; (viii) when outcomes were presented at different times in the study, only the longest follow-up duration was selected. Accordingly, of the 327 published full text articles that were identified during the bibliographic research, 319 were excluded. Data from the selected articles $(n=8)$ were employed for the meta-analysis [177-184]. Since data were accumulated from a series of studies that had been independently performed, all of the selected studies were not functionally equivalent. Consequently, the originated forest plot (Figure 14) was performed using random effect, according to the heterogeneity calculated between the studies. Statistical heterogeneity among studies was checked with the Cochrane $Q$ test (significance level of $p<0.05$ ) and the $\mathrm{I}^{2}$ statistic.

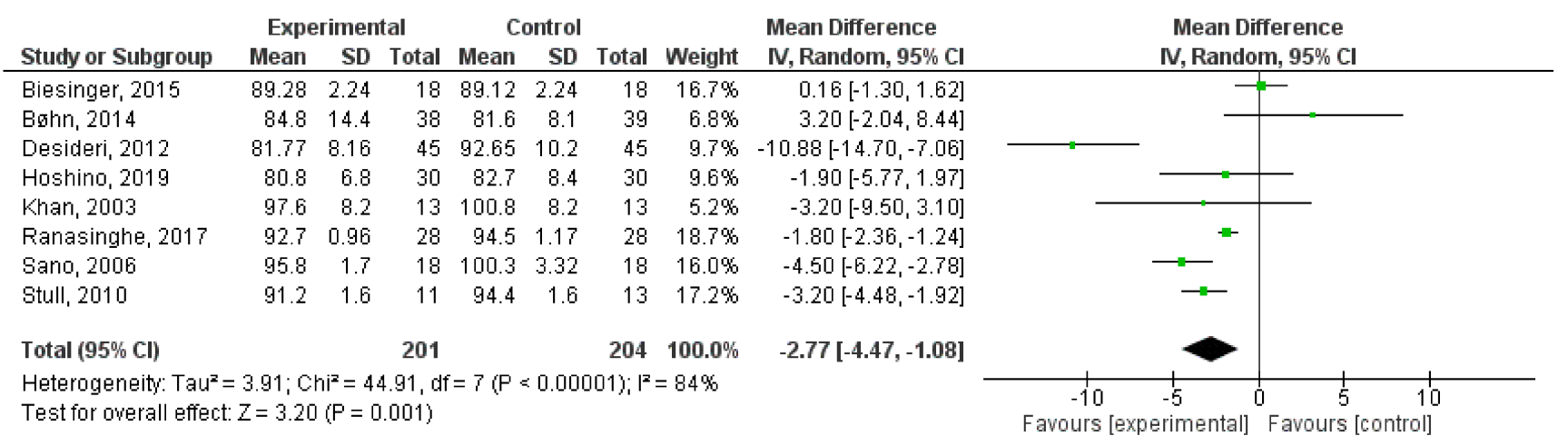

Figure 14. Forest plot representation of the effects derived from the supplementation of PACs on hematic sugar levels. Data were extrapolated from [177-184], and plotted according to the mean difference. Each horizontal line of the plot represents an individual study, reporting the punctual result plotted as green box. The weight of each study is represented by the size of the green box. The horizontal line indicates the lower and upper limit of the $95 \%$ Confidence Interval (CI) of the effect observed for each study. The vertical line represents the no-effect. For each study, if the horizontal line crosses the vertical one, a statistically significant difference between Experimental and Control group is not observed. The black diamond at the bottom of the forest plot represents the average effect size combining together the results of all the selected studies. The horizontal points of the diamond are the limits of the $95 \%$ CI of the average value. The figure was generated by Review Manager Software, version 5.4.1.

The combined results of the selected articles from the random-effect model suggested a significant effect of PAC supplementation on blood glucose levels (WMD: $-2.77 \mathrm{mg} / \mathrm{dL}$; $95 \%$ CI: $\left.-4.47,-1.08 ; \mathrm{I}^{2}=84 \% ; p=0.001\right)$. Furthermore, sensitivity analyses were performed to evaluate the influence of each study on the overall effect size. Finally, potential publication bias was checked by visual inspection of the respective funnel plot. As Supplementary Figure S1A displays, no publication bias was identified among the selected studies.

In the next subsections, we will deepen the potential beneficial effects of PACs on hyperglycemia sustained by several in vivo studies (Table 2). In particular, we will investigate the major molecular mechanisms by which PACs can interfere with metabolic glucose signaling at different levels and in different target organs, including the small and large intestine, liver, pancreas, skeletal muscle, and adipose tissues (Figure 15). 
Table 2. In vitro and in vivo studies on PAC-mediated glucose-lowering effect.

\begin{tabular}{|c|c|c|c|c|}
\hline \multicolumn{5}{|c|}{ Glucose-Lowering/Anti-Diabetic Studies } \\
\hline Reference & & PACs Type or Source & Plasma Parameters & Model \\
\hline Han et al., 2018 & [185] & procyanidin B2 & GLU & Mice \\
\hline Yokozawa et al., 2012 & [186] & PACs & GLU, GP, BUN & Rats \\
\hline Hollands et al., 2018 & [187] & $\begin{array}{l}\text { EC and oligomeric PAC } \\
\text { from apple }\end{array}$ & $\begin{array}{c}\text { GLU, INS, } \\
\text { fructosamine, TG, TC, } \\
\text { HDL, LDL }\end{array}$ & Human \\
\hline El-Alfy et al., 2005 & [188] & grape seed & GLU, INS & Rats \\
\hline Ding et al., 2013 & [189] & grape seed & GLU, INS & Rats \\
\hline Li et al., 2020 & [190] & grape seed & GLU, BUN, DAO & Piglets \\
\hline Pinent et al., 2004 & [191] & GSPE & GLU, INS & Rats \\
\hline Castell-Auvì et al., 2012 & [192] & GSPE & INS & Rats \\
\hline Bao et al., 2014 & [193] & GSPE & GLU, albumin & Rats \\
\hline Li et al., 2015 & [194] & GSPE & GLU, INS, HbA1c & Rats \\
\hline Chen et al., 2015 & [195] & GSPE & GLU & Rats \\
\hline Zhang et al., 2016 & [196] & GSPE & GLU, INS, TG, TC & Rats \\
\hline Sanna et al., 2019 & [197] & GSPE & GLU, INS & Rats \\
\hline Ding et al., 2020 & [198] & GSPE & $\begin{array}{l}\text { GLU, creatinine, BUN, } \\
\text { uric acid, urinary } \\
\text { albumin, renal MDA }\end{array}$ & Rats \\
\hline Desideri et al., 2012 & [179] & cocoa & $\begin{array}{c}\text { GLU, INS, HOMA-IR, } \\
\text { TC, TG, LDL, } \\
\text { HDL, HDL }\end{array}$ & Human \\
\hline Mellor et al., 2013 & [199] & chocolate & $\begin{array}{l}\text { GLU, INS, HbA1c, CRP, } \\
\text { TC, TG, LDL, HDL }\end{array}$ & Human \\
\hline Yamashita et al., 2019 & [200] & cacao liquor & GLU, INS, GLP-1 & Mice \\
\hline Tomaru et al., 2007 & [201] & cacao liquor & GLU, fructosamine & Mice \\
\hline Yamashita et al., 2012 & [202] & cacao liquor & GLU, INS & Mice \\
\hline Rodríguez-Daza et al., 2020 & [203] & blueberry & GLU, INS & Mice \\
\hline Ntemiri et al., 2020 & [204] & blueberry & GLU, CRP, FRAP & Human \\
\hline Liu et al., 2020 & [205] & white bayberry & $\begin{array}{l}\text { GLU, INS, leptin, } \\
\text { glucagon, TG, TC, } \\
\text { LDL, ALT }\end{array}$ & Mice \\
\hline Castro-Acosta et al., 2017 & [206] & apple and blackcurrant & GLU, INS, CRP, GIP & Human \\
\hline Kanamoto et al., 2011 & [207] & black soybean seed & $\begin{array}{c}\text { GLU, INS, HOMA-IR, } \\
\text { TG, TC, leptin, } \\
\text { adiponectin, NEFA }\end{array}$ & Mice \\
\hline Lee et al., 2008 & [208] & persimmon peel & $\begin{array}{c}\text { GLU, GP, TC, TG, } \\
\text { NEFA, OS biomarkers }\end{array}$ & Mice \\
\hline Lin et al., 2018 & [209] & cinnamon twig & $\begin{array}{c}\text { GLU, TG, LDL-C, } \\
\text { HDL-C, ALT, } \\
\text { adiponectin, leptin } \\
\text { GLU, INS, leptin, AST }\end{array}$ & Rats \\
\hline Hsu et al., 2020 & [210] & C. obtusa var. formosana leaf & $\begin{array}{l}\text { ALT, TG, TC, HDL, } \\
\text { LDL, amylase, lipase }\end{array}$ & Rats \\
\hline $\begin{array}{l}\text { Macho-Gonzàlez et al., } \\
2020\end{array}$ & [211] & carob fruit extract & $\begin{array}{l}\text { GLU, INS, HOMA- } \beta \\
\text { index }\end{array}$ & Rats \\
\hline Anunciação et al., 2018 & [212] & extruded sorghum & GLU & Human \\
\hline Wang et al., 2020 & [213] & C. osmophloeum and T. camphoratus & $\begin{array}{l}\text { GLU, TC, BUN, } \\
\text { creatinine }\end{array}$ & Mice \\
\hline Bang et al., 2014 & [214] & Enzogenol & $\begin{array}{c}\text { GLU, INS, } \\
\text { HbA1c, glucagon }\end{array}$ & Mice \\
\hline
\end{tabular}




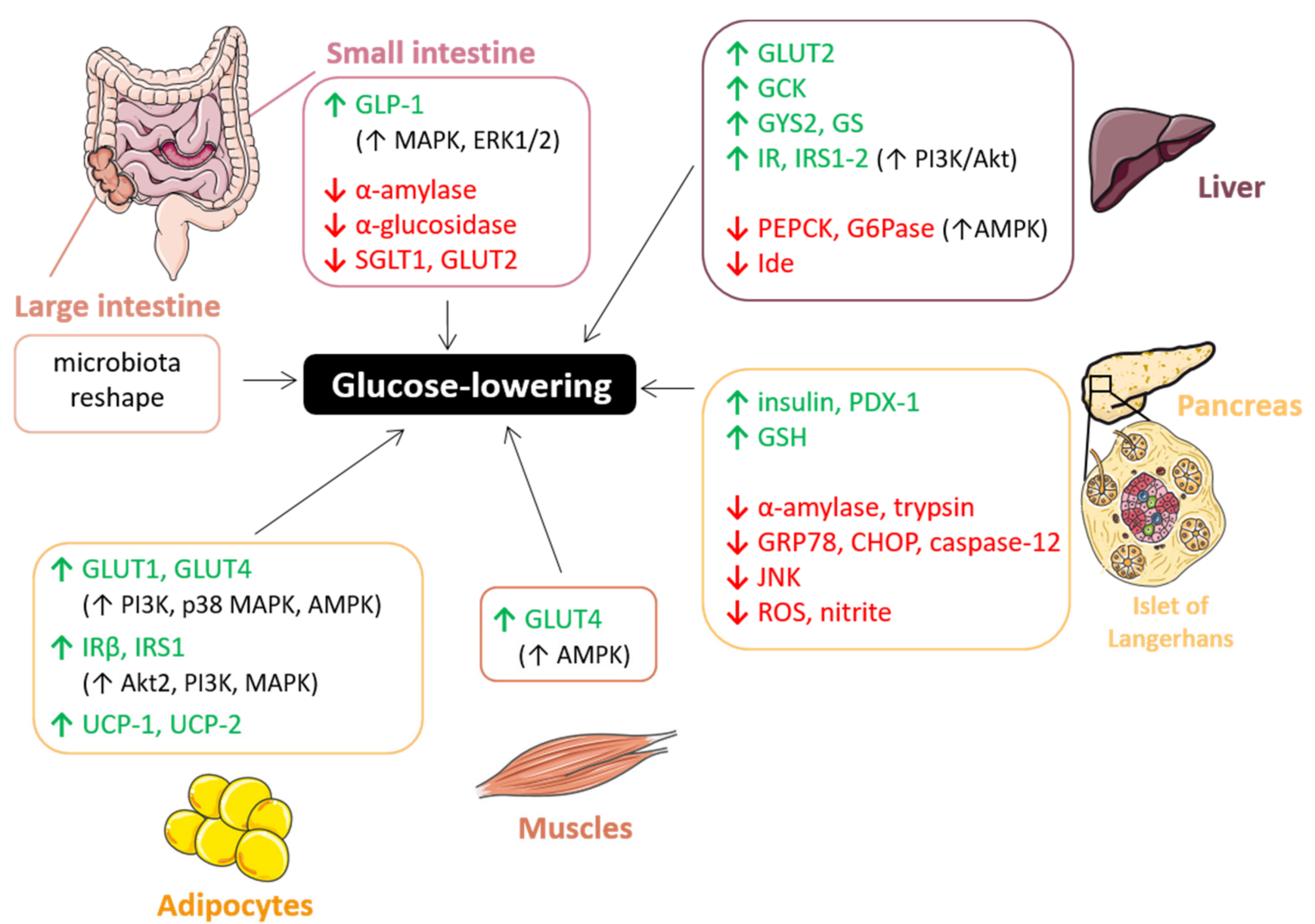

Figure 15. Schematic representation of the molecular mechanisms through which PACs affect glucose metabolism protecting against hyperglycemia. $\uparrow$ increase; $\downarrow$ decrease. The figure was created using Servier Medical Art by Servier (smart.servier.com, accessed on 12 March 2021), licensed under a Creative Commons Attribution 3.0 Unported License).

\subsubsection{Gut: Carbohydrate Digestion and Glucose Absorption}

Complex carbohydrates, once reached the small intestine, are mainly digested by $\alpha$-amylase and $\alpha$-glucosidase, two key carbolytic enzymes involved in post-prandial glycemic response, which convert them into monomers. The latter are then incorporated by enterocytes through specific transporters localized at the apical side of their brush border membrane. Among them, sodium-dependent glucose transporter (SGLT1) and glucose transporter GLUT2are inhibited by PACs [215], thus preventing glucose absorption. Glucose tolerance was also found to be favored by PACs thanks to their capability to promote, both in vitro and ex vivo, the secretion of glucagon-like-peptide-1 (GLP-1), one of the most important satiety-related enterohormones: grape seed proanthocyanidins extracts (GSPE) stimulate GLP-1 secretion in the ileum, whereas unabsorbed or metabolized forms do the same in the colon probably through MAPK and ERK1/2 pathways $[216,217]$. The suppression of GLP-1 secretion seems to be dependent from PAC concentration and its subsequent effect on cellular membrane potential: at low concentrations $(0.05 \mathrm{mg} / \mathrm{l}) \mathrm{GSPE}$ induces depolarization in STC-1 cells, whereas at high concentrations $(50 \mathrm{mg} / \mathrm{l})$ it leads to hyperpolarization and the concomitant suppression of GLP-1 secretion [218]. In regard to carbohydrates digestion, PACs are able to inhibit some digestive enzymes even more than their anthocyanin relatives, suggesting excellent potential in suppressing the early glycemic spike and thus preventing T2DM [215,219-221]. For instance, proanthocyanidin $\mathrm{B} 2\left(\mathrm{~PB}_{2}\right)$ reversibly and significantly inhibits $\alpha$-glucosidase activity $\left(\mathrm{IC}_{50}=0.23 \pm 0.01 \mu \mathrm{g} / \mathrm{mL}\right)$, with only slight effect on $\alpha$-amylase $\left(\mathrm{IC}_{50}=0.86 \mathrm{mmol} / \mathrm{L}\right)$ on everted intestinal sleeves [185]. To 
elaborate- $-\mathrm{PB}_{2}$ inhibited $\alpha$-glucosidase in a mixed-type manner to interrupt the enzymesubstrate intermediate. Finally, molecular docking analysis revealed that $\mathrm{PB}_{2}$ interacts with several amino acid residues of $\alpha$-glucosidase, thus inducing a conformational change, ultimately leading to aggregation [185]. PACs activity on digestive enzymes is strictly dependent on their structure: in particular, the number of hydroxyl groups, their position on the A, B, and C rings [222] and the degree of polymerization are critical $[215,223]$. Interestingly, Zhong and co-workers demonstrated that the PAC-mediated inhibition of some digestive enzymes in the small intestine and pancreas was more pronounced in mice fed high-degree PACs with respect to those fed low-degree PACs [215]. This effect is probably due to the presence of a higher number of phenolic hydroxyl groups in the high-polymer PACs, which may establish a larger number of hydrogen bonds with the peptidyl-NH-CO-, amino- $\mathrm{NH}_{2-}$, and carboxyl-COOH groups of $\alpha$-amylases, thus forming a complex with reduced or lost catalytic capacity. Interestingly, the formation of enzyme aggregates may be affected by carbohydrates: pectin and Arabic gum cannot restore the enzyme activity but are able to reduce the formation of insoluble aggregates [224]. Similar results were also obtained measuring trypsin activity in the small intestine, which resulted inhibited by $32 \%$ in the high-polymer fed mice group and by $15 \%$ in the lowpolymer group, and pepsin activity in the stomach inhibited at a rate of $38 \%$ and $13 \%$ by high- and low-degree PACs, respectively [215]. Conversely, lipase activity was not depressed by PACs, probably due to a lower affinity for this class of polyphenols than the other digestive enzymes [215]. Nevertheless, fat, as well as protein and mineral apparent digestibility is strongly affected by PACs supplementation, thanks to their great capability to interact with macromolecules and metal ions interfering with, and specifically hindering, their absorption and digestion. Furthermore, PACs may affect the discharge of nutrients interacting with polysaccharides, proteins, and phospholipids localized on cell membranes and thus conditioning their permeability. Moreover, in this case polymers showed the highest activity selectively dependent on their structure, molecular mass, and spatial configuration [215].

However, as previously said, $70 \%$ of the total PACs taken with the diet (mostly polymers) are not directly absorbed in the stomach and small intestine, but remain in the lumen of gastrointestinal tract and are massively metabolized in the colon before entering the systemic circulation in the form of metabolites [225]. In most cases, unabsorbed polyphenolic compounds can become substrates for fermentation of the fecal microbiota in the colon [226]. This is especially the case with polymeric PACs, which have revealed good potential against obesity-associated metabolic disorders altering gut microbiota profile. For instance, two very recent studies have shown that polyphenol-rich fractions purified from whole blueberry exert distinct effects on the fecal microbiota composition based on the type of bioactive compound [203,204]. In particular, PAC fractions revealed the greatest impact in promoting $\alpha$ diversity of the fecal microbiota specifically resulting in the most sustained content of Lachnospiraceae and Bacteroidaceae in an in vitro colon system [204]. Interestingly, Ntemiri and co-workers established a correlation between fecal microbiota changes and circulating antioxidant activity, showing that a subset of specific taxonomic groups enriched by blueberry consumption were also significantly and positively associated with ferric-reducing antioxidant power (FRAP), which, in turn, negatively correlated with the plasma glucose levels [204]. Moreover, the polymeric PACrich fraction leads to an improvement of glucose tolerance in vivo that has been strictly related to the modulation of bacterial taxa within the families Coriobacteriaceae and Verrucomicrobiaceae and the maintenance of the colonic mucus layer [203]. The latter is mainly due to an increase of the number of mucin-secreting goblet cells induced by polymeric PACs consumption [203,227]. Moreover, it seems that this protective effect on colonic mucus thickness could be mediated by an increase in acidic-mixed mucin secretion, more resistant against microbiological degradation than neutral mucins [203]. On the other hand, oligomeric PAC-rich fraction stimulates the abundance of bacteria known to play a key role in colonic epithelial immunomodulatory response and to protect 
against metabolic disorders like A. muciniphila [228-230], whose proportion significantly increases following PACs consumption [203,231-233]. Interestingly, this combines to lower urine content of metabolites associated with insulin resistance [233]. Another bacterium stimulated by PAC oligomers is A. equolifaciens [203], known to decrease concomitantly with inflammatory bowel disease development [234] and to be involved in the degradation of phenolic compounds including (-)-epigallocatechin, (-)-epicatechin, (-)-catechin, and $(+)$-catechin into their corresponding metabolites $[235,236]$. This evidence suggests a compelling involvement of PACs in their own metabolism, which is particularly relevant as it can generate bioactive molecules involved in the improvement of metabolic disorders. Finally, several human and animal studies have highlighted a correlation between metabolic disorders such as obesity and T2DM and a higher ratio Firmicutes/Bacteroidetes [237-239]. In this regard, GSPE and highly polymeric procyanidins impact on this ratio increasing Bacteroidetes and decreasing Firmicutes phyla [217,233].

Interestingly, PACs oligomers larger than decamer exhibited a strong absorption capacity of methyl mercaptan, hydrogen sulfide, and other putrefactive products both in vitro and in vivo [240]. The resulting strong deodorizing outcome of PACs on fecal odor may be due not only to the absorption of foul-smelling compounds from stool, but also by PAC-induced changes in the intestinal flora. In fact, proanthocyanidin-rich extract from grape seeds significantly enhances the number of Bifidobacterium and lowers Enterobacteriaceae in human fecal specimens [240].

\subsubsection{Liver: Glucose Uptake and Metabolism}

Most PACs, upon absorption through the gut, travel from the portal bloodstream to the liver, where monomers undergo to phase I and II biotransformation through which they become more hydrophilic, thus favoring their entering the systemic circulation and secretion through the urinary system [241]. However, once in the liver, PACs oligomers may modulate hepatocytes functions and interfere with glucose uptake and metabolism.

For instance, PACs may reduce hyperglycemia through the regulation of GLUT2 transporters: in addition to stimulate basal glucose uptake into human HepG2 cells by significantly increasing GLUT2 expression (1.9-3.12-fold) [220], PACs can revert the decreased extracellular glucose consumption triggered by insulin pre-treatment, leading to an insulin sensitivity improvement similar to that observed upon treatment with metformin [242]. Furthermore, a correlation has been established between PAC exposure and/or supplementation with reduced gluconeogenesis and increased glycolytic and glycogenic activity in the liver, which ultimately results in lower levels of circulating blood sugar [220,242]. Indeed, PACs can inhibit the activity of hepatic glucokinase (GCK), a major player in glucose homeostasis responsible for converting glucose to glucose-6-phosphate [214,242] as well as increase the expression of a critical gene of glycogenesis, GYS2 [220]. PACs have also proved effective in preventing some secondary complications of long-standing hyperglycemia like glycation, a random process that occurs when macromolecules are found in an environment with a high concentration of sugars and impairs the functioning of biomolecules producing the so-called "advanced glycation end products" (AGE) responsible for many vascular complications in T2DM [220].

In addition to these effects, PACs also reduce hepatic glucose production. In particular, they dampen gluconeogenesis mainly through the activation of the adenosine monophosphate-activated protein kinase (AMPK) pathway. As demonstrated both in vitro and in vivo, PACs dose-dependently improve hyperglycemia and insulin sensitivity through the activation of the AMPK signaling pathway, which, in turn, lead to a significant hepatic downregulation of rate-limiting gluconeogenic enzymes, i.e., glucose-6-phosphatase (G6Pase) and phosphoenolpyruvate carboxykinase (PEPCK) [214,243-245]. Moreover, type 2 diabetic mice fed Enzogenol (EZ), a PAC-rich extract from the pine bark New Zealand Pinus radiata trees, showed a dose-dependent increase in the expression of hepatic glycogen synthase (GS), another key enzyme in glucose metabolism that is impaired in diabetes disorder [214]. However, AMPK activation is not the only mechanism through which 
PACs exert their glucose regulatory actions. Indeed, although results from an in vitro study on HepG2 showed that epigallocatechin gallate (EGCG) suppressed gluconeogenesis following ROS production and the subsequent calcium/calmodulin-dependent protein kinase (CaMKK)-mediated AMPK activation and not through the activation of the insulin signaling pathway [246], other pieces of evidence revealed that many PACs' effects on hepatic glucose metabolism are mediated by the latter. For instance, Cordero-Herrera and co-workers demonstrated that EC from cocoa activated not only AMPK but also key proteins of the insulin pathways, including insulin receptor (IR) and insulin receptor substrate (IRS) 1 and 2, through the PI3K/Akt pathway both in vitro and in vivo [245,247,248]. The decrease in tyrosine-phosphorylated and total levels of IR, IRS-1 and -2, as well as PI3K/Akt pathway inhibition observed after high glucose exposure, was reverted after HepG2 pre-treatment with EC [247]. Similarly, in type 2 diabetic Zucker diabetic fatty (ZDF) rats fed a cocoa-rich diet $(10 \%)$, hepatic insulin resistance is improved thanks to a reduced serine-phosphorylation of the IRS-1 and a strongly supported glycogen synthase kinase 3 /glycogen synthase pathway [248]. Moreover, ZDF rats supplemented with cocoa showed significant suppression of events caused by insulin resistance such as c-Jun $\mathrm{N}$-terminal protein kinase (JNK) and p38 activation [248]. These actions, together with GCK and GLUT2 improvement and PEPCK inhibition, give rise to the overall hypoglycemic effects shown by cocoa supplementation, resulting in reduced glucose and insulin levels in ZDF rats blood, as well as an improved glucose tolerance [248]. Consistently, in insulin-resistant Albino Wistar rats, a GSP diet $(100 \mathrm{mg} / \mathrm{kg})$ improves hyperglycemia and hyperinsulinemia, increasing tyrosine phosphorylation of IR- $\beta$ and IRS- 1 and decreased serine phosphorylation of IRS-1. Furthermore, the insulin signaling pathway is enhanced by GSP through the association between the PI3K p $85 \alpha$ subunit and IRS- 1 and the subsequent Akt phosphorylation [249]. Taken together, all of these findings explain the insulin-like effects shown by PACs and support their usefulness in countering what is one of the main issues associated with type 2 diabetes mellitus, namely insulin resistance.

\subsubsection{Pancreas: $\beta$-Cell Functionality}

PACs, besides their inhibitory action on pancreatic digestive enzymes, such as $\alpha$ amylase and trypsin [215,224], explicate their effects on glucose homeostasis also directly affecting major pancreatic $\beta$-cell functions, i.e., prevention of oxidative stress, enhancement of insulin secretion, and promotion of cell survival. The role of free radicals in the etiology of diabetes is well established [250]: starting from the well-known antioxidant properties of PACs, several studies focused on the role of this class of polyphenols in the control of OS in pancreatic $\beta$-cells. Islet cells are particularly susceptible to free radical attacks since their defense against ROS are weak. GSP administration attenuated some ER stress markers such as glucose-regulated protein (GRP) 78, C/-EBP homologous protein (CHOP) and caspase-12 and significantly decreased the activity of JNK, all dramatically elevated in pancreatic islets of diabetic rats [189]. PAC-mediated attenuation of ER stress in $\beta$-cells is also accompanied by an improvement in the pancreatic islet atrophy observed diabetic conditions and a reduction in the number of apoptotic cells both in vitro and in vivo $[189,251,252]$. Moreover, GSP oral administration has been shown to significantly reduce the pancreatic total nitrate/nitrite and ROS content and at the same time to increase pancreatic glutathione (GSH) levels, overall resulting in lower blood glucose and higher insulin levels in diabetic rats [188,251]. Therefore, carrying out their antioxidant activity, PACs promote $\beta$-cell viability, proliferation, and regeneration in a dose-dependent manner [253-255].

In addition to their protective effects against oxidative insults in pancreatic tissues, PACs directly stimulate insulin secretion, probably with greater efficiency the higher the number of hydroxyl groups on the B ring, as assessed for anthocyanins [256]. PACs promote glucose-stimulated insulin secretion (GSIS), both on healthy and diabetic rats [255,257], both on normal isolated Langerhans islets [255], and on $\beta$-cell lines [257,258]. This effect was further pronounced in rats fed with hydrolyzed PACs (HPAC), once again confirming that 
hydrolysis of the PAC polymers allows improving their benefits on glucose homeostasis and pancreatic $\beta$-cell function, by enhancing their bioavailability, as confirmed through the detection of increased PAC metabolites in serum samples from animals fed with HPAC [259]. PACs' role as insulin secretagogues is probably due to their involvement as modulators of specific signaling pathways rather than their antioxidant properties. In fact, in contrast with studies on PACs as $\beta$-cell antioxidants, more than one finding showed that lower doses $(\leq 15 \mathrm{mg} / \mathrm{kg}$ ) of GSPE were more effective than higher doses ( $\geq 25 \mathrm{mg} / \mathrm{kg}$ ) in promoting insulin secretion, especially in long-term treatments ( $\geq 1 \mathrm{month}$ ). Indeed, a prolonged high dose GSPE treatment decreased insulin production both ex vivo [192] and in vivo [192,260], and this was related to the downregulation of proteins involved in insulin synthesis and secretion like the pancreatic and duodenal homeobox 1 (PDX-1) [192,260]. PACs' impact on insulinemia might be also attributable to a direct effect of PACs on insulin clearance: PACs affected mRNA expression of insulin degrading enzyme (Ide), responsible for the removal of insulin and particularly active in the liver [192] However, the specific mechanism through which PACs may regulate Ide expression is still not completely clear. Taking into account the evidence that peroxisome proliferatoractivated receptor- $\gamma(\operatorname{PPAR} \gamma)$ plays an important role in regulating Ide gene expression in rat primary neurons [261], together with the finding that GSPE treatment downregulates PPAR $\gamma$ expression in 3T3-L1 adipocytes [262], PAC-mediated control of Ide expression could occur through PPAR $\gamma$ regulation.

\subsubsection{Insulin-Sensitive Tissues: Adipose Tissue and Muscle}

PACs, thanks to their insulin-mimetic properties, influence glucose homeostasis even in insulin-sensitive tissues, such as adipose tissue and skeletal muscle. For example, as described for the intestine and liver, PACs stimulate glucose absorption in a dose-dependent manner also in adipocytes and myocytes, though different molecular mechanisms. They improve glucose uptake by upregulating GLUT4 expression [191,219,242,263], as well as promote GLUT4 translocation to the plasma membrane like insulin in both adipocytes and myocytes [191,243]. The PAC-mediated GLUT4 recruitment to the cell surface involves the activation of PI3K and p38 MAPK, as demonstrated by the sensitivity to both wortmannin and SB203580 [191]. In addition, pigmented rice bran extracts exerted a positive regulation of GLUT1 mRNA, which is essential for the biosynthesis of GLUT proteins to mediate the glucose uptake into adipocytes [219].

PACs, besides their effect on glucose transporters, increase the expression of genes encoding insulin-signaling pathway proteins, including Akt2, the isoform most strongly linked to GLUT4 translocation, PI3K and the insulin receptor substrate 1 (IRS1), which plays a key role in insulin-stimulated glucose uptake, in addition to the insulin receptor (IR) itself [219]. Procyanidin type-A oligomers, especially trimers and tetramers, increased IR $\beta$ levels in mouse 3T3-L1 adipocytes [263]. Montagut and co-workers demonstrated that PAC oligomers from GSPE are able to directly activate IR and other key targets of the insulin signaling pathway [264]. However, although PACs interact directly with the insulin receptor, the activation mechanism is slightly different from that triggered by insulin. More specifically, PACs phosphorylate Akt at residue Thr308 less than insulin but at Ser473 to a similar extent [264]. Moreover, PAC oligomers were found to phosphorylate $\mathrm{p} 44 / \mathrm{p} 42$ and p38 MAPKs much more than insulin [264]. Finally, PACs ameliorate obesity and glucose intolerance by enhancing energy expenditure in adipose tissues. Black soybean seed coat extract consisting of $39.8 \%$ procyanidins leads to the up-regulation of uncoupling proteins (UCPs), whose role on energy metabolism and obesity has been largely investigated in the last three decades [265]. In particular, PACs enhance UCP-1 expression in brown adipose tissue, where it plays a key role in energy consumption by fat oxidation and following heat generation, and promote UCP-2 expression in white adipose tissue thus interfering with energy metabolism and obesity $[207,266]$. Through this action together with the removal of glucose from the bloodstream into adipocytes and myocytes and the promotion of the insulin signaling pathway, PACs may exert a significant protective activity against 
obesity, diabetes and other metabolic disorders by helping to improve glucose tolerance and homeostasis and reducing complications like insulin resistance.

\subsection{Lipid-Lowering Effect}

Hyperlipidemia, a condition characterized by disrupted lipid levels and dysregulated fatty acid and cholesterol metabolism, is associated with several pathological conditions such as obesity, MetS, coronary heart disease and atherosclerosis [3,5]. This condition is mainly defined by high serum concentration of low-density lipoprotein (LDL), low high-density lipoprotein (HDL) levels, hypertriglyceridemia and imbalanced redox homeostasis due to improved lipid peroxidation and increased LDL susceptibility to oxidation. Oligomeric PACs can act as cell signaling molecules to modulate lipid homeostasis in the systemic circulation, as revealed by numerous in vivo studies, which essentially indicate a PAC-related lowering effect on total cholesterol (TC), triglycerides (TG) or triacylglycerol (TAG), plasma free fatty acid (FFA) and LDL levels (Table 3).

In order to understand if PAC supplementation could affect blood lipid levels, we performed a meta-analysis on data collected from articles published in the last 10 years and that satisfied the inclusion criteria established above. Briefly, the previously published articles $(n=248)$ were obtained by a literature search on PubMed, Scopus, Google Scholar, and ISI Web of Science research tool and using the following keywords: "proanthocyanidin(s)" OR "procyanidin(s)" OR "PAC(s)" AND “cholesterol" OR “LDL" OR “HDL" OR "low density lipoprotein" OR "high density lipoprotein"). Then, a manual screening of the articles was performed by reading the title, abstract, or full text. Original articles were exclusively included if they met the following inclusion criteria: (i) the language should be English; (ii) articles should be published in peer-review journals; and (iii) after the reviewing by experts; (iv) the study design should be a randomized controlled clinical trials on humans; (v) the intervention should be the supplementation of formulation containing PACs only, and not in combination with other substances; (vi) only studies in which the number of participant have been clearly reported should be included; (vii) the parameters measured should be related to total cholesterol level, LDL, or HDL; (viii) when outcomes were presented at different times in the study, only the longest follow-up duration was selected. Accordingly, from the 248 published full text articles identified during the bibliographic search, 238 were excluded. Data from the selected articles $(n=10)$ were employed for the meta-analysis $[187,267-275]$. Since data were accumulated from a series of studies that had been independently performed, all of the selected studies were not functionally equivalent. Consequently, the originated forest plots (Figure 16) were performed using random effect, according to the heterogeneity calculated between the studies. Statistical heterogeneity among studies was checked with the Cochrane $Q$ test (significance level of $p<0.05)$ and the $\mathrm{I}^{2}$ statistic.

Furthermore, sensitivity analyses were performed to evaluate the influence of each study on the overall effect size. Finally, potential publication bias was checked by visual inspection of the respective funnel plot. As the Figure 1 displays, no publication bias was identified among the selected studies for total cholesterol (Figure S1B) and HDL (Figure S1C) levels. However, it was observed on LDL levels (Figure S1D).

The combined results of the selected articles from the random-effect model suggested a significant effect of PAC supplementation on total cholesterol (WMD: $-0.34 \mathrm{mmol} / \mathrm{L}$; $95 \%$ CI: $-0.44,-0.24 ; \mathrm{I}^{2}=83 \% ; p=0.00001$ ) and HDL (WMD: $-0.05 \mathrm{mmol} / \mathrm{L} ; 95 \% \mathrm{CI}$ : $-0.11,-0.01 ; \mathrm{I}^{2}=81 \% ; p=0.05$ ) levels. However, no effects were observed on LDL (WMD: $-0.05, \mathrm{mmol} / \mathrm{L} ; 98 \% \mathrm{CI}:-0.26,+0.21 ; \mathrm{I}^{2}=98 \% ; p=0.83$ ) levels. 


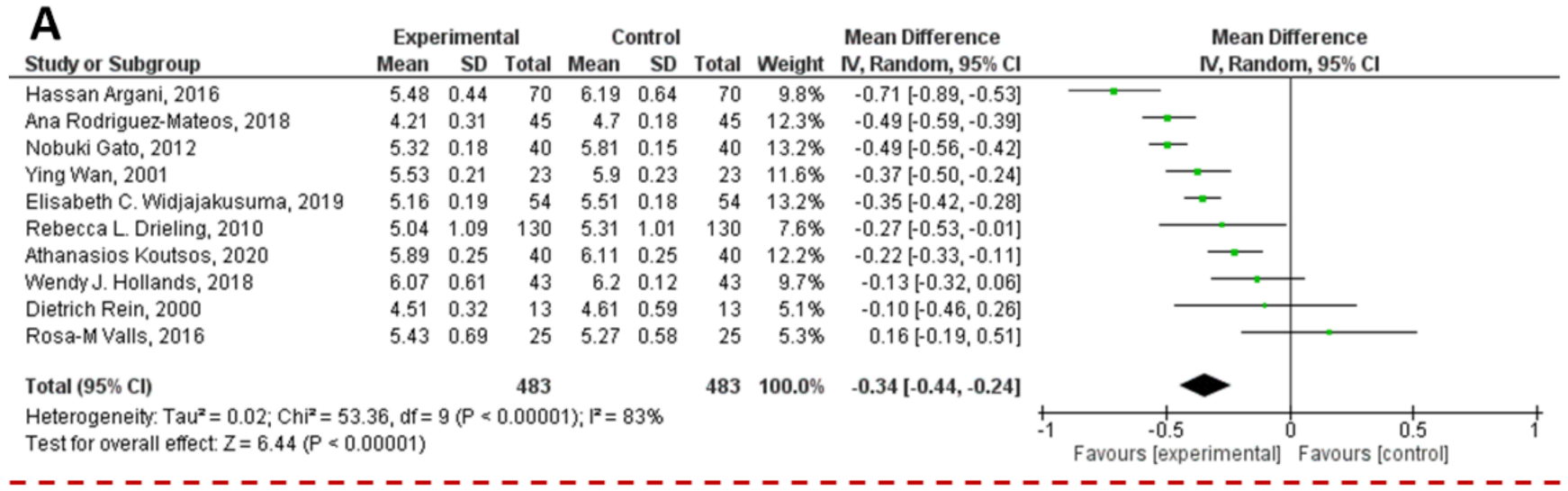

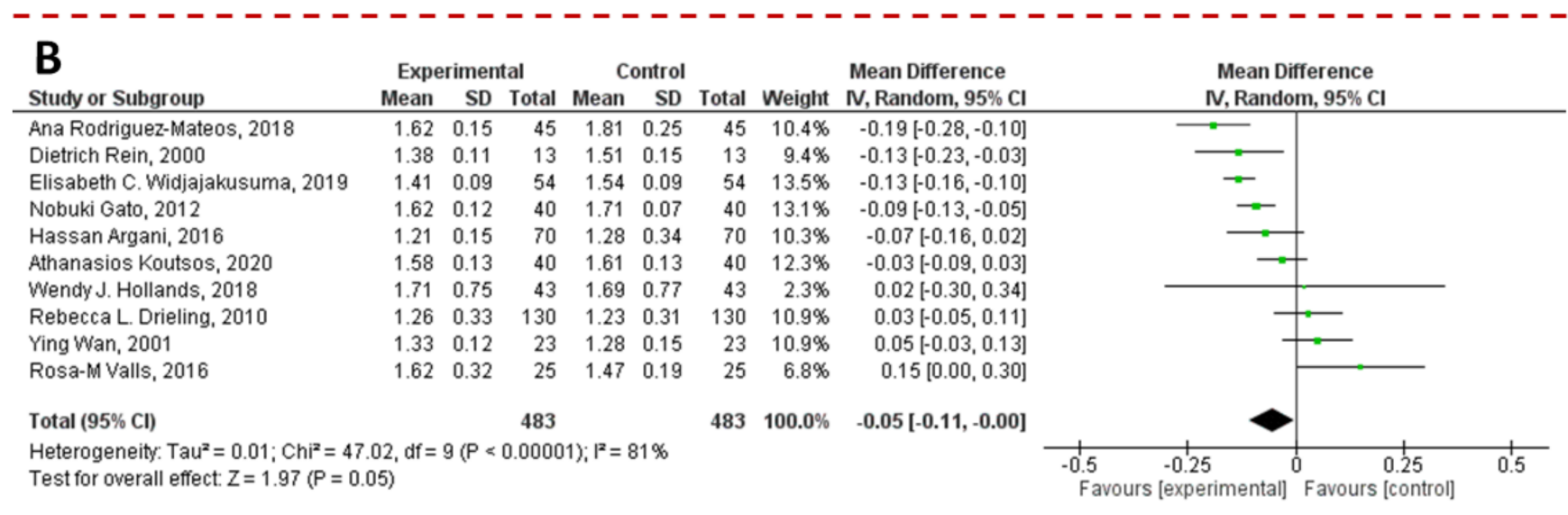

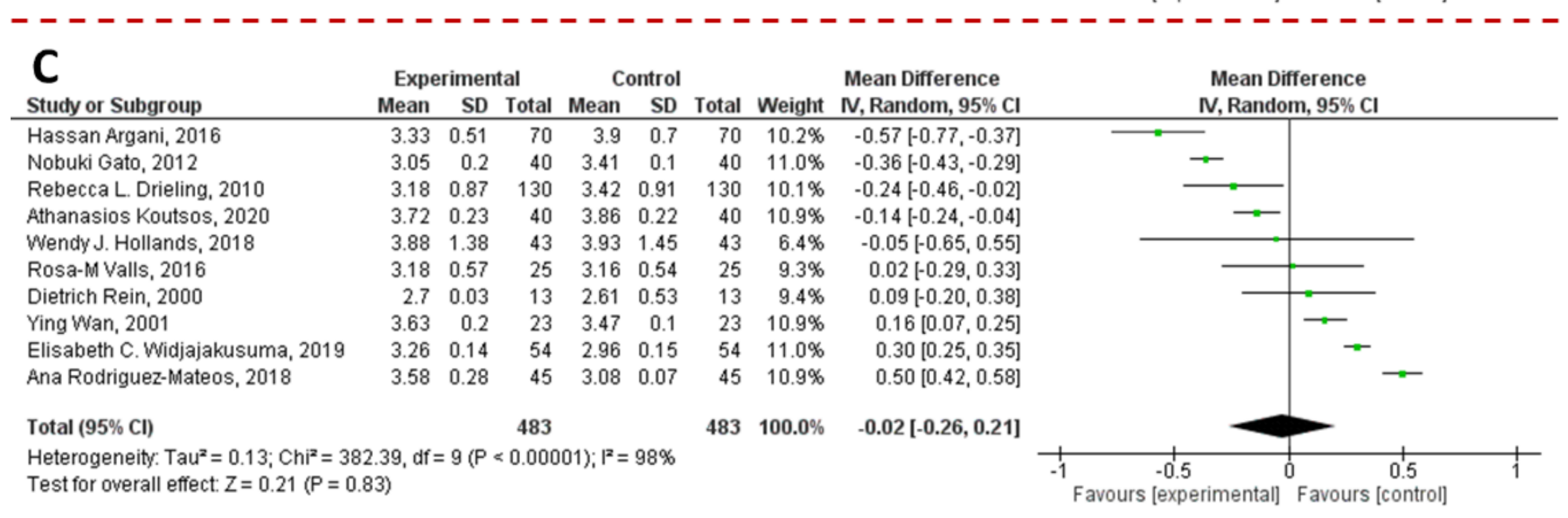

Figure 16. Forest plot representation of the effects derived from the supplementation of PACs on total cholesterol (A), HDL (B), and LDL (C) levels. Data were extrapolated from [187,267-275], and plotted according to the mean difference. Each horizontal line of the plot represents an individual study, reporting the punctual result plotted as green box. The weight of each study is represented by the size of the green box. The horizontal line indicates the lower and upper limit of the $95 \%$ Confidence Interval (CI) of the effect observed for each study. The vertical line represents the no-effect. For each study, if the horizontal line crosses the vertical one, a statistically significant difference between Experimental and Control group is not observed. The black diamond at the bottom of the forest plot represents the average effect size combining together the results of all the selected studies. The horizontal points of the diamond are the limits of the $95 \% \mathrm{CI}$ of the average value. The figure was generated by Review Manager Software, version 5.4.1.

In the next subsections, we will deepen the potential beneficial effects of PACs on hyperlipidemia. In particular, we will investigate the main molecular mechanisms through which PACs can interfere with lipid metabolism (Figure 17) which mainly concern intestinal absorption of lipids and the secretion of chylomicrons (CM) and lipoproteins by the intestine and liver [276]. 
Table 3. In vitro and in vivo studies on PAC-mediated and lipid-lowering effect.

\begin{tabular}{|c|c|c|c|c|}
\hline \multicolumn{5}{|c|}{ Lipid-Lowering/Anti-Obesity Studies } \\
\hline References & & PAC Type or Source & Plasma Parameters & Model \\
\hline Bansode et al., 2014 & [277] & procyanidin A2 & TG, VLDL & Rats \\
\hline Yin et al., 2017 & [278] & procyanidin B2 & TG, TC, FFA & Mice \\
\hline Xing et al., 2019 & [279] & procyanidin B2 & $\begin{array}{l}\text { TG, } \mathrm{TC} \text {, aspartate } \\
\text { transaminase }\end{array}$ & Rabbits \\
\hline Sano et al., 2007 & [183] & PACs tablets & $\begin{array}{l}\text { MDA-LDL, } \\
\text { adiponectin }\end{array}$ & human \\
\hline $\begin{array}{l}\text { Mildner-Szkudlarz et al., } \\
2013\end{array}$ & [280] & grape seed and extract & $\begin{array}{l}\text { TC, LDL-C, HDL-C, } \\
\text { leptin, GLU }\end{array}$ & Rats \\
\hline Natella et al., 2002 & [281] & GSPE & $\begin{array}{l}\text { TC, TAG, LPO, OS } \\
\text { biomarkers }\end{array}$ & human \\
\hline Del Bas et al., 2008 & [282] & GSPE & TG, ApoB & Rats \\
\hline Del Bas et al., 2009 & [283] & GSPE & TG & Mice \\
\hline Quesada et al., 2009 & [284] & GSPE & TG, LDL-C & Rats \\
\hline Adisakwattana et al., 2010 & [285] & GSPE & TG, FC & Rats \\
\hline Jiao et al., 2010 & [286] & GSPE & TC, TAG & Hamsters \\
\hline Pajuelo et al., 2011 & [287] & GSPE & TG, FFA, glycerol, urea & Rats \\
\hline Baselga-Escudero et al., 2013 & [288] & GSPE & TG, TC, LDL-C & Rats \\
\hline Guerrero et al., 2013 & [289] & $\begin{array}{l}\text { GSPE and GSPE } \\
\text { metabolites }\end{array}$ & TG, FC, CE & Rats \\
\hline Caimari et al., 2013 & [290] & GSPE & FFA, PL & Hamsters \\
\hline Hintz et al., 2014 & [291] & GSPE & TG, BA & Mice \\
\hline Downing et al., 2015 & [292] & GSPE & TG, BA & Rats \\
\hline Baselga-Escudero et al., 2015 & [293] & GSPE & $\begin{array}{c}\text { TG, LDL-C, } \\
\text { HDL-C/LDL-C }\end{array}$ & Rats \\
\hline Heidker et al., 2016 & [294] & GSPE & TG, FC, BA, FFA & Mice \\
\hline Shi et al., 2019 & [295] & GSPE & TG, TC, LDL-C, HDL-C & Mice \\
\hline Gonçalves et al., 2017 & [296] & Vitis vinifera extract & $\begin{array}{l}\text { LDL, adiponectin, } \\
\text { leptin }\end{array}$ & human \\
\hline Senault et al., 2000 & [297] & red wine & $\begin{array}{l}\text { HDL-C, Apo A-I, } \\
\text { HDL3-C, LpA-I }\end{array}$ & human \\
\hline Pal et al., 2004 & [298] & red wine & $\begin{array}{c}\text { ApoB48, CM, CMR, TC, } \\
\text { LDL-C, HDL-C, TAG, } \\
\text { GLU, INS }\end{array}$ & human \\
\hline Sugiyama et al., 2007 & [299] & apple & - & $\begin{array}{l}\text { Mice/ } \\
\text { human }\end{array}$ \\
\hline Rein et al., 2000 & [275] & EC from chocolate & $\begin{array}{l}\text { TG, TBARS, OS } \\
\text { biomarkers }\end{array}$ & human \\
\hline Wan et al., 2001 & [274] & $\begin{array}{l}\text { cocoa and dark } \\
\text { chocolate }\end{array}$ & HDL-C, OS biomarkers & human \\
\hline Mursu et al., 2004 & [300] & chocolate & $\begin{array}{l}\text { HDL-C, LDL diene } \\
\text { conjugates }\end{array}$ & human \\
\hline Mellor et al., 2010 & [301] & chocolate & TC, HDL & human \\
\hline Tokede et al., 2011 & [302] & dark chocolate & TC, TG, LDL-C, HDL-C & human \\
\hline Drieling et al., 2011 & [273] & pine bark & LDL-C, GLU, INS, CRP & human \\
\hline Yokozawa et al., 2008 & [303] & Gravinol & $\begin{array}{l}\text { TC, TG, LDL, VLDL, } \\
\text { IDL, GLU, GP, TBARS }\end{array}$ & Rats \\
\hline
\end{tabular}

EC = epicatechin; GSPE = grape seed extract; GLU = glucose; INS = insulin; GLP-1 = glucagon-like peptide-1; TG = triglycerides; TC = total cholesterol; LDL -C = low density lipoprotein-cholesterol; ALT = alanine aminotransferase; HOMA-IR = homeostasis model assessment of insulin resistance; GP = glycosylated protein; NEFA = non-esterified fatty acids; $\mathrm{OS}=$ oxidative stress; $\mathrm{HbA1c}=$ glycosylated haemoglobin; BUN = blood urea nitrogen; HDL-C = high density lipoprotein-cholesterol; AST = aspartate aminotransferase; MDA = malondialdehyde; $\mathrm{DAO}$ = diamine oxidase; $\mathrm{CRP}=\mathrm{C}$-reactive protein; FRAP = ferric-reducing antioxidant power; $\mathrm{GIP}$ = glucose-dependent insulinotropic polypeptide; $\mathrm{BA}=$ bile acids; VLDL = very low density lipoprotein; FFA = free fatty acid; FC = free cholesterol; $\mathrm{CE}=$ cholesterol ester; $\mathrm{PL}=$ phospholipids; TAG = triacylglycerides; $\mathrm{LPO}=$ plasma lipid hydroperoxides; $\mathrm{Apo}=$ apolipoprotein $; \mathrm{IDL}=$ intermediate-density lipoprotein; TBARS = thiobarbituric acid-reactive substance; $\mathrm{CM}=$ chylomicrons; $\mathrm{CMR}=$ chylomicron remnants; LpA-I = lipoprotein particles A-I. 


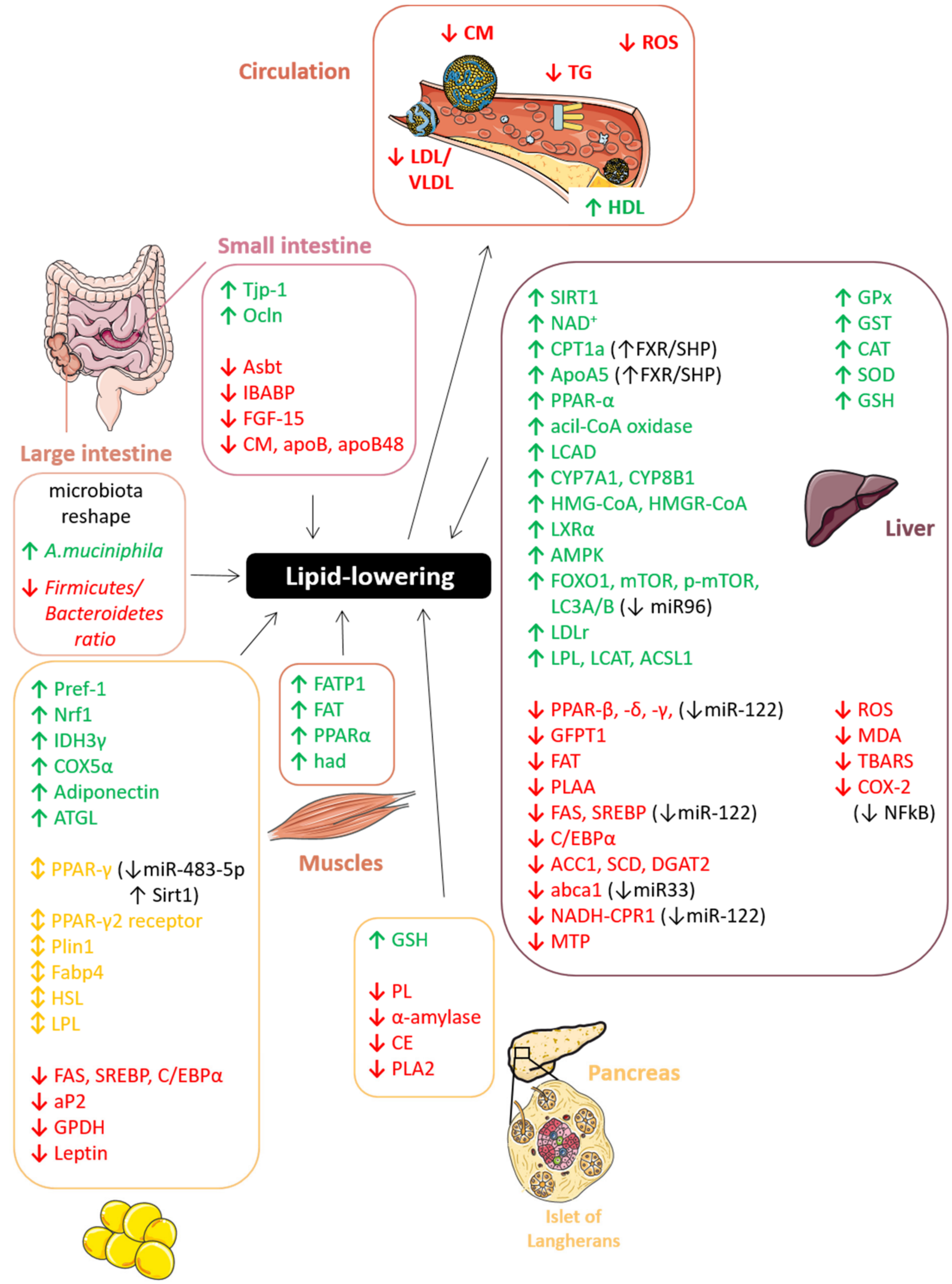

Adipocytes

Figure 17. Schematic representation of the molecular mechanisms through which PACs affect lipid metabolism protecting against hyperlipidemia. $\uparrow$ increase; $\downarrow$ decrease; $\uparrow$ increase/decrease. The figure was created using Servier Medical Art by Servier (smart.servier.com accessed on 12 March 2021), licensed under a Creative Commons Attribution 3.0 Unported License. 


\subsubsection{Gut: Lipid Absorption and Chylomicron Secretion}

The intestine is the first epithelium that dietary compounds encounter and it contributes to lipid homeostasis mainly by secreting triglyceride-rich lipoproteins during the postprandial state and by regulating lipid absorption. Long-chain fatty acids (LCFAs), free cholesterol, $\beta$-acyl glycerol, and bile salts form mixed micelles in enterocytes, whereas glycerol and short-/medium-chain fatty acids are directly absorbed from the intestinal lumen into the portal vein and will be further metabolized into the liver. PACs were found to reduce cholesterol and bile acid (BA) absorption by decreasing the micellar solubility of cholesterol $[304,305]$. It is thought that GSPE binds to BA, such as taurocholic acid, taurodeoxycholic acid, and glycodeoxycholic acid, forming insoluble complexes in the intestine, which inhibit the formation of cholesterol micelles in the intestinal lumen and increase their fecal excretion [285,305]. Moreover, procyanidin A1, and even more epicatechin- $(4 \beta \rightarrow 6)$-epicatechin- $(2 \beta \rightarrow \mathrm{O} \rightarrow 7,4 \beta \rightarrow 8)$-catechin extracted from the skin of the peanut, degrade cholesterol micelles in vitro, thus contributing to the overall cholesterollowering effect observed in rats fed with high-cholesterol diet supplemented with peanut skin [306]. Interestingly, apple highly polymeric procyanidins may mitigate intestinal permeability through the upregulation of tight junction protein-1 (Tjp1) and occludin (Ocln) in mice fed with high-fat/high-sucrose diet [233]; on the other hand, GSPE reduces intestinal apical sodium-dependent bile acid transporter (Asbt) [291,294] and intestinal bile acidbinding protein (IBABP) expression, thereby impacting BA uptake and transport through the enterocyte [291]. BA synthesis is also impacted by GSPE administration, as revealed by the repression of the ileal fibroblast growth factor 15 (FGF-15), a critical gut-liver regulator of cholesterol-7 $\alpha$-hydroxylase (CYP7A1), which is a key rate-limiting enzyme involved in BA synthesis [291].

Once in the intestinal epithelial cells, TGs are packed together with cholesterol and fat-soluble vitamins into CMs. This class of ultra-low-density lipoproteins is responsible for the transport of dietary lipids from the gut to other locations in the body within the water-based solution of the bloodstream. GSPE assumption affects postprandial hypertriacylglycerolemia by CM and/or VLDL regulation in a time-dependent manner. To elaborate, GSPE was shown to restore rat plasma TAG levels upon their high-fat diet (HFD)-induced increase [307]. Concomitantly, VLDL-TAG and CM-TAG levels in the plasma were reduced: after $1 \mathrm{~h}$ the VLDL-rich fraction was the major contributor, while after $3 \mathrm{~h}$ the CM-rich fraction was prevalent (85\%) [307]. However, the lipoprotein decrease mediated by PACs is not due to an increase in lipoprotein lipase (LPL) activity, but rather to repression of lipoprotein secretion [307]. Indeed, PACs reduce CM secretion, delaying the absorption of triglyceride and cholesterol in the intestine. More specifically, apple polyphenol extracts rich in PACs prevent the cholesteryl ester synthesis and lipoprotein secretion by human Caco-2/TC7 enterocytes. The latter is mainly due to the inhibition of ApoB synthesis, a marker of intestinal CM, rather than to its degradation [308]. Similarly, it has been shown that in Caco-2 cells incubated with red wine the intracellular cholesterol availability is brought down as well as CM synthesis and secretion since the expression of apolipoprotein B48 (ApoB48) was significantly reduced in CaCo-2 cells [309]. This result was also confirmed in a clinical study performed on dyslipidemic postmenopausal women, showing that the red wine assumption for 2 weeks induces a decrease in postprandial ApoB48 levels, indicating a delay in the absorption of dietary fat through a reduction in CM and CM remnant plasma levels [298].

Another mechanism through which PACs protect against hyperlipidemia-associated disorders is the regulation of the intestinal microbiota, as already described in the previous paragraph on hypoglycemic action. In particular, the reduction of hypertriglyceridemia plasma markers, such as triglycerides and total cholesterol, correlates with a significant improvement in the proportions of Bacteroidetes at the phylum level and Akkermansia muciniphila at the genus level in rabbits fed with procyanidin B2 [279]. Likewise, highly polymeric procyanidins increase the proportion of $A$. muciniphila by eight times in a mouse model fed a with high-fat/high-sucrose diet [233]. At the same time, they 
significantly decrease the Firmicutes/Bacteroidetes ratio and this change is accompanied by a reduction in butyrate, an energy source for colonocytes, and modulation of the ratio of acetate/propionate/butyrate [217]. The microbiota and the subsequent microbiota-derived short-chain fatty acids (SCFAs) reshaping evoked by PACs might be another mechanism through which this class of polyphenols protect against metabolic disorders, causing a reduction in plasma TAG and adiposity. Finally, as revealed by $16 \mathrm{~S}$ rDNA analyses, Clostridium XIVa, Roseburia, and Prevotella are substantially modulated by GSPE supplementation on mice fed with HFD. Moreover, gut microbiota depletion by antibiotic treatment abolished some beneficial effects of GSPE, i.e., the reduction of the epididymal fat mass, further confirming the close microbiota-PAC activity relationship [310].

\subsubsection{Liver: Lipogenesis, Cholesterol Metabolism and LDL Secretion}

The liver is probably the main organ in which PACs modulate lipid metabolism. Through a metabolomics approach PACs were shown to affect hepatic metabolism, mainly dose-dependently increasing its content in nicotinamide adenine dinucleotide $\left(\mathrm{NAD}^{+}\right)$[311]. The modulation of $\mathrm{NAD}^{+}$precursors and the regulation of the expression of genes involved in its metabolism together with the upregulation of Sirtuin 1 (Sirt1) raises the hepatic activation of SIRT1 and thus reduces TG accumulation in the liver [311]. Moreover, pine bark extracts (Flavangenol) revealed a good potential in the treatment of NAFLD and NASH blocking hepatic fat accumulation both in vivo and in vitro [312]. Among all the components of Flavangenol, procyanidin B1 specifically promotes the oxidation of free fatty acids (FFAs) and regulates the expression of fatty acid oxidative enzymes such as acyl-CoA oxidase and carnitine palmitoyltransferase (CPT1) [312]. Similarly, another pine bark extract named Enzogenol enhanced long-chain acyl-CoA dehydrogenase (LCAD) protein level in $\mathrm{db} / \mathrm{db}$ mice [214]. The expression of genes regulating lipid uptake, such as the proliferator-activated peroxisomal receptor $\gamma(\operatorname{PPAR}-\gamma)$, was downregulated, whereas PPAR- $\alpha$, which leads to decreased TG and cholesterol levels in plasma and liver, was upregulated by PACs $[208,214,313,314]$.

PACs are also actively involved in the suppression of hepatic lipogenesis, leading to reduced cholesterol, TG and FFA levels in a dose-dependent manner [278,303,314]. Liver proteome analysis on rats suffering from MetS revealed 75 proteins showing a differential expression in rats fed with HFD and supplemented with GSPE with respect to the control [315]. More specifically, GSPE downregulates genes involved in hepatic lipogenesis such as glutamine-fructose-6-phosphate transaminase 1 (GFPT1), fatty acid translocase (FAT) and phospholipase A2-activating protein (PLAA) [315]. PACs from cocoa, French maritime pine bark and grape seed were evaluated for their effects on lipid homeostasis evidencing that HepG2 cells treated with sera collected from rats administered PACs display a significant decrease in the de novo lipid synthesis [289]. The reduction observed on cells treated with GSPE rat serum metabolites was significantly higher than that induced by the direct treatment with GSPE extract, supporting the key role of PACs metabolism/conjugation in the expression of their pharmacological activity [289]. The PAC-mediated inhibition of hepatic lipogenesis arise from the downregulation of enzymes involved in the fatty acid synthesis, i.e., fatty acid synthase (FAS), sterol regulatory elementbinding protein (SREBP)1 and 2, CCAAT-enhancer-binding proteins (C/EBP- $\alpha)$, acetyl-CoA carboxylase (ACC1), AMP-activated protein kinase (AMPK), carnitine palmitoyltransferase1a (CPT-1a), and stearoyl-CoA desaturase 1 (SCD) [208,233,279,292,313,314]. More specifically, FAS and C/EBP- $\alpha$ modulation appear to be mediated by the inhibition of the c-Jun $\mathrm{N}$-terminal kinase (JNK) signaling pathway induced by GSPE [316]. These regulatory effects on gene expression are primarily dependent on oligomeric rather than polymeric PACs $[208,279,314]$. One of the molecular mechanisms underlying the anti-lipogenic activity of PACs follows the same pathway as bile acids which involves the activation of the farnesoid $\mathrm{X}$ receptor (FXR) and the nuclear receptor small heterodimer partner (NR0B2/SHP) [282,294]. More specifically, PACs, as well as BA, are able to bind to and activate FXR, thus inducing the expression of its target $\mathrm{SHP}$, which, in turn, regulates the 
expression of several lipogenic genes including SREBP-1c, CPT-1a and apolipoprotein A5 (ApoA5). FXR or SHP suppression via siRNA or knockout completely abolished the TG-lowering action of GSPE both in vitro and in vivo, confirming their essential role as mediators of the hypotriglyceridemic actions of PACs [282,283]. Moreover, a possible interaction of PACs with the transcription factor EB (TFEB) was also highlighted. Procyanidin $\mathrm{B} 2$, probably through direct interaction with TFEB, modulates its activity and consequently the expression of its target genes (Lamp1, Mcoln, Uvrag) involved in the lysosomal pathway in HFD-induced liver steatosis [314]. These results could identify procyanidin B2 as a promising candidate for the prevention and treatment of NAFLD.

PAC hypolipidemic effect is further enhanced thanks to an active role in microRNA regulation (miR). In particular, PACs were shown to rapidly and transiently repress miR-33, which targets ATP-binding cassette A1 (abca1) and genes involved in the modulation of fatty acid and cholesterol homeostasis, and miR-122, which targets fatty acid synthesis genes (e.g., srebp-1c, fas) and fatty acid $\beta$-oxidation genes (e.g., NADPH-cytochrome P450 reductase-1, ppar- $\beta / \delta)[288,293,317,318]$. Their deregulation has been associated with metabolic disorders like obesity and MetS. A correlation of miR-33 and miR-122 levels with lipemia in nutritional rat models, hepatic and peripheral blood mononuclear cell lines (PBMCs) has been established [288]. Their sustained overexpression in dyslipidemia conditions is neutralized by long-term supplementation with GSPE [288,293]. In addition, GSPE attenuates the high-fat diet-induced overexpression of miR-96 and, consequently, of its downstream molecules such as FOXO1, mTOR, p-mTOR, and LC3A/B, which are known for improving the autophagic flux for clearance of lipid accumulation [295]. Going into more detail on the molecules responsible for this miR inhibition, it has been shown that A-type ECG and EGCG dimers specifically ameliorate hepatic steatosis significantly reducing lipid accumulation in L02 cells through the regulation of miR-122 and miR-33b and their target genes [318]. However, the exact molecular mechanism by which PACs may affect miRs regulation has not yet been fully elucidated: it could underlie the binding to components involved in miRs biogenesis or, alternatively, the direct binding of PACs to miRs to modulate their stability or degradation.

Other signaling pathways influenced by PACs involve cholesterol metabolism and catabolism. Under high fat intake, procyanidin B2 from Annurca apples reduces cholesterol synthesis by diverting citrate and acetyl-CoA to the Krebs cycle [319]. Concomitantly, it lowers fatty acid synthesis and promotes lipolysis and fatty acid $\beta$-oxidation thanks to a boost in mitochondrial activity [319]. Moreover, improved cholesterol degradation and excretion contribute to the cholesterol-lowering effect of PACs: GSPE causes a significant decrease in plasma TC and TAG levels in hamsters and rats fed with HFD [286,292]. This effect is mediated by the overexpression of CYP7A1 at both the transcriptional and protein levels [286,294]. Moreover, GSPE decreases serum BA levels improving its fecal excretion [292], as revealed by the upregulation of 3-hydroxy-3-methylglutaryl coenzyme A (HMG-CoA) and HMG-CoA reductase (HMGR-CoA) [233,286,307,320] and liver X receptor alpha (LXR $\alpha)$ mRNA [286]. These results, together with those previously described in enterocytes, support the hypothesis that PACs, acting as intestinal gene selective bile acid receptor modulators (BARM), and contribute to the TG-lowering by altering enterohepatic BA recirculation. Interestingly, co-administration of GSPE with the BA sequestrant cholestyramine ( $\mathrm{CHY}$ ) has been shown to be a valid lipid-lowering combination therapy, effective in further attenuating dyslipidemia by reducing hepatic cholesterol synthesis, improving BA biosynthesis and decreasing lipogenesis in mice [294].

PACs' effects on postprandial hypertriacylglycerolemia are also due to the repression of lipoprotein secretion [284,307]. Indeed, oligomeric PACs increase low-density lipoprotein receptor (LDLr) expression and increase the activity of hepatic LPL, lecithin-cholesterol acyltransferase (LCAT) and serum paraoxonase and arylesterase (PON)-1, which associate with HDL in the circulation [320]. PAC treatment significantly reduces the secretion of VLDL-TAG and affects the hepatic expression of ACSL1 (acyl-coenzyme A synthetase longchain family member 1), Apoc3, ApoA5, ApoB, HMG-CoA, HMGR-CoA, MTP (microsomal 
triglyceride transfer protein), DGAT2 (diacylglycerol O-acyltransferase 2) and the activity of CPT1a in high-fat/high sucrose conditions [233,282,284,307,320]. Differently from what was observed concerning CPT-1a and ApoA5 expression, the inhibition of ApoB secretion in HepG2 seems to be SHP-independent [282]. However, to the best knowledge of the authors, the exact molecular mechanism underlying this inhibition is still unclear.

In the next section, we will explore, in more detail, the mechanisms by which PACs affect blood lipoprotein levels.

\subsubsection{Pancreas: Lipid Degradation and $\beta$-Cell Functionality}

Several pieces of evidence indicate that PACs inhibit pancreatic enzymes involved in lipid metabolism, including lipase, $\alpha$-amylase, phospholipase A2 and cholesterol esterase. In general, this outcome is maximal with pentamer or greater procyanidins, whereas catechins and epicatechins didn't show any activity [299]. PACs from grape seed and cocoa dose-dependently decrease the activity of pancreatic lipase (PL) $\left(\mathrm{IC}_{50}=3.71 \pm 0.03 \mathrm{mg} / \mathrm{mL}\right)$ in vitro $[285,321,322]$. PACs interact with porcine PL inducing and stabilizing aggregate formation; the resulting effect is a non-competitive dose-dependent inhibition of PL activity without variations in the $K_{m}$ value while $V_{\max }$ decreases due to a reduction in the $\alpha$-helix content and an increase in $\beta$-sheets $[323,324]$. The same effect was observed on pancreatic $\alpha$-amylase and also in this case is due to the formation of enzyme aggregates [224,322,324]. Finally, PACs reduce cholesterol esterase activity $\left(\mathrm{IC}_{50}=27.27 \pm 4.12 \mathrm{mg} / \mathrm{mL}\right)[285,305]$ and inhibit secreted phospholipase A2 (PLA2) in a non-competitive manner [324].

Thanks to their lipid-lowering effect, PACs also revealed a protective effect on pancreatic $\beta$-cell functionality [325]. GSPE administration lowers TG content both in vitro and in vivo, consistently with the down-regulation of insulin and Pdx1 observed in pancreas and that of lipid synthesis-related genes like Fasn and Srebf1 in liver [325]. PACs' inhibitory effect on TG accumulation in $\beta$-cells may explain their positive action on glucose homeostasis maintaining healthy levels of insulin production also under hyperlipidemic conditions.

\subsubsection{Adipose Tissue: Adipogenesis, Lipolysis, and Adipocytes Differentiation}

White adipose tissue (WAT) represents the organism's largest energy reservoir in mammals. Its anomalous expansion is closely related to insulin resistance and dyslipidemia and thus to obesity-related metabolic complications. In particular, in pathological conditions, WAT expands mainly through an increase in the size of the adipocytes (hypertrophy) and instead shows an impaired proliferation (hyperplasia). GSPE administration in rats fed with an obesogenic diet promotes a healthier expansion of retroperitoneal WAT (rWAT), by increasing the number of adipocytes and decreasing the adipocyte size in a dose-dependent manner [326,327]. At the molecular level, this effect mainly arises from the PAC-triggered induction of the expression of key lipolytic transcription factors, such as hormone-sensitive lipase (HSL), adipose triglyceride lipase (ATGL), and LPL and the enhanced release of both free fatty acid and glycerol [321,328]. Moreover, GSPE prevents lipid and TG accumulation in WAT, by upregulating the expression of genes involved in $\beta$-oxidation and glycerolipid/free fatty acid (GL/FFA) cycle and improving heparin-releasable LPL activity primarily in retroperitoneal and mesenteric WAT [290]. Furthermore, GSPE enhances adipogenesis in mature adipocytes through a Sirt1-dependent upregulation of PPAR- $\gamma$, which is its master regulator [327] and it improves perilipin 1 (Plin1), fatty acid-binding protein 4 (fabp4), and adiponectin expression thus ameliorating the overall WAT activity [326]. An interesting study by Ardevol and collaborators then showed that the PAC-mediated protective effects on fat deposits strongly depend on the metabolic conditions of the animal model: in Wistar lean rats PACs target mesenteric white adipose tissue (mWAT), whereas in Zucker obese rats they mainly target subcutaneous white adipose tissue (sWAT) [329]. However, whatever adipose tissue is affected, GSPE alters gene expression, but not in adiposity parameters [329]. Nevertheless, another study showed how hamsters fed with an HFD and supplemented with GSPE for 15 days displayed beneficial effects on body weight and fat accumulation: GSPE significantly lowers the adiposity index and the weight 
of all the white adipose tissue depots studied, i.e., rWAT, mWAT, eWAT, and inguinal (iWAT) [290].

Brown adipose tissue (BAT) exerts an anti-obesity effect, consuming energy via heat production. Moreover, it plays an immunometabolic role in the development of obesity, as revealed by the strong attenuation of the obesity-associated inflammatory markers in epididymal white adipose tissue (eWAT) induced by BAT transplantation in obese mice [330]. Obesity impairs BAT mitochondrial function and thermogenic capacity and GSPE can revert these dysfunctions improving the expression of Sirt1, nuclear respiratory factor 1 (Nrf1), isocitrate dehydrogenase $3 \gamma$ (IDH3 $\gamma$ ), and $\operatorname{COX} 5 \alpha$, and, more interestingly, the levels of mitochondrial respiration with both pyruvate and carnitine-palmitoyl-CoA as substrates [287,331]. In addition, it has been recently suggested that PACs might induce WAT browning [332]. However, to date, there is still no evidence of this potential functionality.

PACs have also been related to adipocyte differentiation, showing that GSPE can interfere with the early stages of 3T3-L1 (preadipocyte) differentiation into adipocytes. In particular, GSPE treatment inhibits pre-adipocyte differentiation decreasing the expression of the PPAR- $\gamma 2$ receptor, which is the main regulator of adipocyte differentiation [262]. Accordingly, at the onset of differentiation adipose-specific markers were reduced, whereas pre-adipocyte factor-1 (pref-1) levels were maintained high by GSPE treatment [262,328]. In general, PACs drop lipid accumulation during the early stages of 3T3-L1 differentiation inhibiting both adipogenesis and lipolysis. Indeed, GSPE was shown to downregulate the expression of key regulators of lipid synthesis like PPAR- $\gamma$, C/EBP- $\alpha$, SREBP1, FAS, PLIN1, FABP4, and adipocyte fatty acid-binding protein (aP2) [333,334]. This transcriptional regulation is probably mediated by the PPAR- $\gamma$ signaling pathway, since GSPE treatment also reduced the expression of several genes involved in that pathway, including Adipoq, Scd1, Nr1h3, Fabp5, Scd2, and PPAR- $\gamma$ itself in 3T3-L1 [333,335]. Moreover, PACs from lyophilized cranberries showed an inhibitory effect against lipolytic enzymes including LPL, HSL, and glycerol-3-phosphate dehydrogenase (GPDH) [328,335]. As previously described for the liver, PACs reduce intracellular lipid accumulation in adipose tissue also through the regulation of miRs. In particular, procyanidin B2 from grape seed was shown to impair adipogenesis and adipogenic differentiation in 3T3-L1 cells by repressing miR-483-5p and, thus, leading to lower activation of PPAR- $\gamma$ [336]. Furthermore, PACs inhibit pre-adipocyte proliferation, as revealed by the downregulation of genes involved in the cell cycle and growth, the cell cycle arrest at the $G_{0} / G_{1}$ transition phase and the cell apoptosis observed following GSPE treatment on 3T3-L1 cells [262,328]. Finally, PACs dosedependently increase adiponectin expression and decrease leptin levels, thus interfering with blood glucose levels as well as fatty acid breakdown [335]. The occurrence of obesity is closely related, among others, to the secretion of adipokines by adipose tissue [337]. Indeed, adipokines contribute to peripheral insulin resistance and disorders of lipid metabolism mainly interfering with insulin signaling pathways. In this regard, GSPE's positive effect on adipokine secretion and oxidative stress validates their potential in fighting obesity and metabolic disorders [296,335,338].

As for the impact of PAC intake on the metabolic profile, it has even been shown that this goes beyond the individual to even affect the progeny [339-341]. GSPE administration during pregnancy and lactation might program offspring toward improved metabolism in adulthood. As an example, chicks at hatching and 10 days of age revealed increased live body weight and greater viability associated with a decrease in plasma and liver oxidative stress [338]. Moreover, it has been shown that in the offspring of rats that were fed with an HFD and that were treated with GSPE the expression of 238 eWAT genes was altered mostly toward a better inflammatory profile and an enhanced lipidic and glucosidic metabolic profile [340]. However, also deleterious programming effects on offspring have been reported, raising concerns about the possibility of using GSPE as a nutraceutical supplement during pregnancy. Indeed, adult male offspring of rats assuming GSPE during lactation display increased insulin resistance and impaired adiponectin pathway probably 
due to the higher lipid transfer to the pups through the milk following the GSPE-induced increase in the expression of lipogenic genes in the mother's mammary glands [341].

\subsubsection{Skeletal Muscle}

The role played by the skeletal muscle is well-known in the overall utilization and oxidation of fatty acids, and PACs also affect energetic metabolism in this tissue. Indeed, GSPE improves pyruvate consumption as a substrate for mitochondrial energy production and downregulates the mRNA expression of the fatty acid transport protein 1 (FATP1); thus, promoting glucose metabolism and reducing the insulin-sensitive cellular uptake of LCFAs [287]. Consequently, postprandial serum LCFA levels are altered and lipids are redistributed from adipocyte tissue and muscle to the liver, thereby reducing obesity-related metabolic complications.

Moreover, healthy rat male offspring supplementation with GSPE reduces blood Creactive protein levels, improves lipid oxidation and AMPK expression and activity in the skeletal muscle. Similarly, the expression of genes involved in fatty acid uptake (Fatp1 and fat) and $\beta$-oxidation (PPAR- $\alpha$ and had) are overexpressed in their muscle upon GSPE administration [339].

\subsubsection{Plasma OS and Lipoproteins}

The deregulation of lipid metabolism is closely linked to oxidative stress. Oligomeric PACs significantly affect the LDL/HDL ratio thanks to their antioxidant properties and to their capability to reduce lipid peroxidation. The latter not only depends on their bioavailability, but also on their ability to bind LDL and VLDL [342]. Many in vitro and in vivo studies have demonstrated that PAC assumption significantly improves plasma total antioxidant capacity and decreases plasma lipoprotein oxidation [343,344], by reducing, as an example, the copper-catalyzed oxidation of LDL [345], plasma 2-thiobarbituric acid reactive substances level (TBARS) and the expression of nuclear factor kappa B (NF- $\mathrm{kB}$ ) and cyclooxygenase-2 $[208,275,303]$. Several clinical evidences on healthy volunteers support the PAC-mediated activity on postprandial OS in plasma. For instance, GSPE and red wine assumption not only decreases the content of plasma lipid hydroperoxides (LPO) and malondialdehyde-modified LDL (MDA-LDL) in healthy humans within the postprandial phase [183], but seems also to make LDL less susceptible to oxidative modification [281,346]. Consistently, cocoa powder and dark chocolate supplementation leads to an increase in LDL oxidation lag time, lower serum LDL diene conjugates (used as a marker of lipid peroxidation in vivo) and higher HDL-C plasma levels [274,300]. In addition, a clinical trial performed on 56 healthy young men showed that red wine significantly increased serum HDL-C, HDL3-C, Apo A-I, LpA-I, and LpA-I/LpA-II particles [297]. It should be noted that the HDL containing apo A-I but no apo A-II (LpA-I) can promote cholesterol efflux from cells, thus exerting a protective effect through the reverse cholesterol transport, while HDL containing apo A-I and apo A-II cannot. Then, not by chance, HDL-C, HDL3-C and HDL-phospholipid variations were found to positively correlate with serum-promoted cellular cholesterol efflux from hepatic Fu5AH cells treated with red wine [297]. This finding suggests a double effect of red wine on lipid homeostasis: on one hand, it influences lipoprotein-mediated cholesterol transport in the bloodstream, and on the other hand it gains serum-dependent efflux of cellular cholesterol. The ability of PACs and (+)-catechin from red wine to mainly bind to Apo A-I in humans and transferrin in rats further corroborates an involvement of PACs in reverting cholesterol transport [347]. Going deeper into the molecular details of PACs action it has been observed that they affect ROS, glutathione (GSH), and MDA intracellular levels [208,314]. Oligomers lower the generation of ROS and lipid peroxidation and improve the reduced glutathione/oxidized glutathione ratio [208]. Moreover, PACs can modulate the activity of many critical antioxidant enzymes including glutathione peroxidase (GPx), glutathione S-transferase (GST), catalase (CAT), and superoxide dismutase (SOD) [314,348]. In this context, EGCG treatment promotes Nfr2 nuclear accumulation and transcriptional activity [349]. This action comes from the 
activation of the Akt and ERK1/2 signaling pathways and leads to the modulation of the antioxidant response element (ARE)-mediated expression of many antioxidants as well as detoxifying enzymes. These activities, together with the restoration of lipid regulatory enzyme-like $5^{\prime}$ adenosine monophosphate-activated protein kinase (AMPK) and ACC phosphorylation [278], lead to an improvement in lipid peroxidation damage ultimately resulting in serum LDL/HDL ratio lowering.

\subsection{Intestinal Inflammation}

Intestinal inflammatory diseases are contemporary conditions of industrialized societies. Their increased incidence has been associated with the westernization of diet and environment, with strong changes in intestinal microbiota, and with continuous intestinal epithelial cell exposure to pesticides, food additives, drugs, and other food chemicals [350-352]. To date, adequate strategies for the prevention or treatment of inflammatory gut diseases are still lacking. Several studies have evaluated the influence of dietary components in the prevention and treatment of intestinal inflammation and protective effects of several polyphenols were reported [165]. In particular, increasing data from in vitro and in vivo studies showed protective effects of proanthocyanidins on intestinal epithelium supporting positive effects of PACs and PAC rich-foods for the physiology of the gastrointestinal tract. The main manuscripts describing the anti-inflammatory potential derived from the intake of PACs are reported in Tables 4 and 5.

Several in vivo studies (Table 5), using murine models of experimental colitis, showed that PACs have anti-inflammatory effects in intestinal bowel diseases (IBD). Oral administration of PAC-rich extracts leads to significant protection against epithelial barrier dysfunctions [353-355], mainly exerted through the inhibition of TNF- $\alpha$, INF- $\gamma$, and IL-1 $\beta$ release, reduced myeloperoxidase activity [310,355-357], inhibition of NF- $\mathrm{kB}$ signaling pathway [358-360], and increased antioxidant enzymes (GPx and SOD) activity [361]. Despite these studies revealing a potential beneficial role of PACs in intestinal inflammation, the mechanisms involved in this protective effect have not yet been fully clarified. One of the mechanisms involved undoubtedly concerns the antioxidant properties of PACs: $\mathrm{Wu}$ et al. showed that incubation of intestinal epithelium with proanthocyanidin dimers prevented LPS-mediated oxidative stress increasing SOD, HO-1, CAT, and GSH-Px mRNA expression [362]. Furthermore, the ability of PACs to preserve the barrier function of intestinal epithelial cells mentioned above $[165,363]$ contributes to increasing paracellular permeability in inflammatory conditions, for example, through the overexpression of tight junction proteins [362]. However, intestinal inflammation is a complex process that involves different cell types in the gut. Although activation of mucosal inflammatory cells is important in in vivo inflammatory response, intestinal epithelial cells also play a crucial role by actively releasing inflammatory mediators and modulating the intestinal permeability. Monolayers of differentiated $\mathrm{Caco} 2$ cell line stimulated with pro-inflammatory agents and then treated with PACs showed a decrease in the release of pro-inflammatory cytokines (TNF- $\alpha$, IL-6, IL-8), cyclooxygenase (COX)-2 expression, prostaglandin E2 production, and a reduced activation of NF-KB $[163,165,362,364]$. 
Table 4. In vitro studies reporting the anti-inflammatory activity of PACs.

\begin{tabular}{|c|c|c|c|c|}
\hline Extracts & Concentration & $\begin{array}{l}\text { Pro-Inflammatory } \\
\text { Inductors }\end{array}$ & Results & Ref. \\
\hline $\begin{array}{c}\text { Cranberry } \\
\text { proanthocyanidins } \\
\text { extract }\end{array}$ & $250 \mu \mathrm{g} / \mathrm{mL}$ & $\mathrm{Fe} / \mathrm{Asc}$ mixture and LPS & $\begin{array}{l}\downarrow \text { PGE2, } \downarrow \text { COX-2, } \\
\downarrow \text { TNF- } \alpha, \downarrow \text { IL-6 }\end{array}$ & [364] \\
\hline $\begin{array}{c}\text { Pistachio nut } \\
\text { proanthocyanidins } \\
\text { extract }\end{array}$ & $4.8-12 \mathrm{mg} \mathrm{CE} / \mathrm{ml}$ & IL-1 $\beta$ & 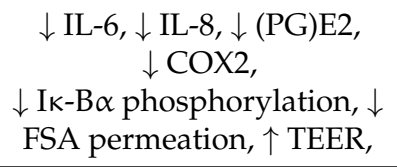 & [165] \\
\hline $\begin{array}{l}\text { Hexameric procyanidins } \\
\text { from GSE }\end{array}$ & $20 \mu \mathrm{M}$ & TNF- $\alpha$ & $\downarrow$ NF- $\kappa$ B activation, $\downarrow$ ROS & [163] \\
\hline $\begin{array}{l}\text { Granny Smith apple } \\
\text { procyanidin extract }\end{array}$ & $12.5-100 \mu \mathrm{g} / \mathrm{mL}$ & LPS & $\begin{array}{c}\uparrow(\mathrm{ZO})-1, \uparrow \mathrm{SOD}, \uparrow \mathrm{HO}-1, \uparrow \\
\mathrm{CAT}, \uparrow \mathrm{GSH}-\mathrm{Px}, \\
\downarrow \mathrm{NF}-\mathrm{K} \beta, \downarrow \mathrm{IL}-6, \downarrow \text { TNF- } \alpha\end{array}$ & [362] \\
\hline $\begin{array}{l}\text { Cocoa procyanidin } \\
\text { polymers }\end{array}$ & $100 \mu \mathrm{g} / \mathrm{mL}$ & $\begin{array}{l}\text { DSS (Caco2 cell line) and } \\
\text { TNF- } \alpha \text { (HT29 cell line) }\end{array}$ & $\downarrow$ IL-8 & [363] \\
\hline
\end{tabular}

Table 5. In vivo studies reporting the anti-inflammatory activity of PACs.

\begin{tabular}{|c|c|c|c|c|}
\hline Extracts & Dose & $\begin{array}{l}\text { Pro-Inflammatory } \\
\text { Inductors }\end{array}$ & Results & Ref. \\
\hline $\begin{array}{c}\text { Grape seed } \\
\text { proanthocyanidin extract }\end{array}$ & $\begin{array}{c}5,25, \text { or } 50 \mathrm{mg} / \mathrm{kg} \\
\text { body weight }\end{array}$ & Cafeteria diet & $\begin{array}{l}\downarrow \mathrm{IL}-1 \beta, \downarrow \text { iNOS, } \downarrow \text { MPO } \\
\text { activity, } \downarrow \text { ROS, } \uparrow \mathrm{ZO}-1\end{array}$ & [354] \\
\hline $\begin{array}{l}\text { Grape seed } \\
\text { proanthocyanidin extract }\end{array}$ & $\begin{array}{c}75 \text { or } 375 \mathrm{mg} / \mathrm{kg} \text { body } \\
\text { weight }\end{array}$ & LPS & $\begin{array}{c}\downarrow \text { COX-2 activity, } \\
\downarrow \text { MPO activity, } \downarrow \text { ROS, } \\
\downarrow \text { Plasma OVA }\end{array}$ & [355] \\
\hline $\begin{array}{l}\text { Pyracantha fortuneana } \\
\text { fruit extract }\end{array}$ & $\begin{array}{l}0.4 \text { or } 1 \mathrm{~g} / 100 \mathrm{~g} \text { of dry } \\
\text { feed weight }\end{array}$ & High-fat diet & $\uparrow$ Occludin, $\uparrow$ ZO-1 & [353] \\
\hline $\begin{array}{c}\text { Grape seed } \\
\text { proanthocyanidin extract }\end{array}$ & $\begin{array}{l}0.1 \mathrm{~g} / 100 \mathrm{~mL} \text { of } \\
\text { drinking water }\end{array}$ & $\begin{array}{l}\text { (Colitis in IL-10 } \\
\text { deficient rats) }\end{array}$ & $\downarrow$ TNF- $\alpha, \downarrow$ IFN- $\gamma, \uparrow$ iNOS & [356] \\
\hline $\begin{array}{c}\text { Grape seed } \\
\text { proanthocyanidin extract }\end{array}$ & $\begin{array}{c}300 \mathrm{mg} / \mathrm{kg} \text { body } \\
\text { weight }\end{array}$ & High-fat diet & $\downarrow$ TNF- $\alpha, \downarrow$ IL-6, $\downarrow$ MCP-1 & [310] \\
\hline Procyanidin B2 & 10,20, or $40 \mathrm{mg} / \mathrm{Kg}$ & DSS & 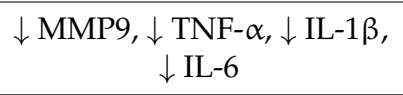 & [360] \\
\hline $\begin{array}{c}\text { Grape seed } \\
\text { proanthocyanidin extract }\end{array}$ & $\begin{array}{l}100,200, \text { and } \\
400 \mathrm{mg} / \mathrm{kg}\end{array}$ & TNBS & $\downarrow \mathrm{NF}-\mathrm{Kb}, \downarrow \mathrm{pI} \kappa \mathrm{B} \alpha, \downarrow$ I $\kappa \mathrm{K}$ & [359] \\
\hline $\begin{array}{c}\text { Grape seed } \\
\text { proanthocyanidin extract }\end{array}$ & 25 and $50 \mathrm{mg} / \mathrm{kg}$ & Cafeteria diet & $\begin{array}{c}\downarrow \text { TNF- } \alpha, \downarrow \text { IL-6, } \downarrow \text { NF-Kb } \\
\downarrow \downarrow \text { Emr1, } \downarrow \text { CPR }\end{array}$ & [358] \\
\hline $\begin{array}{c}\text { Grape seed } \\
\text { proanthocyanidin extract }\end{array}$ & $\begin{array}{l}100,200, \text { and } \\
400 \mathrm{mg} / \mathrm{kg}\end{array}$ & TNBS & $\begin{array}{c}\uparrow \text { GSH-Px, } \text { SOD }, \downarrow \text { TNF- } \alpha, \\
\downarrow \text { p-IKK } \alpha / \beta, \downarrow \text { NF- } \mathrm{b} b\end{array}$ & [361] \\
\hline
\end{tabular}

$\uparrow$ increase; $\downarrow$ decrease.

Literature data demonstrating protective effects of PAC-rich extracts in intestinal inflammation tend to attribute the observed effects to the high molecular weight proanthocyanidin fraction $[163,165]$. Furthermore, the demonstrated activity of these extracts in in vitro models of intestinal epithelium would suggest protective actions of physiological relevance. In fact, high molecular weight PACs, thanks to their stability under gastrointestinal digestion conditions and their reduced ability to cross biological membranes, can reach significant concentrations in the intestinal lumen. In this context, the anti-inflammatory proprieties of large PACs could involve events initiated at the level of cell membranes with modulation of proteins at key sites of different signaling pathways [365]. In this regard, 
several studies have demonstrated the interaction of large proanthocyanidin with areas of cell membrane with reduced mobility, such as lipid rafts [366,367] and its central role in mediating the anti-inflammatory activity shown by polymeric PACs [163].

\section{Conclusions}

PACs are polyphenolic compounds that have been shown to have an interesting and wide range of bioactivities. The information contained in this review clarifies the particular chemical characteristics of PACs, explaining their highly variable chemical scaffold. Furthermore, in this review, the biosynthetic pathway was deeply discussed, also highlighting the main shortcomings of this processes. In particular, the potential mechanisms of transport and polymerization of PACs in plant cells was hypothesized. From an analytic point of view, the main protocols aimed at identifying and quantifying PACs in plant sources have been described, also emphasizing the main advantages and limitations of each methodology. Moreover, the meta-analytic approaches carried out in this review have identified 35 different plant families and 60 edible sources, which can be used both as raw material for PAC extraction at industrial level and to introduce PACs through the diet. Finally, literature searches coupled with forest plot analyses have shown how PACs can have potential beneficial effects on human health. In particular, in this review we have explained how PACs can modulate the cholesterol content in the blood through a systematic action at different organ levels, or display local anti-inflammatory activity on the intestinal epithelium after the intake of PAC-enriched foods.

Supplementary Materials: The following are available online at https:/ / www.mdpi.com/article/ 10.3390/antiox10081229/s1, Figure S1: Funnel plot representation of the effects derived from the supplementation of PACs on hematic levels of sugar (A), cholesterol (B), HDL (C) and LDL (D).

Author Contributions: Bibliographic research and writing: G.M., G.C., G.S., T.G., C.G., L.M. and C.M.B. All authors have read and agreed to the published version of the manuscript.

Funding: This research received no external funding.

Conflicts of Interest: The authors declare no conflict of interest.

\section{References}

1. World Health Organization. The World Health Report 2001: Mental Health: New Understanding, New Hope; World Health Organization: Geneva, Switzerland, 2001.

2. Vigliante, I.; Mannino, G.; Maffei, M.E. Chemical Characterization and DNA Fingerprinting of Griffonia simplicifolia Baill. Molecules 2019, 24, 1032. [CrossRef] [PubMed]

3. Mannino, G.; Iovino, P.; Lauria, A.; Genova, T.; Asteggiano, A.; Notarbartolo, M.; Porcu, A.; Serio, G.; Chinig, G.; Occhipinti, A.; et al. Bioactive Triterpenes of Protium heptaphyllum Gum Resin Extract Display Cholesterol-Lowering Potential. Int. J. Mol. Sci. 2021, 22, 2664. [CrossRef] [PubMed]

4. Chen, Z.Y.; Jiao, R.; Ka, Y.M. Cholesterol-lowering nutraceuticals and functional foods. J. Agric. Food Chem. 2008, 56, 8761-8773. [CrossRef] [PubMed]

5. Carson, J.A.S.; Lichtenstein, A.H.; Anderson, C.A.M.; Appel, L.J.; Kris-Etherton, P.M.; Meyer, K.A.; Petersen, K.; Polonsky, T.; Van Horn, L. Dietary cholesterol and cardiovascular risk: A science advisory from the American heart association. Circulation 2020, 141, e39-e53. [CrossRef]

6. González, S. Dietary Bioactive Compounds and Human Health and Disease. Nutrients 2020, 12, 348. [CrossRef]

7. Quideau, S.; Deffieux, D.; Douat-Casassus, C.; Pouységu, L. Plant polyphenols: Chemical properties, biological activities, and synthesis. Angew. Chemie Int. Ed. 2011, 50, 586-621. [CrossRef]

8. Ky, I.; Le Floch, A.; Zeng, L.; Pechamat, L.; Jourdes, M.; Teissedre, P.L. Tannins. Encycl. Food Health 2015, $247-255$.

9. Gentile, C.; Tesoriere, L.; Butera, D.; Fazzari, M.; Monastero, M.; Allegra, M.; Livrea, M.A. Antioxidant activity of Sicilian pistachio (Pistacia vera L. Var. Bronte) nut extract and its bioactive components. J. Agric. Food Chem. 2007, 55, 643-648. [CrossRef]

10. Vigliante, I.; Mannino, G.; Maffei, M.E. OxiCyan ${ }^{\circledR}$, a phytocomplex of bilberry (Vaccinium myrtillus) and spirulina (Spirulina platensis), exerts both direct antioxidant activity and modulation of ARE/Nrf2 pathway in HepG2 cells. J. Funct. Foods 2019, 61, 103508. [CrossRef]

11. Bell, A.A.; El-Zik, K.M.; Thaxton, P.M. Chemistry, biological significance, and genetic control of proanthocyanidins in cotton (Gossypium spp.). In Plant Polyphenols; Springer: Berlin/Heidelberg, Germany, 1992; pp. 571-595. 
12. Ferreira, D.; van Rensburg, H.; Malan, E.; Coetzee, J.; Nel, R.J.J. Recent advances in the chemistry of proanthocyanidins. Phytochem. Hum. Health Prot. Nutr. Plant Def. 1999, 255-288.

13. Porter, L.J. Flavans and proanthocyanidins. In The Flavonoids; Springer: Berlin/Heidelberg, Germany, 1988; pp. $21-62$.

14. Heim, K.E.; Tagliaferro, A.R.; Bobilya, D.J. Flavonoid antioxidants: Chemistry, metabolism and structure-activity relationships. J. Nutr. Biochem. 2002, 13, 572-584. [CrossRef]

15. Mannino, G.; Gentile, C.; Ertani, A.; Serio, G.; Bertea, C.M. Anthocyanins: Biosynthesis, Distribution, Ecological Role, and Use of Biostimulants to Increase Their Content in Plant Foods-A Review. Agriculture 2021, 11, 212. [CrossRef]

16. Xie, D.-Y.; Dixon, R.A. Proanthocyanidin biosynthesis-still more questions than answers? Phytochemistry 2005, 66, 2127-2144. [CrossRef]

17. Constabel, C.P. Molecular controls of proanthocyanidin synthesis and structure: Prospects for genetic engineering in crop plants. J. Agric. Food Chem. 2018, 66, 9882-9888. [CrossRef]

18. Jun, J.H.; Xiao, X.; Rao, X.; Dixon, R.A. Proanthocyanidin subunit composition determined by functionally diverged dioxygenases. Nat. Plants 2018, 4, 1034-1043. [CrossRef]

19. Zhao, J.; Pang, Y.; Dixon, R.A. The mysteries of proanthocyanidin transport and polymerization. Plant Physiol. 2010, 153, 437-443. [CrossRef]

20. Sharma, P.K.; Romanczyk, L.J.; Kondaveti, L.; Reddy, B.; Arumugasamy, J.; Lombardy, R.; Gou, Y.; Schroeter, H. Total Synthesis of Proanthocyanidin A1, A2, and Their Stereoisomers. Org. Lett. 2015, 17, 2306-2309. [CrossRef]

21. Wang, J.; Xu, J.; Gong, X.; Yang, M.; Zhang, C.; Li, M. Biosynthesis, chemistry, and pharmacology of polyphenols from Chinese Salvia species: A review. Molecules 2019, 24, 155. [CrossRef]

22. Herrmann, K.M.; Weaver, L.M. The shikimate pathway. Annu. Rev. Plant Biol. 1999, 50, 473-503. [CrossRef]

23. Tanner, G.J.; Francki, K.T.; Abrahams, S.; Watson, J.M.; Larkin, P.J.; Ashton, A.R. Proanthocyanidin biosynthesis in plants: Purification of legume leucoanthocyanidin reductase and molecular cloning of its cDNA. J. Biol. Chem. 2003, 278, 31647-31656. [CrossRef]

24. Li, H.; Han, M.; Yu, L.; Wang, S.; Zhang, J.; Tian, J.; Yao, Y. Transcriptome analysis identifies two ethylene response factors that regulate proanthocyanidin biosynthesis during Malus Crabapple fruit development. Front. Plant Sci. 2020, 11, 76. [CrossRef]

25. Herrmann, K.M. The shikimate pathway as an entry to aromatic secondary metabolism. Plant Physiol. 1995, 107, 7. [CrossRef]

26. Yadav, V.; Wang, Z.; Wei, C.; Amo, A.; Ahmed, B.; Yang, X.; Zhang, X. Phenylpropanoid pathway engineering: An emerging approach towards plant defense. Pathogens 2020, 9, 312. [CrossRef]

27. Shirley, B.W. Flavonoid biosynthesis:'new'functions for an 'old'pathway. Trends Plant Sci. 1996, 1, 377-382.

28. Biała, W.; Jasiński, M. The phenylpropanoid case-it is transport that matters. Front. Plant Sci. 2018, 9, 1610. [CrossRef]

29. He, F.; Pan, Q.-H.; Shi, Y.; Duan, C.-Q. Biosynthesis and genetic regulation of proanthocyanidins in plants. Molecules 2008, 13, 2674-2703. [CrossRef] [PubMed]

30. Rauf, A.; Imran, M.; Abu-Izneid, T.; Patel, S.; Pan, X.; Naz, S.; Sanches Silva, A.; Saeed, F.; Rasul Suleria, H.A. Proanthocyanidins: A comprehensive review. Biomed. Pharmacother. 2019, 116, 108999. [CrossRef] [PubMed]

31. Kim, E.-G.; Yun, S.; Park, J.-R.; Kim, K.-M. Identification of F3H, Major Secondary Metabolite-Related Gene That Confers Resistance against Whitebacked Planthopper through QTL Mapping in Rice. Plants 2021, 10, 81. [CrossRef]

32. Štiasna, K.; Presinszká, M.; Vyhnánek, T.; Trojan, V.; Hanáček, P.; Havel, L. Sequence analysis of flavanone 3-hydroxylase and dihydroflavonol 4-reductase genes in wheat with nonstandard coloured caryopses. Genetika 2019, 51, 93-102. [CrossRef]

33. Shoeva, O.Y.; Glagoleva, A.Y.; Khlestkina, E.K. The factors affecting the evolution of the anthocyanin biosynthesis pathway genes in monocot and dicot plant species. BMC Plant Biol. 2017, 17, 5-14. [CrossRef]

34. Pérez-Díaz, R.; Madrid-Espinoza, J.; Salinas-Cornejo, J.; González-Villanueva, E.; Ruiz-Lara, S. Differential roles for VviGST1, VviGST3, and VviGST4 in proanthocyanidin and anthocyanin transport in Vitis vinifera. Front. Plant Sci. 2016, 7, 1166. [CrossRef]

35. Coutin, J.A.F.; Munholland, S.; Silva, A.; Subedi, S.; Lukens, L.; Crosby, W.L.; Pauls, K.P.; Bozzo, G.G. Proanthocyanidin accumulation and transcriptional responses in the seed coat of cranberry beans (Phaseolus vulgaris L.) with different susceptibility to postharvest darkening. BMC Plant Biol. 2017, 17, 1-23.

36. Zhao, J.; Dixon, R.A. The 'ins' and 'outs' of flavonoid transport. Trends Plant Sci. 2010, 15, 72-80. [CrossRef]

37. Zhao, J. Flavonoid transport mechanisms: How to go, and with whom. Trends Plant Sci. 2015, 20, 576-585. [CrossRef]

38. Poustka, F.; Irani, N.G.; Feller, A.; Lu, Y.; Pourcel, L.; Frame, K.; Grotewold, E. A trafficking pathway for anthocyanins overlaps with the endoplasmic reticulum-to-vacuole protein-sorting route in Arabidopsis and contributes to the formation of vacuolar inclusions. Plant Physiol. 2007, 145, 1323-1335. [CrossRef]

39. Gonzalez, A.; Brown, M.; Hatlestad, G.; Akhavan, N.; Smith, T.; Hembd, A.; Moore, J.; Montes, D.; Mosley, T.; Resendez, J. TTG2 controls the developmental regulation of seed coat tannins in Arabidopsis by regulating vacuolar transport steps in the proanthocyanidin pathway. Dev. Biol. 2016, 419, 54-63. [CrossRef]

40. Pinkus, R.; Weiner, L.M.; Daniel, V. Role of Oxidants and Antioxidants in the Induction of AP-1, NF-kB, and Glutathione S-Transferase Gene Expression*. J. Biol. Chem. 1996, 271, 13422-13429. [CrossRef]

41. Alla, M.M.N.; Hassan, N.M.; El-Bastawisy, Z.M. Changes in antioxidants and kinetics of glutathione-S-transferase of maize in response to isoproturon treatment. Plant Biosyst. Int. J. Deal. Asp. Plant Biol. 2008, 142, 5-16.

42. Liu, C.; Wang, X.; Shulaev, V.; Dixon, R.A. A role for leucoanthocyanidin reductase in the extension of proanthocyanidins. Nat. Plants 2016, 2, 1-7. [CrossRef] 
43. Wang, P.; Liu, Y.; Zhang, L.; Wang, W.; Hou, H.; Zhao, Y.; Jiang, X.; Yu, J.; Tan, H.; Wang, Y. Functional demonstration of plant flavonoid carbocations proposed to be involved in the biosynthesis of proanthocyanidins. Plant J. 2020, 101, 18-36. [CrossRef]

44. Yu, D.; Huang, T.; Tian, B.; Zhan, J. Advances in Biosynthesis and Biological Functions of Proanthocyanidins in Horticultural Plants. Foods 2020, 9, 1774. [CrossRef] [PubMed]

45. Harding, S.A. Condensed tannins: Arbiters of abiotic stress tolerance? Tree Physiol. 2019, 39, 341-344. [CrossRef]

46. Zhu, L.; Deng, X.; Zou, L.; Wu, J.; Zhang, D.; Lin, H. Proanthocyanidins accelerate the germination of cucumber (Cucumis sativus L.) seeds. J. Plant Biol. 2016, 59, 143-151. [CrossRef]

47. Campobenedetto, C.; Grange, E.; Mannino, G.; Van Arkel, J.; Beekwilder, J.; Karlova, R.; Garabello, C.; Contartese, V.; Bertea, C.M. A Biostimulant Seed Treatment Improved Heat Stress Tolerance during Cucumber Seed Germination by Acting on the Antioxidant System and Glyoxylate Cycle. Front. Plant Sci. 2020, 11, 836. [CrossRef]

48. Shah, F.A.; Ni, J.; Chen, J.; Wang, Q.; Liu, W.; Chen, X.; Tang, C.; Fu, S.; Wu, L. Proanthocyanidins in seed coat tegmen and endospermic cap inhibit seed germination in Sapium sebiferum. PeerJ 2018, 6, e4690. [CrossRef]

49. Jia, L.-G.; Sheng, Z.-W.; Xu, W.-F.; Li, Y.-X.; Liu, Y.-G.; Xia, Y.-J.; Zhang, J.-H. Modulation of anti-oxidation ability by proanthocyanidins during germination of Arabidopsis thaliana seeds. Mol. Plant 2012, 5, 472-481. [CrossRef] [PubMed]

50. Jia, L.; Wu, Q.; Ye, N.; Liu, R.; Shi, L.; Xu, W.; Zhi, H.; Rahman, A.N.M.R.B.; Xia, Y.; Zhang, J. Proanthocyanidins inhibit seed germination by maintaining a high level of abscisic acid in Arabidopsis thaliana F. J. Integr. Plant Biol. 2012, 54, 663-673. [CrossRef] [PubMed]

51. Hernández, I.; Alegre, L.; Munné-Bosch, S. Plant aging and excess light enhance flavan-3-ol content in Cistus clusii. J. Plant Physiol. 2011, 168, 96-102. [CrossRef]

52. Nagpala, E.G.; Guidarelli, M.; Gasperotti, M.; Masuero, D.; Bertolini, P.; Vrhovsek, U.; Baraldi, E. Polyphenols Variation in Fruits of the Susceptible Strawberry Cultivar Alba during Ripening and upon Fungal Pathogen Interaction and Possible Involvement in Unripe Fruit Tolerance. J. Agric. Food Chem. 2016, 64, 1869-1878. [CrossRef]

53. Carbone, F.; Preuss, A.; De Vos, R.C.H.; D’AMICO, E.; Perrotta, G.; Bovy, A.G.; Martens, S.; Rosati, C. Developmental, genetic and environmental factors affect the expression of flavonoid genes, enzymes and metabolites in strawberry fruits. Plant. Cell Environ. 2009, 32, 1117-1131. [CrossRef]

54. Gesell, A.; Yoshida, K.; Tran, L.T.; Constabel, C.P. Characterization of an apple TT2-type R2R3 MYB transcription factor functionally similar to the poplar proanthocyanidin regulator PtMYB134. Planta 2014, 240, 497-511. [CrossRef]

55. Yan, J.X.; Lu, Y.F.; Yan, S.C. The effects of irradiance on the production of phenolic compounds and condensed tannins in Larix gmelinii needles. Biol. Plant. 2014, 58, 159-163. [CrossRef]

56. Gourlay, G.; Constabel, C.P. Condensed tannins are inducible antioxidants and protect hybrid poplar against oxidative stress. Tree Physiol. 2019, 39, 345-355. [CrossRef]

57. Mellway, R.D.; Tran, L.T.; Prouse, M.B.; Campbell, M.M.; Constabel, C.P. The wound-, pathogen-, and ultraviolet B-responsive MYB134 gene encodes an R2R3 MYB transcription factor that regulates proanthocyanidin synthesis in poplar. Plant Physiol. 2009, 150, 924-941. [CrossRef]

58. Poudel, P.R.; Koyama, K.; Goto-Yamamoto, N. Evaluating the influence of temperature on proanthocyanidin biosynthesis in developing grape berries (Vitis vinifera L.). Mol. Biol. Rep. 2020, 47, 3501-3510. [CrossRef]

59. Bonada, M.; Jeffery, D.W.; Petrie, P.R.; Moran, M.A.; Sadras, V.O. Impact of elevated temperature and water deficit on the chemical and sensory profiles of B arossa S hiraz grapes and wines. Aust. J. Grape Wine Res. 2015, 21, 240-253. [CrossRef]

60. Jeon, J.; Kim, J.K.; Wu, Q.; Park, S.U. Effects of cold stress on transcripts and metabolites in tartary buckwheat (Fagopyrum tataricum). Environ. Exp. Bot. 2018, 155, 488-496. [CrossRef]

61. An, J.; Li, R.; Qu, F.; You, C.; Wang, X.; Hao, Y. R2R3-MYB transcription factor Md MYB 23 is involved in the cold tolerance and proanthocyanidin accumulation in apple. Plant J. 2018, 96, 562-577. [CrossRef]

62. Wang, N.; Qu, C.; Jiang, S.; Chen, Z.; Xu, H.; Fang, H.; Su, M.; Zhang, J.; Wang, Y.; Liu, W. The proanthocyanidin-specific transcription factor Md MYBPA 1 initiates anthocyanin synthesis under low-temperature conditions in red-fleshed apples. Plant J. 2018, 96, 39-55. [CrossRef]

63. Zhu, L.J.; Deng, X.G.; Zou, L.J.; Zhang, D.W.; Lin, H.H. Enhancement of stress tolerance in cucumber seedlings by proanthocyanidins. Biol. Plant. 2017, 61, 323-332. [CrossRef]

64. Campobenedetto, C.; Mannino, G.; Beekwilder, J.; Contartese, V.; Karlova, R.; Bertea, C.M. The application of a biostimulant based on tannins affects root architecture and improves tolerance to salinity in tomato plants. Sci. Rep. 2021, 11, 354. [CrossRef] [PubMed]

65. Cáceres-Mella, A.; Talaverano, M.I.; Villalobos-González, L.; Ribalta-Pizarro, C.; Pastenes, C. Controlled water deficit during ripening affects proanthocyanidin synthesis, concentration and composition in Cabernet Sauvignon grape skins. Plant Physiol. Biochem. 2017, 117, 34-41. [CrossRef] [PubMed]

66. Bucchetti, B.; Matthews, M.A.; Falginella, L.; Peterlunger, E.; Castellarin, S.D. Effect of water deficit on Merlot grape tannins and anthocyanins across four seasons. Sci. Hortic. 2011, 128, 297-305. [CrossRef]

67. Roby, G.; Harbertson, J.F.; Adams, D.A.; Matthews, M.A. Berry size and vine water deficits as factors in winegrape composition: Anthocyanins and tannins. Aust. J. Grape Wine Res. 2004, 10, 100-107. [CrossRef]

68. Li, D.; Hu, X.; Li, C. Overexpression of the LoMYB29 gene of Larix olgensis contributes to the regulation of proanthocyanidin biosynthesis in Arabidopsis thaliana. J. For. Res. 2019, 30, 1793-1804. [CrossRef] 
69. Zhang, W.; Liu, S.; Li, C.; Zhang, P.; Zhang, P. Transcriptome sequencing of Antarctic moss under salt stress emphasizes the important roles of the ROS-scavenging system. Gene 2019, 696, 122-134. [CrossRef]

70. Ma, W.; Kim, J.K.; Jia, C.; Yin, F.; Kim, H.J.; Akram, W.; Hu, X.; Li, X. Comparative transcriptome and metabolic profiling analysis of buckwheat (Fagopyrum tataricum (L.) Gaertn.) under salinity stress. Metabolites 2019, 9, 225. [CrossRef]

71. Miranda, M.; Ralph, S.G.; Mellway, R.; White, R.; Heath, M.C.; Bohlmann, J.; Constabel, C.P. The transcriptional response of hybrid poplar (Populus trichocarpa x P. deltoids) to infection by Melampsora medusae leaf rust involves induction of flavonoid pathway genes leading to the accumulation of proanthocyanidins. Mol. Plant-Microbe Interact. 2007, 20, 816-831. [CrossRef]

72. Ullah, C.; Unsicker, S.B.; Fellenberg, C.; Constabel, C.P.; Schmidt, A.; Gershenzon, J.; Hammerbacher, A. Flavan-3-ols are an effective chemical defense against rust infection. Plant Physiol. 2017, 175, 1560-1578. [CrossRef]

73. Iriti, M.; Rossoni, M.; Borgo, M.; Ferrara, L.; Faoro, F. Induction of resistance to gray mold with benzothiadiazole modifies amino acid profile and increases proanthocyanidins in grape: Primary versus secondary metabolism. J. Agric. Food Chem. 2005, 53, 9133-9139. [CrossRef]

74. Haile, Z.M.; Malacarne, G.; Pilati, S.; Sonego, P.; Moretto, M.; Masuero, D.; Vrhovsek, U.; Engelen, K.; Baraldi, E.; Moser, C. Dual transcriptome and metabolic analysis of Vitis vinifera $\mathrm{cv}$. Pinot Noir berry and Botrytis cinerea during quiescence and egressed Infection. Front. Plant Sci. 2020, 10, 1704. [CrossRef]

75. Koskimäki, J.J.; Hokkanen, J.; Jaakola, L.; Suorsa, M.; Tolonen, A.; Mattila, S.; Pirttilä, A.M.; Hohtola, A. Flavonoid biosynthesis and degradation play a role in early defence responses of bilberry (Vaccinium myrtillus) against biotic stress. Eur. J. Plant Pathol. 2009, 125, 629-640. [CrossRef]

76. Haile, Z.M.; Guzman, N.-D.; Grace, E.; Moretto, M.; Sonego, P.; Engelen, K.; Zoli, L.; Moser, C.; Baraldi, E. Transcriptome profiles of strawberry (Fragaria vesca) fruit interacting with Botrytis cinerea at different ripening stages. Front. Plant Sci. 2019, $10,1131$. [CrossRef]

77. Yuan, L.; Wang, L.; Han, Z.; Jiang, Y.; Zhao, L.; Liu, H.; Yang, L.; Luo, K. Molecular cloning and characterization of PtrLAR3, a gene encoding leucoanthocyanidin reductase from Populus trichocarpa, and its constitutive expression enhances fungal resistance in transgenic plants. J. Exp. Bot. 2012, 63, 2513-2524. [CrossRef]

78. Guidarelli, M.; Carbone, F.; Mourgues, F.; Perrotta, G.; Rosati, C.; Bertolini, P.; Baraldi, E. Colletotrichum acutatum interactions with unripe and ripe strawberry fruits and differential responses at histological and transcriptional levels. Plant Pathol. 2011, 60, 685-697. [CrossRef]

79. Boeckler, G.A.; Gershenzon, J.; Unsicker, S.B. Gypsy Moth Caterpillar Feeding has Only a Marginal Impact on Phenolic Compounds in Old-Growth Black Poplar. J. Chem. Ecol. 2013, 39, 1301-1312. [CrossRef]

80. Peters, D.J.; Constabel, C.P. Molecular analysis of herbivore-induced condensed tannin synthesis: Cloning and expression of dihydroflavonol reductase from trembling aspen (Populus tremuloides). Plant J. 2002, 32, 701-712. [CrossRef]

81. Lu, N.; Rao, X.; Li, Y.; Jun, J.H.; Dixon, R.A. Dissecting the transcriptional regulation of proanthocyanidin and anthocyanin biosynthesis in soybean (Glycine max). Plant Biotechnol. J. 2021, 19, 1429-1442. [CrossRef]

82. Singh, S.; Kaur, I.; Kariyat, R. The Multifunctional Roles of Polyphenols in Plant-Herbivore Interactions. Int. J. Mol. Sci. 2021, 22, 1442. [CrossRef]

83. Prior, R.L.; Fan, E.; Ji, H.; Howell, A.; Nio, C.; Payne, M.J.; Reed, J. Multi-laboratory validation of a standard method for quantifying proanthocyanidins in cranberry powders. J. Sci. Food Agric. 2010, 90, 1473-1478. [CrossRef]

84. Molinari, R.; Buonomenna, M.G.; Cassano, A.; Drioli, E. Rapid determination of tannins in tanning baths by adaptation of BSA method. Ann. Chim. 2001, 91, 255-263.

85. Makkar, H.P.S.; Blümmel, M.; Borowy, N.K.; Becker, K. Gravimetric determination of tannins and their correlations with chemical and protein precipitation methods. J. Sci. Food Agric. 1993, 61, 161-165. [CrossRef]

86. Gessner, M.O.; Steiner, D. Acid butanol assay for proanthocyanidins (condensed tannins). In Methods to Study Litter Decomposition; Springer: Berlin/Heidelberg, Germany, 2005; pp. 107-114.

87. Hemingway, R.W. Reactions at the interflavanoid bond of proanthocyanidins. In Chemistry and Significance of Condensed Tannins; Springer: Berlin/Heidelberg, Germany, 1989; pp. 265-283.

88. Dalzell, S.A.; Kerven, G.L. A rapid method for the measurement of Leucaena spp. proanthocyanidins by the proanthocyanidin (butanol/HCl) assay. J. Sci. Food Agric. 1998, 78, 405-416. [CrossRef]

89. Schofield, P.; Mbugua, D.M.; Pell, A.N. Analysis of condensed tannins: A review. Anim. Feed Sci. Technol. 2001, 91, 21-40. [CrossRef]

90. Makkar, H.P.S.; Gamble, G.; Becker, K. Limitation of the butanol-hydrochloric acid-iron assay for bound condensed tannins. Food Chem. 1999, 66, 129-133. [CrossRef]

91. Pharmacopoeia, J. European Pharmacopoeia; Council of Europe: Strasbourg, France, 2002.

92. Hellenbrand, N.; Sendker, J.; Lechtenberg, M.; Petereit, F.; Hensel, A. Isolation and quantification of oligomeric and polymeric procyanidins in leaves and flowers of Hawthorn (Crataegus spp.). Fitoterapia 2015, 104, 14-22. [CrossRef] [PubMed]

93. Price, M.L.; Van Scoyoc, S.; Butler, L.G. A critical evaluation of the vanillin reaction as an assay for tannin in sorghum grain. J. Agric. Food Chem. 1978, 26, 1214-1218. [CrossRef]

94. Sun, B.; Ricardo-da-Silva, J.M.; Spranger, I. Critical Factors of Vanillin Assay for Catechins and Proanthocyanidins. J. Agric. Food Chem. 1998, 46, 4267-4274. [CrossRef]

95. Waterman, P.G.; Mole, S. Analysis of Phenolic Plant Metabolites; Blackwell Scientific: Oxford, UK, 1994 ; Volume 83. 
96. Payne, M.J.; Hurst, W.J.; Stuart, D.A.; Ou, B.; Fan, E.; Ji, H.; Kou, Y. Determination of total procyanidins in selected chocolate and confectionery products using DMAC. J. AOAC Int. 2010, 93, 89-96. [CrossRef]

97. Mannino, G.; Gentile, C.; Maffei, M.E. Chemical partitioning and DNA fingerprinting of some pistachio (Pistacia vera L.) varieties of different geographical origin. Phytochemistry 2019, 160, 40-47. [CrossRef]

98. Mannino, G.; Perrone, A.; Campobenedetto, C.; Schittone, A.; Margherita Bertea, C.; Gentile, C. Phytochemical profile and antioxidative properties of Plinia trunciflora fruits: A new source of nutraceuticals. Food Chem. 2020, 307, 125515. [CrossRef]

99. Gentile, C.; Mannino, G.; Palazzolo, E.; Gianguzzi, G.; Perrone, A.; Serio, G.; Farina, V. Pomological, Sensorial, Nutritional and Nutraceutical Profile of Seven Cultivars of Cherimoya (Annona cherimola Mill). Foods 2021, 10, 35. [CrossRef]

100. Mannino, G.; Gentile, C.; Porcu, A.; Agliassa, C.; Caradonna, F.; Bertea, C.M. Chemical Profile and Biological Activity of Cherimoya (Annona cherimola Mill.) and Atemoya (Annona atemoya) Leaves. Molecules 2020, 25, 2612. [CrossRef]

101. Zhu, F. Proanthocyanidins in cereals and pseudocereals. Crit. Rev. Food Sci. Nutr. 2019, 59, 1521-1533. [CrossRef]

102. de Carvalho, M.V.O.; de Oliveira, L.; Costa, A.M. Effect of training system and climate conditions on phytochemicals of Passiflora setacea, a wild Passiflora from Brazilian savannah. Food Chem. 2018, 266, 350-358. [CrossRef]

103. Cáceres-Mella, A.; Peña-Neira, Á.; Narváez-Bastias, J.; Jara-Campos, C.; López-Solís, R.; Canals, J.M. Comparison of analytical methods for measuring proanthocyanidins in wines and their relationship with perceived astringency. Int. J. Food Sci. Technol. 2013, 48, 2588-2594. [CrossRef]

104. Wilkes, K.; Howard, L.R.; Brownmiller, C.; Prior, R.L. Changes in chokeberry (Aronia melanocarpa L.) polyphenols during juice processing and storage. J. Agric. Food Chem. 2014, 62, 4018-4025. [CrossRef]

105. Gurak, P.D.; De Bona, G.S.; Tessaro, I.C.; Marczak, L.D.F. Jaboticaba pomace powder obtained as a co-product of juice extraction: A comparative study of powder obtained from peel and whole fruit. Food Res. Int. 2014, 62, 786-792. [CrossRef]

106. Li, H.-J.; Deinzer, M.L. Tandem mass spectrometry for sequencing proanthocyanidins. Anal. Chem. 2007, 79, 1739-1748. [CrossRef]

107. Lazarus, S.A.; Adamson, G.E.; Hammerstone, J.F.; Schmitz, H.H. High-performance liquid chromatography/mass spectrometry analysis of proanthocyanidins in foods and beverages. J. Agric. Food Chem. 1999, 47, 3693-3701. [CrossRef]

108. Kelm, M.A.; Hammerstone, J.F.; Schmitz, H.H. Identification and quantitation of flavanols and proanthocyanidins in foods: How good are the datas? Clin. Dev. Immunol. 2005, 12, 35-41. [CrossRef] [PubMed]

109. Sintara, M.; Wang, Y.; Li, L.; Liu, H.; Cunningham, D.G.; Prior, R.R.; Chen, P.; Chang, T.; Wu, X. Quantification of cranberry proanthocyanidins by normal-phase high-performance liquid chromatography using relative response factors. Phytochem. Anal. 2020, 31, 874-883. [CrossRef] [PubMed]

110. Morazzoni, P.; Vanzani, P.; Santinello, S.; Gucciardi, A.; Zennaro, L.; Miotto, G.; Ursini, F. Grape Seeds Proanthocyanidins: Advanced Technological Preparation and Analytical Characterization. Antioxidants 2021, 10, 418. [CrossRef] [PubMed]

111. Wang, J.; Sporns, P. MALDI-TOF MS analysis of food flavonol glycosides. J. Agric. Food Chem. 2000, 48, 1657-1662. [CrossRef]

112. Domínguez, I.; Frenich, A.G.; Romero-González, R. Mass spectrometry approaches to ensure food safety. Anal. Methods 2020, 12, 1148-1162. [CrossRef]

113. Monagas, M.; Quintanilla-López, J.E.; Gómez-Cordovés, C.; Bartolomé, B.; Lebrón-Aguilar, R. MALDI-TOF MS analysis of plant proanthocyanidins. J. Pharm. Biomed. Anal. 2010, 51, 358-372. [CrossRef]

114. Esquivel-Alvarado, D.; Alfaro-Viquez, E.; Krueger, C.G.; Vestling, M.M.; Reed, J.D. Classification of proanthocyanidin profiles using matrix-assisted laser desorption/ionization time-of-flight mass spectrometry (MALDI-TOF MS) spectra data combined with multivariate analysis. Food Chem. 2021, 336, 127667. [CrossRef]

115. Mannino, G.; Di Stefano, V.; Lauria, A.; Pitonzo, R.; Gentile, C. Vaccinium macrocarpon (Cranberry)-Based Dietary Supplements: Variation in Mass Uniformity, Proanthocyanidin Dosage and Anthocyanin Profile Demonstrates Quality Control Standard Needed. Nutrients 2020, 12, 992. [CrossRef]

116. Ma, S.; Kim, C.; Neilson, A.P.; Griffin, L.E.; Peck, G.M.; O’Keefe, S.F.; Stewart, A.C. Comparison of common analytical methods for the quantification of total polyphenols and flavanols in fruit juices and ciders. J. Food Sci. 2019, 84, 2147-2158. [CrossRef]

117. Sanches Azevedo, M.C.; Silva, R.R.E.; Jacomino, A.P.; Genovese, M.I. Physicochemical variability of cambuci fruit (Campomanesia phaea) from the same orchard, from different locations and at different ripening stages. J. Sci. Food Agric. 2017, 97, 526-535. [CrossRef]

118. Araya, M.; Carvajal, Y.; Alvarez, V.; Orozco, R.; Rodriguez, G. Polyphenol characterization of three varieties of Blackberry fruits (Rubus adenotrichos), cultivated in Costa Rica. J. Berry Res. 2017, 7, 97-107. [CrossRef]

119. Lv, Q.; Luo, F.; Zhao, X.; Liu, Y.; Hu, G.; Sun, C.; Li, X.; Chen, K. Identification of proanthocyanidins from litchi (Litchi chinensis Sonn.) pulp by LC-ESI-Q-TOF-MS and their antioxidant activity. PLoS ONE 2015, 10, 1-17. [CrossRef]

120. Grace, M.H.; Xiong, J.; Esposito, D.; Ehlenfeldt, M.; Lila, M.A. Simultaneous LC-MS quantification of anthocyanins and nonanthocyanin phenolics from blueberries with widely divergent profiles and biological activities. Food Chem. 2019, 277, 336-346. [CrossRef]

121. Carpenter, J.L.; Caruso, F.L.; Tata, A.; Vorsa, N.; Neto, C.C. Variation in proanthocyanidin content and composition among commonly grown North American cranberry cultivars (Vaccinium macrocarpon). J. Sci. Food Agric. 2014, 94, 2738-2745. [CrossRef]

122. Yang, W.; Laaksonen, O.; Kallio, H.; Yang, B. Effects of latitude and weather conditions on proanthocyanidins in berries of Finnish wild and cultivated sea buckthorn (Hippophaë rhamnoides L. ssp. rhamnoides). Food Chem. 2017, 216, 87-96. [CrossRef] 
123. Taheri, R.; Connolly, B.A.; Brand, M.H.; Bolling, B.W. Underutilized chokeberry (Aronia melanocarpa, Aronia arbutifolia, Aronia prunifolia) accessions are rich sources of anthocyanins, flavonoids, hydroxycinnamic acids, and proanthocyanidins. J. Agric. Food Chem. 2013, 61, 8581-8588. [CrossRef]

124. Crozier, S.J.; Preston, A.G.; Hurst, J.W.; Payne, M.J.; Mann, J.; Hainly, L.; Miller, D.L. Cacao seeds are a "Super Fruit": A comparative analysis of various fruit powders and products. Chem. Cent. J. 2011, 5, 4-9. [CrossRef]

125. Baydar, N.G.; Baydar, H. Phenolic compounds, antiradical activity and antioxidant capacity of oil-bearing rose (Rosa damascena Mill.) extracts. Ind. Crops Prod. 2013, 41, 375-380. [CrossRef]

126. Grace, M.H.; Esposito, D.; Dunlap, K.L.; Lila, M.A. Comparative Analysis of Phenolic Content and Profile, Antioxidant Capacity and Anti-inflammatory Bioactivity in Wild Alaskan and Commercial Vaccinium Berries. J. Agric. Food Chem. 2014, 62, 4007-4017. [CrossRef]

127. Minker, C.; Duban, L.; Karas, D.; Järvinen, P.; Lobstein, A.; Muller, C.D. Impact of procyanidins from different berries on caspase 8 activation in colon cancer. Oxid. Med. Cell. Longev. 2015, 2015, 154164. [CrossRef]

128. Nemes, A.; Szollosi, E.; Stündl, L.; Biró, A.; Homoki, J.R.; Szarvas, M.M.; Balogh, P.; Cziáky, Z.; Remenyik, J. Determination of flavonoid and proanthocyanidin profile of Hungarian sour cherry. Molecules 2018, 23, 3278. [CrossRef] [PubMed]

129. Grace, M.H.; Massey, A.R.; Mbeunkui, F.; Yousef, G.G.; Lila, M.A. Comparison of health-relevant flavonoids in commonly consumed cranberry products. J. Food Sci. 2012, 77, H176-H183. [CrossRef] [PubMed]

130. Chen, M.H.; Choi, S.H.; Kozukue, N.; Kim, H.J.; Friedman, M. Growth-inhibitory effects of pigmented rice bran extracts and three red bran fractions against human cancer cells: Relationships with composition and antioxidative activities. J. Agric. Food Chem. 2012, 60, 9151-9161. [CrossRef] [PubMed]

131. Buendía, A.S.A.; González, M.T.; Reyes, O.S.; Arroyo, F.E.G.; García, R.A.; Tapia, E.; Lozada, L.G.S.; Alonso, H.O. Immunomodulatory effects of the nutraceutical garlic derivative allicin in the progression of diabetic nephropathy. Int. J. Mol. Sci. 2018, 19, $1-13$.

132. Costamagna, M.S.; Ordoñez, R.M.; Zampini, I.C.; Sayago, J.E.; Isla, M.I. Nutritional and antioxidant properties of Geoffroea decorticans, an Argentinean fruit, and derived products (flour, arrope, decoction and hydroalcoholic beverage). Food Res. Int. 2013, 54, 160-168. [CrossRef]

133. De Souza Schmidt Gonçalves, A.E.; Lellis-Santos, C.; Curi, R.; Lajolo, F.M.; Genovese, M.I. Frozen pulp extracts of camu-camu (Myrciaria dubia McVaugh) attenuate the hyperlipidemia and lipid peroxidation of Type 1 diabetic rats. Food Res. Int. 2014, 64, 1-8. [CrossRef]

134. Pei, R.; Yu, M.; Bruno, R.; Bolling, B.W. Phenolic and tocopherol content of autumn olive (Elaeagnus umbellate) berries. J. Funct. Foods 2015, 16, 305-314. [CrossRef]

135. Ma, X.; Yang, W.; Laaksonen, O.; Nylander, M.; Kallio, H.; Yang, B. Role of Flavonols and Proanthocyanidins in the Sensory Quality of Sea Buckthorn (Hippophaë rhamnoides L.) Berries. J. Agric. Food Chem. 2017, 65, 9871-9879. [CrossRef]

136. Lu, Y.; Pekerti, B.N.; Toh, Z.S.; Broom, F.; Savage, G.; Liu, S.Q.; Huang, D. Physico-chemical parameters and proanthocyanidin profiles of cranberries cultivated in New Zealand. J. Food Compos. Anal. 2017, 63, 1-7. [CrossRef]

137. Esquivel-Alvarado, D.; Munõz-Arrieta, R.; Alfaro-Viquez, E.; Madrigal-Carballo, S.; Krueger, C.G.; Reed, J.D. Composition of Anthocyanins and Proanthocyanidins in Three Tropical Vaccinium Species from Costa Rica. J. Agric. Food Chem. 2020, 68, 2872-2879. [CrossRef]

138. Zhang, Y.; Santosa, R.W.; Zhang, M.; Huo, J.; Huang, D. Characterization and bioactivity of proanthocyanidins during Malay cherry (Lepisanthes alata) fruit ripening. Food Biosci. 2020, 36, 100617. [CrossRef]

139. Yang, W.; Ma, X.; Laaksonen, O.; He, W.; Kallio, H.; Yang, B. Effects of Latitude and Weather Conditions on Proanthocyanidins in Blackcurrant (Ribes nigrum) of Finnish Commercial Cultivars. J. Agric. Food Chem. 2019, 67, 14038-14047. [CrossRef]

140. Zhang, Y.; Hu, W.; Peng, X.; Sun, B.; Wang, X.; Tang, H. Characterization of anthocyanin and proanthocyanidin biosynthesis in two strawberry genotypes during fruit development in response to different light qualities. J. Photochem. Photobiol. B Biol. 2018, 186, 225-231. [CrossRef]

141. Cao, J.; Chen, L.; Li, M.; Cao, F.; Zhao, L.; Su, E. Efficient extraction of proanthocyanidin from Ginkgo biloba leaves employing rationally designed deep eutectic solvent-water mixture and evaluation of the antioxidant activity. J. Pharm. Biomed. Anal. 2018, 158, 317-326. [CrossRef]

142. Sakulnarmrat, K.; Srzednicki, G.; Konczak, I. Composition and inhibitory activities towards digestive enzymes of polyphenolicrich fractions of Davidson's plum and quandong. LWT Food Sci. Technol. 2014, 57, 366-375. [CrossRef]

143. Aldayel, T.S.; Grace, M.H.; Lila, M.A.; Yahya, M.A.; Omar, U.M.; Alshammary, G. LC-MS characterization of bioactive metabolites from two Yemeni Aloe spp. with antioxidant and antidiabetic properties. Arab. J. Chem. 2020, 13, 5040-5049. [CrossRef]

144. Ma, Y.; Kosińska-Cagnazzo, A.; Kerr, W.L.; Amarowicz, R.; Swanson, R.B.; Pegg, R.B. Separation and characterization of phenolic compounds from dry-blanched peanut skins by liquid chromatography-electrospray ionization mass spectrometry. J. Chromatogr. A 2014, 1356, 64-81. [CrossRef]

145. Siah, S.D. Health Benefits of Australian Grown Faba Beans (Vicia faba L.): Effects of Food Processing. P.h.D. Thesis, Charles Sturt University (Bathurst), Bathurst, Australia, 2012.

146. Oki, T.; Sugawara, T.; Sato-Furukawa, M.; Suda, I. 4-dimethylaminocinnamaldehyde (DMAC) method for determination of total proanthocyanidin content in grain legumes. Nippon Shokuhin Kagaku Kogaku Kaishi J. Jpn. Soc. Food Sci. Technol. 2013, 60, 301-309. [CrossRef] 
147. Timmers, M.A.; Guerrero-Medina, J.L.; Esposito, D.; Grace, M.H.; Paredes-López, O.; García-Saucedo, P.A.; Lila, M.A. Characterization of phenolic compounds and antioxidant and anti-inflammatory activities from mamuyo (Styrax ramirezii Greenm.) fruit. J. Agric. Food Chem. 2015, 63, 10459-10465. [CrossRef]

148. Robbins, K.S.; Gong, Y.; Wells, M.L.; Greenspan, P.; Pegg, R.B. Investigation of the antioxidant capacity and phenolic constituents of US pecans. J. Funct. Foods 2015, 15, 11-22. [CrossRef]

149. Scalbert, A.; Morand, C.; Manach, C.; Rémésy, C. Absorption and metabolism of polyphenols in the gut and impact on health. 2002, 56, 276-282. Biomed. Pharmacother. 2002, 56, 276-282. [CrossRef]

150. Spencer, J.P.E.; Schroeter, H.; Rechner, A.R.; Rice-Evans, C. Bioavailability of flavan-3-ols and procyanidins: Gastrointestinal tract influences and their relevance to bioactive forms in vivo. Antioxid. Redox Signal. 2001, 3, 1023-1039. [CrossRef]

151. Chen, L.; Cao, H.; Xiao, J. Polyphenols: Absorption, Bioavailability, and Metabolomics; Elsevier: Amsterdam, The Netherlands, 2018; Volume 10, ISBN 9780128135723.

152. Zhang, L.; Wang, Y.; Li, D.; Ho, C.T.; Li, J.; Wan, X. The absorption, distribution, metabolism and excretion of procyanidins. Food Funct. 2016, 7, 1273-1281. [CrossRef]

153. Lafay, S.; Morand, C.; Manach, C.; Besson, C.; Scalbert, A. Absorption and metabolism of caffeic acid and chlorogenic acid in the small intestine of rats. Br. J. Nutr. 2006, 96, 39-46. [CrossRef] [PubMed]

154. Olthof, M.R.; Hollman, P.C.H.; Katan, M.B. Chlorogenic acid and caffeic acid are absorbed in humans. J. Nutr. 2001, 131, 66-71. [CrossRef] [PubMed]

155. Zumdick, S.; Deters, A.; Hensel, A. In vitro intestinal transport of oligomeric procyanidins (DP 2 to 4) across monolayers of Caco-2 cells. Fitoterapia 2012, 83, 1210-1217. [CrossRef] [PubMed]

156. Tao, W.; Wei, C.; Shen, S.; Wang, M.; Chen, S.; Ye, X.; Cao, Y. Mainly dimers and trimers of Chinese bayberry leaves proanthocyanidins (BLPs) are utilized by gut microbiota: In vitro digestion and fermentation coupled with caco- 2 transportation. Molecules 2020, 25, 184. [CrossRef] [PubMed]

157. Ou, K.; Percival, S.S.; Zou, T.; Khoo, C.; Gu, L. Transport of cranberry A-type procyanidin dimers, trimers, and tetramers across monolayers of human intestinal epithelial caco-2 cells. J. Agric. Food Chem. 2012, 60, 1390-1396. [CrossRef]

158. Déprez, S.; Brezillon, C.; Rabot, S.; Philippe, C.; Mila, I.; Lapierre, C.; Scalbert, A. Polymeric proanthocyanidins are catabolized by human colonic microflora into low-molecular-weight phenolic acids. J. Nutr. 2000, 130, 2733-2738. [CrossRef]

159. Hemingway, R.W. Practical Polyphenolics: From Structure to Molecular Recognition and Physiological Action by Edwin Haslam (University of Sheffield). Cambridge University Press, New York, NY. 1998. xv +422 pp. $17 \times 24.5$ cm. $\$ 100.00$. J. Nat. Prod. 1998, 61, 1454-1455. [CrossRef]

160. D'Costa, A.S.; Bordenave, N. Inhibition of starch digestion by flavonoids: Role of flavonoid-amylase binding kinetics. Food Chem. 2021, 341, 128256. [CrossRef]

161. Takahama, U.; Hirota, S. Interactions of flavonoids with $\alpha$-amylase and starch slowing down its digestion. Food Funct. 2018, 9 , 677-687. [CrossRef]

162. Da Silva, M.; Jaggers, G.K.; Verstraeten, S.V.; Erlejman, A.G.; Fraga, C.G.; Oteiza, P.I. Large procyanidins prevent bile-acid-induced oxidant production and membrane-initiated ERK1/2, p38, and Akt activation in Caco-2 cells. Free Radic. Biol. Med. 2012, 52, 151-159. [CrossRef]

163. Erlejman, A.G.; Jaggers, G.; Fraga, C.G.; Oteiza, P.I. TNF $\alpha$-induced NF-кB activation and cell oxidant production are modulated by hexameric procyanidins in Caco-2 cells. Arch. Biochem. Biophys. 2008, 476, 186-195. [CrossRef]

164. Erlejman, A.G.; Fraga, C.G.; Oteiza, P.I. Procyanidins protect Caco-2 cells from bile acid-and oxidant-induced damage. Free Radic. Biol. Med. 2006, 41, 1247-1256. [CrossRef]

165. Gentile, C.; Perrone, A.; Attanzio, A.; Tesoriere, L.; Livrea, M.A.A. Sicilian pistachio (Pistacia vera L.) nut inhibits expression and release of inflammatory mediators and reverts the increase of paracellular permeability in IL-1 $\beta$-exposed human intestinal epithelial cells. Eur. J. Nutr. 2015, 54, 811-821. [CrossRef]

166. Spencer, J.P.E.; Chaudry, F.; Pannala, A.S.; Srai, S.K.; Debnam, E.; Rice-Evans, C. Decomposition of cocoa procyanidins in the gastric milieu. Biochem. Biophys. Res. Commun. 2000, 272, 236-241. [CrossRef]

167. Rios, L.Y.; Bennett, R.N.; Lazarus, S.A.; Rémésy, C.; Scalbert, A.; Williamson, G. Cocoa procyanidins are stable during gastric transit in humans. Am. J. Clin. Nutr. 2002, 76, 1106-1110. [CrossRef]

168. Serra, A.; MacI, A.; Romero, M.P.; Valls, J.; Bladé, C.; Arola, L.; Motilva, M.J. Bioavailability of procyanidin dimers and trimers and matrix food effects in in vitro and in vivo models. Br. J. Nutr. 2010, 103, 944-952. [CrossRef]

169. Wiese, S.; Esatbeyoglu, T.; Winterhalter, P.; Kruse, H.P.; Winkler, S.; Bub, A.; Kulling, S.E. Comparative biokinetics and metabolism of pure monomeric, dimeric, and polymeric flavan-3-ols: A randomized cross-over study in humans. Mol. Nutr. Food Res. 2015, 59, 610-621. [CrossRef]

170. Li, Q.; Chen, J.; Li, T.; Liu, C.; Wang, X.; Dai, T.; McClements, D.J.; Liu, J. Impact of in vitro simulated digestion on the potential health benefits of proanthocyanidins from Choerospondias axillaris peels. Food Res. Int. 2015, 78, 378-387. [CrossRef]

171. Appeldoorn, M.M.; Vincken, J.-P.; Gruppen, H.; Hollman, P.C.H. Procyanidin dimers A1, A2, and B2 are absorbed without conjugation or methylation from the small intestine of rats. J. Nutr. 2009, 139, 1469-1473. [CrossRef]

172. Rossi, M.; Negri, E.; Parpinel, M.; Lagiou, P.; Bosetti, C.; Talamini, R.; Montella, M.; Giacosa, A.; Franceschi, S.; La Vecchia, C. Proanthocyanidins and the risk of colorectal cancer in Italy. Cancer Causes Control 2010, 21, 243-250. [CrossRef] 
173. Akaberi, M.; Hosseinzadeh, H. Grapes (Vitis vinifera) as a Potential Candidate for the Therapy of the Metabolic Syndrome. Phyther. Res. 2016, 30, 540-556. [CrossRef]

174. Francini-Pesenti, F.; Spinella, P.; Calò, L.A. Potential role of phytochemicals in metabolic syndrome prevention and therapy. Diabetes, Metab. Syndr. Obes. Targets Ther. 2019, 12, 1987-2002. [CrossRef]

175. Márquez Campos, E.; Jakobs, L.; Simon, M.C. Antidiabetic Effects of Flavan-3-ols and Their Microbial Metabolites. Nutrients 2020, 12, 1592. [CrossRef]

176. Santos-Buelga, C.; Scalbert, A. Proanthocyanidins and tannin-like compounds-Nature, occurrence, dietary intake and effects on nutrition and health. J. Sci. Food Agric. 2000, 80, 1094-1117. [CrossRef]

177. Biesinger, S.; Michaels, H.A.; Quadros, A.S.; Qian, Y.; Rabovsky, A.B.; Badger, R.S.; Jalili, T. A combination of isolated phytochemicals and botanical extracts lowers diastolic blood pressure in a randomized controlled trial of hypertensive subjects. Eur. J. Clin. Nutr. 2016, 70, 10-16. [CrossRef]

178. Bøhn, S.K.; Croft, K.D.; Burrows, S.; Puddey, I.B.; Mulder, T.P.J.; Fuchs, D.; Woodman, R.J.; Hodgson, J.M. Effects of black tea on body composition and metabolic outcomes related to cardiovascular disease risk: A randomized controlled trial. Food Funct. 2014, 5, 1613-1620. [CrossRef]

179. Desideri, G.; Kwik-Uribe, C.; Grassi, D.; Necozione, S.; Ghiadoni, L.; Mastroiacovo, D.; Raffaele, A.; Ferri, L.; Bocale, R.; Lechiara, M.C.; et al. Benefits in cognitive function, blood pressure, and insulin resistance through cocoa flavanol consumption in elderly subjects with mild cognitive impairment: The cocoa, cognition, and aging (CoCoA) study. Hypertension 2012, 60, 794-801. [CrossRef] [PubMed]

180. Hoshino, T.; Yamashita, S.I.; Suzuki, N.; Baba, A.; Ogawa, S.; Izumi, T. Impact of Acacia bark extract tablets on the skin of healthy humans: A randomized, double-blind, placebo-controlled study. Biosci. Biotechnol. Biochem. 2019, 83, 538-550. [CrossRef] [PubMed]

181. Khan, A.; Safdar, M.; Ali Khan, M.M.; Khattak, K.N.; Anderson, R.A. Cinnamon Improves Glucose and Lipids of People with Type 2 Diabetes. Diabetes Care 2003, 26, 3215-3218. [CrossRef] [PubMed]

182. Ranasinghe, P.; Jayawardena, R.; Pigera, S.; Wathurapatha, W.S.; Weeratunga, H.D.; Premakumara, G.A.S.; Katulanda, P.; Constantine, G.R.; Galappaththy, P. Evaluation of pharmacodynamic properties and safety of Cinnamomum zeylanicum (Ceylon cinnamon) in healthy adults: A phase I clinical trial. BMC Complement. Altern. Med. 2017, 17, 1-9. [CrossRef] [PubMed]

183. Sano, A.; Uchida, R.; Saito, M.; Shioya, N.; Komori, Y.; Tho, Y.; Hashizume, N. Beneficial effects of grape seed extract on malondialdehyde-modified LDL. J. Nutr. Sci. Vitaminol. 2007, 53, 174-182. [CrossRef]

184. Stull, A.J.; Cash, K.C.; Johnson, W.D.; Champagne, C.M.; Cefalu, W.T. Bioactives in blueberries improve insulin sensitivity in obese, insulin-resistant men and women. J. Nutr. 2010, 140, 1764-1768. [CrossRef]

185. Han, L.; Zhang, L.; Ma, W.; Li, D.; Shi, R.; Wang, M. Proanthocyanidin B2 attenuates postprandial blood glucose and its inhibitory effect on alpha-glucosidase: Analysis by kinetics, fluorescence spectroscopy, atomic force microscopy and molecular docking. Food Funct. 2018, 9, 4673-4682. [CrossRef]

186. Yokozawa, T.; Cho, E.J.; Park, C.H.; Kim, J.H. Protective effect of proanthocyanidin against diabetic oxidative stress. Evid.-Based Complement. Altern. Med. 2012, 2012, 623879. [CrossRef]

187. Hollands, W.J.; Tapp, H.; Defernez, M.; Moral, N.P.; Winterbone, M.S.; Philo, M.; Lucey, A.J.; Kiely, M.E.; Kroon, P.A. Lack of acute or chronic effects of epicatechin-rich and procyanidin-rich apple extracts on blood pressure and cardiometabolic biomarkers in adults with moderately elevated blood pressure: A randomized, placebo-controlled crossover trial. Am. J. Clin. Nutr. 2018, 108, 1006-1014. [CrossRef]

188. El-Alfy, A.T.; Ahmed, A.A.E.; Fatani, A.J. Protective effect of red grape seeds proanthocyanidins against induction of diabetes by alloxan in rats. Pharmacol. Res. 2005, 52, 264-270. [CrossRef]

189. Ding, Y.; Zhang, Z.; Dai, X.; Jiang, Y.; Bao, L.; Li, Y.; Li, Y. Grape seed proanthocyanidins ameliorate pancreatic beta-cell dysfunction and death in low-dose streptozotocin- and high-carbohydrate/high-fat diet-induced diabetic rats partially by regulating endoplasmic reticulum stress. Nutr. Metab. 2013, 10, 51. [CrossRef]

190. Li, Q.H.; Yan, H.S.; Li, H.Q.; Gao, J.J.; Hao, R.R. Effects of dietary supplementation with grape seed procyanidins on nutrient utilisation and gut function in weaned piglets. Animal 2020, 14, 491-498. [CrossRef]

191. Pinent, M.; Blay, M.; Bladé, M.C.; Salvadó, M.J.; Arola, L.; Ardévol, A. Grape seed-derived procyanidins have an antihyperglycemic effect in streptozotocin-induced diabetic rats and insulinomimetic activity in insulin-sensitive cell lines. Endocrinology 2004, 145, 4985-4990. [CrossRef]

192. Castell-Auví, A.; Cedó, L.; Pallarès, V.; Blay, M.T.; Pinent, M.; Motilva, M.J.; Garcia-Vallvé, S.; Pujadas, G.; Maechler, P.; Ardévol, A. Procyanidins modify insulinemia by affecting insulin production and degradation. J. Nutr. Biochem. 2012, 23, 1565-1572. [CrossRef]

193. Bao, L.; Cai, X.; Dai, X.; Ding, Y.; Jiang, Y.; Li, Y.; Zhang, Z.; Li, Y. Grape seed proanthocyanidin extracts ameliorate podocyte injury by activating peroxisome proliferator-activated receptor- $\gamma$ coactivator $1 \alpha$ in low-dose streptozotocin-and high-carbohydrate/highfat diet-induced diabetic rats. Food Funct. 2014, 5, 1872-1880. [CrossRef]

194. Li, Y.; Bao, L.; Zhang, Z.; Dai, X.; Ding, Y.; Jiang, Y.; Li, Y. Effects of grape seed proanthocyanidin extract on renal injury in type 2 diabetic rats. Mol. Med. Rep. 2015, 11, 645-652.

195. Chen, S.; Zhu, Y.; Liu, Z.; Gao, Z.; Li, B.; Zhang, D.; Zhang, Z.; Jiang, X.; Liu, Z.; Meng, L.; et al. Grape seed proanthocyanidin extract ameliorates diabetic bladder dysfunction via the activation of the Nrf2 pathway. PLoS ONE 2015, 10, e0126457. [CrossRef] 
196. Zhang, Z.; Li, Y.; Li, Y. Grape seed proanthocyanidin extracts prevent hyperglycemia-induced monocyte adhesion to aortic endothelial cells and ameliorates vascular inflammation in high-carbohydrate/high-fat diet and streptozotocin-induced diabetic rats. Int. J. Food Sci. Nutr. 2016, 67, 524-534. [CrossRef]

197. Sanna, R.S.; Muthangi, S.; Chandrasekhar, C.S.; Devi, S.A. Grape seed proanthocyanidin extract and insulin prevents cognitive decline in type 1 diabetic rat by impacting Bcl-2 and Bax in the prefrontal cortex. Metab. Brain Dis. 2019, 34, 103-117. [CrossRef]

198. Ding, Y.; Li, H.; Li, Y.; Liu, D.; Zhang, L.; Wang, T.; Liu, T.; Ma, L. Protective Effects of Grape Seed Proanthocyanidins on the Kidneys of Diabetic Rats through the Nrf2 Signalling Pathway. Evid.-Based Complement. Altern. Med. 2020, 2020, 5205903. [CrossRef]

199. Mellor, D.D.; Madden, L.A.; Smith, K.A.; Kilpatrick, E.S.; Atkin, S.L. High-polyphenol chocolate reduces endothelial dysfunction and oxidative stress during acute transient hyperglycaemia in Type 2 diabetes: A pilot randomized controlled trial. Diabet. Med. 2013, 30, 478-483. [CrossRef]

200. Yamashita, Y.; Okabe, M.; Natsume, M.; Ashida, H. Cacao liquor procyanidins prevent postprandial hyperglycaemia by increasing glucagon-like peptide-1 activity and AMP-activated protein kinase in mice. J. Nutr. Sci. 2019, 8, E2. [CrossRef] [PubMed]

201. Tomaru, M.; Takano, H.; Osakabe, N.; Yasuda, A.; Inoue, K.I.; Yanagisawa, R.; Ohwatari, T.; Uematsu, H. Dietary supplementation with cacao liquor proanthocyanidins prevents elevation of blood glucose levels in diabetic obese mice. Nutrition 2007, 23, 351-355. [CrossRef] [PubMed]

202. Yamashita, Y.; Okabe, M.; Natsume, M.; Ashida, H. Cacao liquor procyanidin extract improves glucose tolerance by enhancing GLUT4 translocation and glucose uptake in skeletal muscle. J. Nutr. Sci. 2012, 1, 1-9. [CrossRef] [PubMed]

203. Rodríguez-Daza, M.C.; Daoust, L.; Boutkrabt, L.; Pilon, G.; Varin, T.; Dudonné, S.; Levy, É.; Marette, A.; Roy, D.; Desjardins, Y. Wild blueberry proanthocyanidins shape distinct gut microbiota profile and influence glucose homeostasis and intestinal phenotypes in high-fat high-sucrose fed mice. Sci. Rep. 2020, 10, 2217. [CrossRef]

204. Ntemiri, A.; Ghosh, T.S.; Gheller, M.E.; Tran, T.T.T.; Blum, J.E.; Pellanda, P.; Vlckova, K.; Neto, M.C.; Howell, A.; ThalackerMercer, A.; et al. Whole blueberry and isolated polyphenol-rich fractions modulate specific gut microbes in an in vitro colon model and in a pilot study in human consumers. Nutrients 2020, 12, 2800. [CrossRef]

205. Liu, Y.; Zhang, X.; Zhan, L.; Xu, C.; Sun, L.; Jiang, H.; Sun, C.; Li, X. LC-Q-TOF-MS Characterization of Polyphenols from White Bayberry Fruit and Its Antidiabetic Effect in KK-AyMice. ACS Omega 2020, 5, 17839-17849. [CrossRef]

206. Castro-Acosta, M.L.; Stone, S.G.; Mok, J.E.; Mhajan, R.K.; Fu, C.I.; Lenihan-Geels, G.N.; Corpe, C.P.; Hall, W.L. Apple and blackcurrant polyphenol-rich drinks decrease postprandial glucose, insulin and incretin response to a high-carbohydrate meal in healthy men and women. J. Nutr. Biochem. 2017, 49, 53-62. [CrossRef]

207. Kanamoto, Y.; Yamashita, Y.; Nanba, F.; Yoshida, T.; Tsuda, T.; Fukuda, I.; Nakamura-Tsuruta, S.; Ashida, H. A black soybean seed coat extract prevents obesity and glucose intolerance by up-regulating uncoupling proteins and down-regulating inflammatory cytokines in high-fat diet-fed mice. J. Agric. Food Chem. 2011, 59, 8985-8993. [CrossRef]

208. Lee, Y.A.; Eun, J.C.; Yokozawa, T. Effects of proanthocyanidin preparations on hyperlipidemia and other biomarkers in mouse model of type 2 diabetes. J. Agric. Food Chem. 2008, 56, 7781-7789. [CrossRef]

209. Lin, G.M.; Hsu, C.Y.; Chang, S.T. Antihyperglycemic activities of twig extract of indigenous cinnamon (Cinnamomum osmophloeum) on high-fat diet and streptozotocin-induced hyperglycemic rats. J. Sci. Food Agric. 2018, 98, 5908-5915. [CrossRef]

210. Hsu, C.Y.; Lin, G.M.; Chang, S.T. Hypoglycemic activity of extracts of Chamaecyparis obtusa var. formosana leaf in rats with hyperglycemia induced by high-fat diets and streptozotocin. J. Tradit. Complement. Med. 2020, 10, 389-395. [CrossRef]

211. Macho-González, A.; López-Oliva, M.E.; Merino, J.J.; García-Fernández, R.A.; Garcimartín, A.; Redondo-Castillejo, R.; Bastida, S.; Sánchez-Muniz, F.J.; Benedí, J. Carob fruit extract-enriched meat improves pancreatic beta-cell dysfunction, hepatic insulin signaling and lipogenesis in late-stage type 2 diabetes mellitus model. J. Nutr. Biochem. 2020, 84, 108461. [CrossRef]

212. Anunciação, P.C.; de Morais Cardoso, L.; Queiroz, V.A.V.; de Menezes, C.B.; de Carvalho, C.W.P.; Pinheiro-Sant'Ana, H.M.; Alfenas, R.D.C.G. Consumption of a drink containing extruded sorghum reduces glycaemic response of the subsequent meal. Eur. J. Nutr. 2018, 57, 251-257. [CrossRef]

213. Wang, Y.-Y.; Hsieh, Y.-H.; Kumar, K.J.S.; Hsieh, H.-W.; Lin, C.-C.; Wang, S.-Y. The Regulatory Effects of a Formulation of Cinnamomum osmophloeum Kaneh and Taiwanofungus camphoratus on Metabolic Syndrome and the Gut Microbiome. Plants 2020, 9, 383. [CrossRef]

214. Bang, C.Y.; Choung, S.Y. Enzogenol improves diabetes-related metabolic change in C57BL/KsJ-db/db mice, a model of type 2 diabetes mellitus. J. Pharm. Pharmacol. 2014, 66, 875-885. [CrossRef]

215. Zhong, H.; Xue, Y.; Lu, X.; Shao, Q.; Cao, Y.; Wu, Z.; Chen, G. The effects of different degrees of procyanidin polymerization on the nutrient absorption and digestive enzyme activity in mice. Molecules 2018, 23, 2916. [CrossRef]

216. Casanova-Martí, À.; Serrano, J.; Blay, M.T.; Terra, X.; Ardévol, A.; Pinent, M. Acute selective bioactivity of grape seed proanthocyanidins on enteroendocrine secretions in the gastrointestinal tract. Food Nutr. Res. 2017, 61, 1321347. [CrossRef]

217. Casanova-Martí, À.; Serrano, J.; Portune, K.J.; Sanz, Y.; Blay, M.T.; Terra, X.; Ardévol, A.; Pinent, M. Grape seed proanthocyanidins influence gut microbiota and enteroendocrine secretions in female rats. Food Funct. 2018, 9, 1672-1682. [CrossRef]

218. González-Abuín, N.; Martínez-Micaelo, N.; Blay, M.; Green, B.D.; Pinent, M.; Ardévol, A. Grape-seed procyanidins modulate cellular membrane potential and nutrient-induced GLP-1 secretion in STC-1 cells. Am. J. Physiol. Cell Physiol. 2014, 306, C485-C492. [CrossRef] 
219. Boue, S.M.; Daigle, K.W.; Chen, M.H.; Cao, H.; Heiman, M.L. Antidiabetic potential of purple and red rice (Oryza sativa L.) bran extracts. J. Agric. Food Chem. 2016, 64, 5345-5353. [CrossRef]

220. Krishnan, V.; Rani, R.; Awana, M.; Pitale, D.; Kulshreshta, A.; Sharma, S.; Bollinedi, H.; Singh, A.; Singh, B.; Singh, A.K.; et al. Role of nutraceutical starch and proanthocyanidins of pigmented rice in regulating hyperglycemia: Enzyme inhibition, enhanced glucose uptake and hepatic glucose homeostasis using in vitro model. Food Chem. 2021, 335, 127505. [CrossRef] [PubMed]

221. Johnson, M.H.; De Mejia, E.G.; Fan, J.; Lila, M.A.; Yousef, G.G. Anthocyanins and proanthocyanidins from blueberry-blackberry fermented beverages inhibit markers of inflammation in macrophages and carbohydrate-utilizing enzymes in vitro. Mol. Nutr. Food Res. 2013, 57, 1182-1197. [CrossRef]

222. Xiao, J.; Kai, G.; Yamamoto, K.; Chen, X. Advance in Dietary Polyphenols as $\alpha$-Glucosidases Inhibitors: A Review on StructureActivity Relationship Aspect. Crit. Rev. Food Sci. Nutr. 2013, 53, 818-836. [CrossRef] [PubMed]

223. Lee, Y.A.; Cho, E.J.; Tanaka, T.; Yokozawa, T. Inhibitory Activities of Proanthocyanidins from Persimmon against Oxidative Stress and Digestive Enzymes Related to Diabetes. J. Nutr. Sci. Vitaminol. 2007, 53, 287-292. [CrossRef] [PubMed]

224. Gonçalves, R.; Mateus, N.; de Freitas, V. Inhibition of $\alpha$-amylase activity by condensed tannins. Food Chem. 2011, 125, 665-672. [CrossRef]

225. Stalmach, A.; Mullen, W.; Steiling, H.; Williamson, G.; Lean, M.E.J.; Crozier, A. Absorption, metabolism, and excretion of green tea flavan-3-ols in humans with an ileostomy. Mol. Nutr. Food Res. 2010, 54, 323-334. [CrossRef] [PubMed]

226. Rowland, I.; Gibson, G.; Heinken, A.; Scott, K.; Swann, J.; Thiele, I.; Tuohy, K. Gut microbiota functions: Metabolism of nutrients and other food components. Eur. J. Nutr. 2018, 57, 1-24. [CrossRef] [PubMed]

227. Pierre, J.F.; Heneghan, A.F.; Feliciano, R.P.; Shanmuganayagam, D.; Roenneburg, D.A.; Krueger, C.G.; Reed, J.D.; Kudsk, K.A. Cranberry proanthocyanidins improve the gut mucous layer morphology and function in mice receiving elemental enteral nutrition. J. Parenter. Enter. Nutr. 2013, 37, 401-409. [CrossRef]

228. Everard, A.; Belzer, C.; Geurts, L.; Ouwerkerk, J.P.; Druart, C.; Bindels, L.B.; Guiot, Y.; Derrien, M.; Muccioli, G.G.; Delzenne, N.M.; et al. Cross-talk between Akkermansia muciniphila and intestinal epithelium controls diet-induced obesity. Proc. Natl. Acad. Sci. USA 2013, 110, 9066-9071. [CrossRef]

229. Shin, N.R.; Lee, J.C.; Lee, H.Y.; Kim, M.S.; Whon, T.W.; Lee, M.S.; Bae, J.W. An increase in the Akkermansia spp. population induced by metformin treatment improves glucose homeostasis in diet-induced obese mice. Gut 2014, 63, 727-735. [CrossRef]

230. Gómez-Gallego, C.; Pohl, S.; Salminen, S.; De Vos, W.M.; Kneifel, W. Akkermansia muciniphila: A novel functional microbe with probiotic properties. Benef. Microbes 2016, 7, 571-584. [CrossRef]

231. Roopchand, D.E.; Carmody, R.N.; Kuhn, P.; Moskal, K.; Rojas-Silva, P.; Turnbaugh, P.J.; Raskin, I. Dietary polyphenols promote growth of the gut bacterium akkermansia muciniphila and attenuate high-fat diet-induced metabolic syndrome. Diabetes 2015, 64, 2847-2858. [CrossRef]

232. Anhê, F.F.; Roy, D.; Pilon, G.; Dudonné, S.; Matamoros, S.; Varin, T.V.; Garofalo, C.; Moine, Q.; Desjardins, Y.; Levy, E.; et al. A polyphenol-rich cranberry extract protects from diet-induced obesity, insulin resistance and intestinal inflammation in association with increased Akkermansia spp. population in the gut microbiota of mice. Gut 2015, 64, 872-883. [CrossRef]

233. Masumoto, S.; Terao, A.; Yamamoto, Y.; Mukai, T.; Miura, T.; Shoji, T. Non-absorbable apple procyanidins prevent obesity associated with gut microbial and metabolomic changes. Sci. Rep. 2016, 6, 31208. [CrossRef]

234. Shaw, K.A.; Bertha, M.; Hofmekler, T.; Chopra, P.; Vatanen, T.; Srivatsa, A.; Prince, J.; Kumar, A.; Sauer, C.; Zwick, M.E.; et al. Dysbiosis, inflammation, and response to treatment: A longitudinal study of pediatric subjects with newly diagnosed inflammatory bowel disease. Genome Med. 2016, 8, 75. [CrossRef]

235. Takagaki, A.; Nanjo, F. Bioconversion of (-)-epicatechin, (+)-epicatechin, (-)-catechin, and (+)-catechin by (-)-epigallocatechinmetabolizing bacteria. Biol. Pharm. Bull. 2015, 38, 789-794. [CrossRef]

236. Mena, P.; Bresciani, L.; Brindani, N.; Ludwig, I.A.; Pereira-Caro, G.; Angelino, D.; Llorach, R.; Calani, L.; Brighenti, F.; Clifford, M.N.; et al. Phenyl- $\gamma$-valerolactones and phenylvaleric acids, the main colonic metabolites of flavan-3-ols: Synthesis, analysis, bioavailability, and bioactivity. Nat. Prod. Rep. 2019, 36, 714-752. [CrossRef]

237. Ley, R.E.; Bäckhed, F.; Turnbaugh, P.; Lozupone, C.A.; Knight, R.D.; Gordon, J.I. Obesity alters gut microbial ecology. Proc. Natl. Acad. Sci. USA 2005, 102, 11070-11075. [CrossRef]

238. Ley, R.E.; Turnbaugh, P.J.; Klein, S.; Gordon, J.I. Microbial ecology: Human gut microbes associated with obesity. Nature 2006, 444, 1022-1023. [CrossRef]

239. Duncan, S.H.; Lobley, G.E.; Holtrop, G.; Ince, J.; Johnstone, A.M.; Louis, P.; Flint, H.J. Human colonic microbiota associated with diet, obesity and weight loss. Int. J. Obes. 2008, 32, 1720-1724. [CrossRef]

240. Yamakoshi, J.; Tokutake, S.; Kikuchi, M.; Kubota, Y.; Konishi, H.; Mitsuoka, T. Effect of proanthocyanidin-rich extract from grape seeds on human fecal flora and fecal odor. Microb. Ecol. Health Dis. 2001, 13, 25-31.

241. Monagas, M.; Urpi-Sarda, M.; Sánchez-Patán, F.; Llorach, R.; Garrido, I.; Gómez-Cordovés, C.; Andres-Lacueva, C.; Bartolomé, B. Insights into the metabolism and microbial biotransformation of dietary flavan-3-ols and the bioactivity of their metabolites. Food Funct. 2010, 1, 233-253. [CrossRef]

242. Zhang, H.J.; Ji, B.P.; Chen, G.; Zhou, F.; Luo, Y.C.; Yu, H.Q.; Gao, F.Y.; Zhang, Z.P.; Li, H.Y. A combination of grape seed-derived procyanidins and gypenosides alleviates insulin resistance in mice and HepG2 cells. J. Food Sci. 2009, 74, H1-H7. [CrossRef] [PubMed] 
243. Kurimoto, Y.; Shibayama, Y.; Inoue, S.; Soga, M.; Takikawa, M.; Ito, C.; Nanba, F.; Yoshida, T.; Yamashita, Y.; Ashida, H.; et al. Black soybean seed coat extract ameliorates hyperglycemia and insulin sensitivity via the activation of AMP-activated protein kinase in diabetic mice. J. Agric. Food Chem. 2013, 61, 5558-5564. [CrossRef] [PubMed]

244. Huang, P.L.; Chi, C.W.; Liu, T.Y. Areca nut procyanidins ameliorate streptozocin-induced hyperglycemia by regulating gluconeogenesis. Food Chem. Toxicol. 2013, 55, 137-143. [CrossRef] [PubMed]

245. Cordero-Herrera, I.; Martín, M.A.; Bravo, L.; Goya, L.; Ramos, S. Cocoa flavonoids improve insulin signalling and modulate glucose production via AKT and AMPK in HepG2 cells. Mol. Nutr. Food Res. 2013, 57, 974-985. [CrossRef]

246. Collins, Q.F.; Liu, H.Y.; Pi, J.; Liu, Z.; Quon, M.J.; Cao, W. Epigallocatechin-3-gallate (EGCG), a green tea polyphenol, suppresses hepatic gluconeogenesis through 5'-AMP-activated protein kinase. J. Biol. Chem. 2007, 282, 30143-30149. [CrossRef]

247. Cordero-Herrera, I.; Martín, M.Á.; Goya, L.; Ramos, S. Cocoa flavonoids attenuate high glucose-induced insulin signalling blockade and modulate glucose uptake and production in human HepG2 cells. Food Chem. Toxicol. 2014, 64, 10-19. [CrossRef]

248. Cordero-Herrera, I.; Martín, M.Á.; Escrivá, F.; álvarez, C.; Goya, L.; Ramos, S. Cocoa-rich diet ameliorates hepatic insulin resistance by modulating insulin signaling and glucose homeostasis in Zucker diabetic fatty rats. J. Nutr. Biochem. 2015, 26, 704-712. [CrossRef]

249. Yogalakshmi, B.; Bhuvaneswari, S.; Sreeja, S.; Anuradha, C.V. Grape seed proanthocyanidins and metformin act by different mechanisms to promote insulin signaling in rats fed high calorie diet. J. Cell Commun. Signal. 2014, 8, 13-22. [CrossRef]

250. Singh, R.; Devi, S.; Gollen, R. Role of free radical in atherosclerosis, diabetes and dyslipidaemia: Larger-than-life. Diabetes. Metab. Res. Rev. 2015, 31, 113-126. [CrossRef]

251. Kim, M.J.; Ryu, G.R.; Chung, J.S.; Sim, S.S.; Min, D.S.; Rhie, D.J.; Yoon, S.H.; Hahn, S.J.; Kim, M.S.; Jo, Y.H. Protective effects of epicatechin against the toxic effects of streptozotocin on rat pancreatic islets: In vivo and in vitro. Pancreas 2003, 26, 292-299. [CrossRef]

252. Martín, M.Á.; Fernández-Millán, E.; Ramos, S.; Bravo, L.; Goya, L. Cocoa flavonoid epicatechin protects pancreatic beta cell viability and function against oxidative stress. Mol. Nutr. Food Res. 2014, 58, 447-456. [CrossRef]

253. Cedó, L.; Castell-Auví, A.; Pallarès, V.; Blay, M.; Ardévol, A.; Arola, L.; Pinent, M. Grape seed procyanidin extract modulates proliferation and apoptosis of pancreatic beta-cells. Food Chem. 2013, 138, 524-530. [CrossRef]

254. Ansarullah; Bharucha, B.; Dwivedi, M.; Laddha, N.C.; Begum, R.; Hardikar, A.A.; Ramachandran, A.V. Antioxidant rich flavonoids from Oreocnide integrifolia enhance glucose uptake and insulin secretion and protects pancreatic $\beta$-cells from streptozotocin insult. BMC Complement. Altern. Med. 2011, 11, 126. [CrossRef]

255. Hii, C.S.T.; Howell, S.L. Effects of epicatechin on rat islets of Langerhans. Diabetes 1984, 33, 291-296. [CrossRef]

256. Jayaprakasam, B.; Vareed, S.K.; Olson, L.K.; Nair, M.G. Insulin secretion by bioactive anthocyanins and anthocyanidins present in fruits. J. Agric. Food Chem. 2005, 53, 28-31. [CrossRef]

257. Zhu, M.; Hu, J.; Perez, E.; Phillips, D.; Kim, W.; Ghaedian, R.; Napora, J.K.; Zou, S. Effects of long-term cranberry supplementation on endocrine pancreas in aging rats. J. Gerontol. Ser. A Biol. Sci. Med. Sci. 2011, 66A, 1139-1151. [CrossRef]

258. Chemler, J.A.; Lock, L.T.; Koffas, M.A.G.; Tzanakakis, E.S. Standardized biosynthesis of flavan-3-ols with effects on pancreatic beta-cell insulin secretion. Appl. Microbiol. Biotechnol. 2007, 77, 797-807. [CrossRef]

259. Yang, K.; Hashemi, Z.; Han, W.; Jin, A.; Yang, H.; Ozga, J.; Li, L.; Chan, C.B. Hydrolysis enhances bioavailability of proanthocyanidin-derived metabolites and improves $\beta$-cell function in glucose intolerant rats. J. Nutr. Biochem. 2015, 26, 850-859. [CrossRef]

260. Cedó, L.; Castell-Auví, A.; Pallarès, V.; Mohien, C.U.; Baiges, I.; Blay, M.; Ardévol, A.; Pinent, M. Pancreatic islet proteome profile in Zucker fatty rats chronically treated with a grape seed procyanidin extract. Food Chem. 2012, 135, 1948-1956. [CrossRef]

261. Du, J.; Zhang, L.; Liu, S.; Zhang, C.; Huang, X.; Li, J.; Zhao, N.; Wang, Z. PPAR $\gamma$ transcriptionally regulates the expression of insulin-degrading enzyme in primary neurons. Biochem. Biophys. Res. Commun. 2009, 383, 485-490. [CrossRef]

262. Pinent, M.; Bladé, M.C.; Salvadó, M.J.; Arola, L.; Hackl, H.; Quackenbush, J.; Trajanoski, Z.; Ardévol, A. Grape-seed derived procyanidins interfere with adipogenesis of 3T3-L1 cells at the onset of differentiation. Int. J. Obes. 2005, 29, 934-941. [CrossRef]

263. Cao, H.; Polansky, M.M.; Anderson, R.A. Cinnamon extract and polyphenols affect the expression of tristetraprolin, insulin receptor, and glucose transporter 4 in mouse 3T3-L1 adipocytes. Arch. Biochem. Biophys. 2007, 459, 214-222. [CrossRef] [PubMed]

264. Montagut, G.; Onnockx, S.; Vaqué, M.; Bladé, C.; Blay, M.; Fernández-Larrea, J.; Pujadas, G.; Salvadó, M.J.; Arola, L.; Pirson, I.; et al. Oligomers of grape-seed procyanidin extract activate the insulin receptor and key targets of the insulin signaling pathway differently from insulin. J. Nutr. Biochem. 2010, 21, 476-481. [CrossRef] [PubMed]

265. Ricquier, D.; Bouillaud, F. The uncoupling protein homologues: UCP1, UCP2, UCP3, StUCP and AtUCP. Biochem. J. 2000, 345, 161-179. [CrossRef]

266. Chen, N.; Bezzina, R.; Hinch, E.; Lewandowski, P.A.; Cameron-Smith, D.; Mathai, M.L.; Jois, M.; Sinclair, A.J.; Begg, D.P.; Wark, J.D.; et al. Green tea, black tea, and epigallocatechin modify body composition, improve glucose tolerance, and differentially alter metabolic gene expression in rats fed a high-fat diet. Nutr. Res. 2009, 29, 784-793. [CrossRef]

267. Koutsos, A.; Riccadonna, S.; Ulaszewska, M.M.; Franceschi, P.; Trošt, K.; Galvin, A.; Braune, T.; Fava, F.; Perenzoni, D.; Mattivi, F.; et al. Two apples a day lower serum cholesterol and improve cardiometabolic biomarkers in mildly hypercholesterolemic adults: A randomized, controlled, crossover trial. Am. J. Clin. Nutr. 2020, 111, 307-318. [CrossRef] 
268. Widjajakusuma, E.C.; Jonosewojo, A.; Hendriati, L.; Wijaya, S.; Ferawati; Surjadhana, A.; Sastrowardoyo, W.; Monita, N.; Muna, N.M.; Fajarwati, R.P.; et al. Phytochemical screening and preliminary clinical trials of the aqueous extract mixture of Andrographis paniculata (Burm. f.) Wall. ex Nees and Syzygium polyanthum (Wight.) Walp leaves in metformin treated patients with type 2 diabetes. Phytomedicine 2019, 55, 137-147. [CrossRef] [PubMed]

269. Rodriguez-Mateos, A.; Weber, T.; Skene, S.S.; Ottaviani, J.I.; Crozier, A.; Kelm, M.; Schroeter, H.; Heiss, C. Assessing the respective contributions of dietary flavanol monomers and procyanidins in mediating cardiovascular effects in humans: Randomized, controlled, double-masked intervention trial. Am. J. Clin. Nutr. 2018, 108, 1229-1237. [CrossRef] [PubMed]

270. Valls, R.M.; Llauradó, E.; Fernández-Castillejo, S.; Puiggrós, F.; Solà, R.; Arola, L.; Pedret, A. Effects of low molecular weight procyanidin rich extract from french maritime pine bark on cardiovascular disease risk factors in stage- 1 hypertensive subjects: Randomized, double-blind, crossover, placebo-controlled intervention trial. Phytomedicine 2016, 23, 1451-1461. [CrossRef]

271. Argani, H.; Ghorbanihaghjo, A.; Vatankhahan, H.; Rashtchizadeh, N.; Raeisi, S.; Ilghami, H. O efeito do extrato de semente de uva vermelha na atividade do soro paraoxonase em doentes com hiperlipidemia leve a moderada. Sao Paulo Med. J. 2016, 134, 234-239. [CrossRef]

272. Gato, N.; Kadowaki, A.; Hashimoto, N.; Yokoyama, S.I.; Matsumoto, K. Persimmon fruit tannin-rich fiber reduces cholesterol levels in humans. Ann. Nutr. Metab. 2013, 62, 1-6. [CrossRef]

273. Drieling, R.L.; Gardner, C.D.; Ma, J.; Ahn, D.K.; Stafford, R.S. No beneficial effects of pine bark extract on cardiovascular disease risk factors. Arch. Intern. Med. 2010, 170, 1541-1547. [CrossRef]

274. Wan, Y.; Vinson, J.A.; Etherton, T.D.; Proch, J.; Lazarus, S.A.; Kris-Etherton, P.M. Effects of cocoa powder and dark chocolate on LDL oxidative susceptibility and prostaglandin concentrations in humans. Am. J. Clin. Nutr. 2001, 74, 596-602. [CrossRef]

275. Rein, D.; Lotito, S.; Holt, R.R.; Keen, C.L.; Schmitz, H.H.; Fraga, C.G. Epicatechin in human plasma: In vivo determination and effect of chocolate consumption on plasma oxidation status. J. Nutr. 2000, 130, 2109-2114. [CrossRef]

276. Bladé, C.; Arola, L.; Salvadó, M.J. Hypolipidemic effects of proanthocyanidins and their underlying biochemical and molecular mechanisms. Mol. Nutr. Food Res. 2010, 54, 37-59. [CrossRef]

277. Bansode, R.R.; Randolph, P.; Ahmedna, M.; Hurley, S.; Hanner, T.; Baxter, S.A.S.; Johnston, T.A.; Su, M.; Holmes, B.M.; Yu, J.; et al. Bioavailability of polyphenols from peanut skin extract associated with plasma lipid lowering function. Food Chem. 2014, 148, 24-29. [CrossRef]

278. Yin, M.; Zhang, P.; Yu, F.; Zhang, Z.; Cai, Q.; Lu, W.; Li, B.; Qin, W.; Cheng, M.; Wang, H.; et al. Grape seed procyanidin B2 ameliorates hepatic lipid metabolism disorders in db/db mice. Mol. Med. Rep. 2017, 16, 2844-2850. [CrossRef]

279. Xing, Y.W.; Wu, Q.H.; Jiang, Y.; Huang, M.X.; Lei, G.T. Procyanidin B2 protects against diet-induced obesity and nonalcoholic fatty liver disease via the modulation of the gut microbiota in rabbits. World J. Gastroenterol. 2019, 25, 955-966. [CrossRef]

280. Mildner-Szkudlarz, S.; Bajerska, J. Protective effect of grape by-product-fortified breads against cholesterol/cholic acid dietinduced hypercholesterolaemia in rats. J. Sci. Food Agric. 2013, 93, 3271-3278. [CrossRef]

281. Natella, F.; Belelli, F.; Gentili, V.; Ursini, F.; Scaccini, C. Grape seed proanthocyanidins prevent plasma postprandial oxidative stress in humans. J. Agric. Food Chem. 2002, 50, 7720-7725. [CrossRef]

282. Del Bas, J.M.; Ricketts, M.L.; Baiges, I.; Quesada, H.; Ardevol, A.; Salvadó, M.J.; Pujadas, G.; Blay, M.; Arola, L.; Bladé, C.; et al. Dietary procyanidins lower triglyceride levels signaling through the nuclear receptor small heterodimer partner. Mol. Nutr. Food Res. 2008, 52, 1172-1181. [CrossRef]

283. Del Bas, J.M.; Ricketts, M.L.; Vaqué, M.; Sala, E.; Quesada, H.; Ardevol, A.; Salvadó, M.J.; Blay, M.; Arola, L.; Moore, D.D.; et al. Dietary procyanidins enhance transcriptional activity of bile acid-activated FXR in vitro and reduce triglyceridemia in vivo in a FXR-dependent manner. Mol. Nutr. Food Res. 2009, 53, 805-814. [CrossRef]

284. Quesada, H.; Del Bas, J.M.; Pajuelo, D.; Díaz, S.; Fernandez-Larrea, J.; Pinent, M.; Arola, L.; Salvadó, M.J.; Bladé, C. Grape seed proanthocyanidins correct dyslipidemia associated with a high-fat diet in rats and repress genes controlling lipogenesis and VLDL assembling in liver. Int. J. Obes. 2009, 33, 1007-1012. [CrossRef]

285. Adisakwattana, S.; Moonrat, J.; Srichairat, S.; Chanasit, C.; Tirapongporn, H.; Chanathong, B.; Ngamukote, S.; Mäkynen, K.; Sapwarobol, S. Lipid-lowering mechanisms of grape seed extract (Vitis vinifera L.) and its antihyperlidemic activity. J. Med. Plants Res. 2010, 4, 2113-2120.

286. Jiao, R.; Zhang, Z.; Yu, H.; Huang, Y.; Chen, Z.Y. Hypocholesterolemic activity of grape seed proanthocyanidin is mediated by enhancement of bile acid excretion and up-regulation of CYP7A1. J. Nutr. Biochem. 2010, 21, 1134-1139. [CrossRef]

287. Pajuelo, D.; Díaz, S.; Quesada, H.; Fernández-Iglesias, A.; Mulero, M.; Arola-Arnal, A.; Salvadó, M.J.; Bladé, C.; Arola, L. Acute administration of grape seed proanthocyanidin extract modulates energetic metabolism in skeletal muscle and BAT mitochondria. J. Agric. Food Chem. 2011, 59, 4279-4287. [CrossRef]

288. Baselga-Escudero, L.; Arola-Arnal, A.; Pascual-Serrano, A.; Ribas-Latre, A.; Casanova, E.; Salvadó, M.J.; Arola, L.; Blade, C. Chronic Administration of Proanthocyanidins or Docosahexaenoic Acid Reversess the Increase of miR-33a and miR-122 in Dyslipidemic Obese Rats. PLoS ONE 2013, 8, e69817. [CrossRef]

289. Guerrero, L.; Margalef, M.; Pons, Z.; Quiñones, M.; Arola, L.; Arola-Arnal, A.; Muguerza, B. Serum metabolites of proanthocyanidin-administered rats decrease lipid synthesis in HepG2 cells. J. Nutr. Biochem. 2013, 24, 2092-2099. [CrossRef]

290. Caimari, A.; Del Bas, J.M.; Crescenti, A.; Arola, L. Low doses of grape seed procyanidins reduce adiposity and improve the plasma lipid profile in hamsters. Int. J. Obes. 2013, 37, 576-583. [CrossRef] [PubMed] 
291. Hintz, R.; Caiozzi, G.; Ricketts, M. A grape seed procyanidin extract lowers serum triglyceride levels via selective modulation of intestinal FXR-target gene expression and inhibition of enterohepatic bile acid recirculation. FASEB J. 2014, 28, 1045.35. [CrossRef]

292. Downing, L.E.; Heidker, R.M.; Caiozzi, G.C.; Wong, B.S.; Rodriguez, K.; Del Rey, F.; Ricketts, M.L. A grape seed procyanidin extract ameliorates fructose-induced hypertriglyceridemia in rats via enhanced fecal bile acid and cholesterol excretion and inhibition of hepatic lipogenesis. PLoS ONE 2015, 10, e0140267. [CrossRef] [PubMed]

293. Baselga-Escudero, L.; Pascual-Serrano, A.; Ribas-Latre, A.; Casanova, E.; Salvadó, M.J.; Arola, L.; Arola-Arnal, A.; Bladé, C. Long-term supplementation with a low dose of proanthocyanidins normalized liver miR-33a and miR-122 levels in high-fat diet-induced obese rats. Nutr. Res. 2015, 35, 337-345. [CrossRef]

294. Heidker, R.M.; Caiozzi, G.C.; Ricketts, M.L. Grape seed procyanidins and cholestyramine differentially alter bile acid and cholesterol homeostatic gene expression in mouse intestine and liver. PLoS ONE 2016, 11, e0154305. [CrossRef]

295. Shi, Y.; Jia, M.; Xu, L.; Fang, Z.; Wu, W.; Zhang, Q.; Chung, P.; Lin, Y.; Wang, S.; Zhang, Y. miR-96 and autophagy are involved in the beneficial effect of grape seed proanthocyanidins against high-fat-diet-induced dyslipidemia in mice. Phyther. Res. 2019, 33, 1222-1232. [CrossRef]

296. Gonçalves, M.C.; Passos, M.C.F.; de Oliveira, C.F.; Daleprane, J.B.; Koury, J.C. Effects of proanthocyanidin on oxidative stress biomarkers and adipokines in army cadets: A placebo-controlled, double-blind study. Eur. J. Nutr. 2017, 56, 893-900. [CrossRef]

297. Senault, C.; Betoulle, D.; Luc, G.; Hauw, P.; Rigaud, D.; Fumeron, F. Beneficial effects of a moderate consumption of red wine on cellular cholesterol efflux in young men. Nutr. Metab. Cardiovasc. Dis. 2000, 10, 63-69.

298. Pal, S.; Naissides, M.; Mamo, J. Polyphenolics and fat absorption. Int. J. Obes. 2004, 28, 324-326. [CrossRef]

299. Sugiyama, H.; Akazome, Y.; Shoji, T.; Yamaguchi, A.; Yasue, M.; Kanda, T.; Ohtake, Y. Oligomeric procyanidins in apple polyphenol are main active components for inhibition of pancreatic lipase and triglyceride absorption. J. Agric. Food Chem. 2007, 55, 4604-4609. [CrossRef]

300. Mursu, J.; Voutilainen, S.; Nurmi, T.; Rissanen, T.H.; Virtanen, J.K.; Kaikkonen, J.; Nyyssönen, K.; Salonen, J.T. Dark chocolate consumption increases HDL cholesterol concentration and chocolate fatty acids may inhibit lipid peroxidation in healthy humans. Free Radic. Biol. Med. 2004, 37, 1351-1359. [CrossRef]

301. Mellor, D.D.; Sathyapalan, T.; Kilpatrick, E.S.; Beckett, S.; Atkin, S.L. High-cocoa polyphenol-rich chocolate improves HDL cholesterol in Type 2 diabetes patients. Diabet. Med. 2010, 27, 1318-1321. [CrossRef]

302. Tokede, O.A.; Gaziano, J.M.; Djoussé, L. Effects of cocoa products/dark chocolate on serum lipids: A meta-analysis. Eur. J. Clin. Nutr. 2011, 65, 879-886. [CrossRef]

303. Yokozawa, T.; Hyun, J.K.; Eun, J.C. Gravinol ameliorates high-fructose-induced metabolic syndrome through regulation of lipid metabolism and proinflammatory state in rats. J. Agric. Food Chem. 2008, 56, 5026-5032. [CrossRef]

304. Yasuda, A.; Natsume, M.; Sasaki, K.; Baba, S.; Nakamura, Y.; Kanegae, M.; Nagaoka, S. Cacao procyanidins reduce plasma cholesterol and increase fecal steroid excretion in rats fed a high-cholesterol diet. BioFactors 2008, 33, 211-223. [CrossRef]

305. Ngamukote, S.; Mäkynen, K.; Thilawech, T.; Adisakwattana, S. Cholesterol-lowering activity of the major polyphenols in grape seed. Molecules 2011, 16, 5054-5061. [CrossRef]

306. Tamura, T.; Inoue, N.; Ozawa, M.; Shimizu-Ibuka, A.; Arai, S.; Abe, N.; Koshino, H.; Mura, K. Peanut-skin polyphenols, procyanidin A1 and epicatechin-( $4 \beta \rightarrow 6)$ - epicatechin- $(2 \beta \rightarrow \mathrm{O} \rightarrow 7,4 \beta \rightarrow 8)$-catechin, exert cholesterol micelle-degrading activity in vitro. Biosci. Biotechnol. Biochem. 2013, 77, 1306-1309. [CrossRef]

307. Quesada, H.; Díaz, S.; Pajuelo, D.; Fernández-Iglesias, A.; Garcia-Vallvé, S.; Pujadas, G.; Salvadó, M.J.; Arola, L.; Bladé, C. The lipid-lowering effect of dietary proanthocyanidins in rats involves both chylomicron-rich and VLDL-rich fractions. Br. J. Nutr. 2012, 108, 208-217. [CrossRef]

308. Vidal, R.; Hernandez-Vallejo, S.; Pauquai, T.; Texier, O.; Rousset, M.; Chambaz, J.; Demignot, S.; Lacorte, J.M. Apple procyanidins decrease cholesterol esterification and lipoprotein secretion in Caco-2/TC7 enterocytes. J. Lipid Res. 2005, 46, 258-268. [CrossRef]

309. Pal, S.; Ho, S.S.; Takechi, R. Red wine polyphenolics suppress the secretion of ApoB48 from human intestinal CaCo-2 cells. J. Agric. Food Chem. 2005, 53, 2767-2772. [CrossRef]

310. Liu, W.; Zhao, S.; Wang, J.; Shi, J.; Sun, Y.; Wang, W.; Ning, G.; Hong, J.; Liu, R. Grape seed proanthocyanidin extract ameliorates inflammation and adiposity by modulating gut microbiota in high-fat diet mice. Mol. Nutr. Food Res. 2017, 61, 1601082. [CrossRef] [PubMed]

311. Aragonès, G.; Suárez, M.; Ardid-Ruiz, A.; Vinaixa, M.; Rodríguez, M.A.; Correig, X.; Arola, L.; Bladé, C. Dietary proanthocyanidins boost hepatic NAD + metabolism and SIRT1 expression and activity in a dose-dependent manner in healthy rats. Sci. Rep. 2016, 6, 24977. [CrossRef]

312. Shimada, T.; Tokuhara, D.; Tsubata, M.; Kamiya, T.; Kamiya-Sameshima, M.; Nagamine, R.; Takagaki, K.; Sai, Y.; Miyamoto, K.I.; Aburada, M. Flavangenol (pine bark extract) and its major component procyanidin B1 enhance fatty acid oxidation in fat-loaded models. Eur. J. Pharmacol. 2012, 677, 147-153. [CrossRef]

313. Bansode, R.R.; Randolph, P.; Hurley, S.; Ahmedna, M. Evaluation of hypolipidemic effects of peanut skin-derived polyphenols in rats on Western-diet. Food Chem. 2012, 135, 1659-1666. [CrossRef] [PubMed]

314. Su, H.; Li, Y.; Hu, D.; Xie, L.; Ke, H.; Zheng, X.; Chen, W. Procyanidin B2 ameliorates free fatty acids-induced hepatic steatosis through regulating TFEB-mediated lysosomal pathway and redox state. Free Radic. Biol. Med. 2018, 126, 269-286. [CrossRef] [PubMed] 
315. Baiges, I.; Palmfeldt, J.; Bladé, C.; Gregersen, N.; Arola, L. Lipogenesis is decreased by grape seed proanthocyanidins according to liver proteomics of rats fed a high fat diet. Mol. Cell. Proteom. 2010, 9, 1499-1513. [CrossRef] [PubMed]

316. Bagchi, D.; Sen, C.K.; Ray, S.D.; Das, D.K.; Bagchi, M.; Preuss, H.G.; Vinson, J.A. Molecular mechanisms of cardioprotection by a novel grape seed proanthocyanidin extract. Mutat. Res. Fundam. Mol. Mech. Mutagenesis 2003, 523-524, 87-97. [CrossRef]

317. Baselga-Escudero, L.; Bladé, C.; Ribas-Latre, A.; Casanova, E.; Salvadó, M.J.; Arola, L.; Arola-Arnal, A. Grape seed proanthocyanidins repress the hepatic lipid regulators miR-33 and miR-122 in rats. Mol. Nutr. Food Res. 2012, 56, 1636-1646. [CrossRef]

318. Zou, B.; Nie, R.; Zeng, J.; Ge, Z.; Xu, Z.; Li, C. Persimmon tannin alleviates hepatic steatosis in L02 cells by targeting miR-122 and miR-33b and its effects closely associated with the A type ECG dimer and EGCG dimer structural units. J. Funct. Foods 2014, 11, 330-341. [CrossRef]

319. Sommella, E.; Badolati, N.; Riccio, G.; Salviati, E.; Bottone, S.; Dentice, M.; Campiglia, P.; Tenore, G.C.; Stornaiuolo, M.; Novellino, E. A boost in mitochondrial activity underpins the cholesterol-lowering effect of annurca apple polyphenols on hepatic cells. Nutrients 2019, 11, 163. [CrossRef]

320. Sankar, J.; Rathinavel, A.; Mohammed Sadullah, S.S.; Devaraj, S.N. Oligomeric proanthocyanidins mitigate cholesterol and cholic acid diet-induced hepatic dysfunction in male Sprague Dawley rats. J. Biochem. Mol. Toxicol. 2019, 33, e22234. [CrossRef]

321. Moreno, D.A.; Ilic, N.; Poulev, A.; Brasaemle, D.L.; Fried, S.K.; Raskin, I. Inhibitory effects of grape seed extract on lipases. Nutrition 2003, 19, 876-879. [CrossRef]

322. Hassan, H.M. Inhibitory Effects of Red Grape Seed Extracts on Pancreatic $\alpha$-amylase and Lipase. Glob. J. Biotech. Biochem 2014, 9 , 130-136.

323. Wang, S.; Dong, S.; Zhang, R.; Shao, H.; Liu, Y. Effects of proanthocyanidins on porcine pancreatic lipase: Conformation, activity, kinetics and thermodynamics. Process Biochem. 2014, 49, 237-243. [CrossRef]

324. Gu, Y.; Hurst, W.J.; Stuart, D.A.; Lambert, J.D. Inhibition of key digestive enzymes by cocoa extracts and procyanidins. J. Agric. Food Chem. 2011, 59, 5305-5311. [CrossRef]

325. Castell-Auví, A.; Cedó, L.; Pallarès, V.; Blay, M.; Pinent, M.; Ardévol, A. Grape seed procyanidins improve $\beta$-cell functionality under lipotoxic conditions due to their lipid-lowering effect. J. Nutr. Biochem. 2013, 24, 948-953. [CrossRef]

326. Pascual-Serrano, A.; Arola-Arnal, A.; Suárez-García, S.; Bravo, F.I.; Suárez, M.; Arola, L.; Bladé, C. Grape seed proanthocyanidin supplementation reduces adipocyte size and increases adipocyte number in obese rats. Int. J. Obes. 2017, 41, 1246-1255. [CrossRef]

327. Pascual-Serrano, A.; Bladé, C.; Suárez, M.; Arola-Arnal, A. Grape seed proanthocyanidins improve white adipose tissue expansion during diet-induced obesity development in rats. Int. J. Mol. Sci. 2018, 19, 2632. [CrossRef]

328. Wei, S.; Zheng, Y.; Zhang, M.; Zheng, H.; Yan, P. Grape seed procyanidin extract inhibits adipogenesis and stimulates lipolysis of porcine adipocytes in vitro. J. Anim. Sci. 2018, 96, 2753-2762. [CrossRef]

329. Ardévol, A.; Motilva, M.J.; Serra, A.; Blay, M.; Pinent, M. Procyanidins target mesenteric adipose tissue in Wistar lean rats and subcutaneous adipose tissue in Zucker obese rat. Food Chem. 2013, 141, 160-166. [CrossRef]

330. Shankar, K.; Kumar, D.; Gupta, S.; Varshney, S.; Rajan, S.; Srivastava, A.; Gupta, A.; Gupta, A.P.; Vishwakarma, A.L.; Gayen, J.R.; et al. Role of brown adipose tissue in modulating adipose tissue inflammation and insulin resistance in highfat diet fed mice. Eur. J. Pharmacol. 2019, 854, 354-364. [CrossRef]

331. Pajuelo, D.; Quesada, H.; Díaz, S.; Fernández-Iglesias, A.; Arola-Arnal, A.; Bladé, C.; Salvadó, J.; Arola, L. Chronic dietary supplementation of proanthocyanidins corrects the mitochondrial dysfunction of brown adipose tissue caused by diet-induced obesity in Wistar rats. Br. J. Nutr. 2012, 107, 170-178. [CrossRef]

332. Liu, M.; Yun, P.; Hu, Y.; Yang, J.; Khadka, R.B.; Peng, X. Effects of Grape Seed Proanthocyanidin Extract on Obesity. Obes. Facts 2020, 13, 279-291. [CrossRef]

333. Jeong, Y.S.; Hong, J.H.; Cho, K.H.; Jung, H.K. Grape skin extract reduces adipogenesis- and lipogenesis-related gene expression in 3T3-L1 adipocytes through the peroxisome proliferator-activated receptor- $\gamma$ signaling pathway. Nutr. Res. 2012, 32, 514-521. [CrossRef]

334. Yang, K.; Gitter, B.; Rüger, R.; Albrecht, V.; Wieland, G.D.; Fahr, A. Wheat germ agglutinin modified liposomes for the photodynamic inactivation of bacteria. Photochem. Photobiol. 2012, 88, 548-556. [CrossRef]

335. Kowalska, K.; Olejnik, A.; Rychlik, J.; Grajek, W. Cranberries (Oxycoccus quadripetalus) inhibit lipid metabolism and modulate leptin and adiponectin secretion in 3T3-L1 adipocytes. Food Chem. 2015, 185, 383-388. [CrossRef]

336. Zhang, J.; Huang, Y.; Shao, H.; Bi, Q.; Chen, J.; Ye, Z. Grape seed procyanidin B2 inhibits adipogenesis of 3T3-L1 cells by targeting peroxisome proliferator-activated receptor $\gamma$ with miR-483-5p involved mechanism. Biomed. Pharmacother. 2017, 86, 292-296. [CrossRef] [PubMed]

337. Ouchi, N.; Parker, J.L.; Lugus, J.J.; Walsh, K. Adipokines in inflammation and metabolic disease. Nat. Rev. Immunol. 2011, 11, 85-97. [CrossRef] [PubMed]

338. Barbe, A.; Mellouk, N.; Ramé, C.; Grandhaye, J.; Staub, C.; Venturi, E.; Cirot, M.; Petit, A.; Anger, K.; Chahnamian, M.; et al. A grape seed extract maternal dietary supplementation in reproductive hens reduces oxidative stress associated to modulation of plasma and tissue adipokines expression and improves viability of offsprings. PLoS ONE 2020, 15, e0231131. [CrossRef] [PubMed]

339. Crescenti, A.; del Bas, J.M.; Arola-Arnal, A.; Oms-Oliu, G.; Arola, L.; Caimari, A. Grape seed procyanidins administered at physiological doses to rats during pregnancy and lactation promote lipid oxidation and up-regulate AMPK in the muscle of male offspring in adulthood. J. Nutr. Biochem. 2015, 26, 912-920. [CrossRef] [PubMed] 
340. Del Bas, J.M.; Crescenti, A.; Arola-Arnal, A.; Oms-Oliu, G.; Arola, L.; Caimari, A. Grape seed procyanidin supplementation to rats fed a high-fat diet during pregnancy and lactation increases the body fat content and modulates the inflammatory response and the adipose tissue metabolism of the male offspring in youth. Int. J. Obes. 2015, 39, 7-15. [CrossRef]

341. Caimari, A.; Mariné-Casadó, R.; Boqué, N.; Crescenti, A.; Arola, L.; Del Bas, J.M. Maternal intake of grape seed procyanidins during lactation induces insulin resistance and an adiponectin resistance-like phenotype in rat offspring. Sci. Rep. 2017, 7, 12573. [CrossRef]

342. Vinson, J.A.; Jang, J.; Dabbagh, Y.A.; Serry, M.M.; Cai, S. Plant Polyphenols Exhibit Lipoprotein-Bound Antioxidant Activity Using an in Vitro Oxidation Model for Heart Disease. J. Agric. Food Chem. 1995, 43, 2798-2799. [CrossRef]

343. Wang, T.K.; Xu, S.; Li, S.; Zhang, Y. Proanthocyanidins Should Be a Candidate in the Treatment of Cancer, Cardiovascular Diseases and Lipid Metabolic Disorder. Molecules 2020, 25, 5971. [CrossRef]

344. Bearden, M.M.; Pearson, D.A.; Rein, D.; Chevaux, K.A.; Carpenter, D.R.; Keen, C.L.; Schmitz, H. Potential cardiovascular health benefits of procyanidins present in chocolate and cocoa. ACS Symp. Ser. 2000, 754, 177-186.

345. Frankel, E.N.; German, J.B.; Kinsella, J.E.; Parks, E.; Kanner, J. Inhibition of oxidation of human low-density lipoprotein by phenolic substances in red wine. Lancet 1993, 341, 454-457. [CrossRef]

346. Natella, F.; Ghiselli, A.; Guidi, A.; Ursini, F.; Scaccini, C. Red wine mitigates the postprandial increase of LDL susceptibility to oxidation. Free Radic. Biol. Med. 2001, 30, 1036-1044. [CrossRef]

347. Brunet, M.J.; Bladé, C.; Salvadó, M.J.; Arola, L. Human apo A-I and rat transferrin are the principal plasma proteins that bind wine catechins. J. Agric. Food Chem. 2002, 50, 2708-2712. [CrossRef]

348. Kim, Y.; Choi, Y.; Ham, H.; Jeong, H.S.; Lee, J. Protective effects of oligomeric and polymeric procyanidin fractions from defatted grape seeds on tert-butyl hydroperoxide-induced oxidative damage in HepG2 cells. Food Chem. 2013, 137, 136-141. [CrossRef]

349. Na, H.K.; Kim, E.H.; Jung, J.H.; Lee, H.H.; Hyun, J.W.; Surh, Y.J. (-)-Epigallocatechin gallate induces Nrf2-mediated antioxidant enzyme expression via activation of PI3K and ERK in human mammary epithelial cells. Arch. Biochem. Biophys. 2008, 476, 171-177. [CrossRef]

350. Danese, S.; Sans, M.; Fiocchi, C. Inflammatory bowel disease: The role of environmental factors. Autoimmun. Rev. 2004, 3, 394-400. [CrossRef]

351. Kaplan, G.G.; Ng, S.C. Understanding and Preventing the Global Increase of Inflammatory Bowel Disease. Gastroenterology 2017, 152, 313-321. [CrossRef]

352. Mannino, G.; Caradonna, F.; Cruciata, I.; Lauria, A.; Perrone, A.; Gentile, C. Melatonin reduces inflammatory response in human intestinal epithelial cells stimulated by interleukin-1ß. J. Pineal Res. 2019, 67, e12598. [CrossRef]

353. Xu, H.; Zhao, C.; Li, Y.; Liu, R.; Ao, M.; Li, F.; Yao, Y.; Tao, Z.; Yu, L. The ameliorative effect of the: Pyracantha fortuneana (Maxim.) H. L. Li extract on intestinal barrier dysfunction through modulating glycolipid digestion and gut microbiota in high fat diet-fed rats. Food Funct. 2019, 10, 6517-6532. [CrossRef]

354. Gil-Cardoso, K.; Ginés, I.; Pinent, M.; Ardévol, A.; Arola, L.; Blay, M.; Terra, X. Chronic supplementation with dietary proanthocyanidins protects from diet-induced intestinal alterations in obese rats. Mol. Nutr. Food Res. 2017, 61, 1-38. [CrossRef]

355. Gil-Cardoso, K.; Comitato, R.; Ginés, I.; Ardévol, A.; Pinent, M.; Virgili, F.; Terra, X.; Blay, M. Protective Effect of Proanthocyanidins in a Rat Model of Mild Intestinal Inflammation and Impaired Intestinal Permeability Induced by LPS. Mol. Nutr. Food Res. 2019, 63, 1-10. [CrossRef]

356. Bibi, S.; Kang, Y.; Yang, G.; Zhu, M.J. Grape seed extract improves small intestinal health through suppressing inflammation and regulating alkaline phosphatase in IL-10-deficient mice. J. Funct. Foods 2016, 20, 245-252. [CrossRef]

357. González-Quilen, C.; Rodríguez-Gallego, E.; Beltrán-Debón, R.; Pinent, M.; Ardévol, A.; Blay, M.T.; Terra, X. Health-promoting properties of proanthocyanidins for intestinal dysfunction. Nutrients 2020, 12, 130. [CrossRef]

358. Terra, X.; Pallarés, V.; Ardèvol, A.; Bladé, C.; Fernández-Larrea, J.; Pujadas, G.; Salvadó, J.; Arola, L.; Blay, M. Modulatory effect of grape-seed procyanidins on local and systemic inflammation in diet-induced obesity rats. J. Nutr. Biochem. 2011, 22, 380-387. [CrossRef]

359. Li, X.; Yang, X.; Cai, Y.; Qin, H.; Wang, L.; Wang, Y.; Huang, Y.; Wang, X.; Yan, S.; Wang, L.; et al. Proanthocyanidins from grape seeds modulate the NF- $\mathrm{B}$ signal transduction pathways in rats with tnbs-induced ulcerative colitis. Molecules 2011, 16, 6721-6731. [CrossRef] [PubMed]

360. Chen, L.; You, Q.; Hu, L.; Gao, J.; Meng, Q.; Liu, W.; Wu, X.; Xu, Q. The Antioxidant Procyanidin reduces reactive oxygen species signaling in macrophages and ameliorates experimental colitis in mice. Front. Immunol. 2018, 8, 1-13. [CrossRef]

361. Wang, Y.H.; Ge, B.; Yang, X.L.; Zhai, J.; Yang, L.N.; Wang, X.X.; Liu, X.; Shi, J.C.; Wu, Y.J. Proanthocyanidins from grape seeds modulates the nuclear factor-kappa B signal transduction pathways in rats with TNBS-induced recurrent ulcerative colitis. Int. Immunopharmacol. 2011, 11, 1620-1627. [CrossRef]

362. Wu, H.; Luo, T.; Li, Y.M.; Gao, Z.P.; Zhang, K.Q.; Song, J.Y.; Xiao, J.S.; Cao, Y.P. Granny Smith apple procyanidin extract upregulates tight junction protein expression and modulates oxidative stress and inflammation in lipopolysaccharide-induced Caco-2 cells. Food Funct. 2018, 9, 3321-3329. [CrossRef] [PubMed]

363. Bitzer, Z.T.; Glisan, S.L.; Dorenkott, M.R.; Goodrich, K.M.; Ye, L.; O’Keefe, S.F.; Lambert, J.D.; Neilson, A.P. Cocoa procyanidins with different degrees of polymerization possess distinct activities in models of colonic inflammation. J. Nutr. Biochem. 2015, 26, 827-831. [CrossRef] 
364. Denis, M.C.; Desjardins, Y.; Furtos, A.; Marcil, V.; Dudonné, S.; Montoudis, A.; Garofalo, C.; Delvin, E.; Marette, A.; Levy, E. Prevention of oxidative stress, inflammation and mitochondrial dysfunction in the intestine by different cranberry phenolic fractions. Clin. Sci. 2015, 128, 197-212. [CrossRef]

365. Erlejman, A.G.; Verstraeten, S.V.; Fraga, C.G.; Oteiza, P.I. The interaction of flavonoids with membranes: Potential determinant of flavonoid antioxidant effects. Free Radic. Res. 2004, 38, 1311-1320. [CrossRef]

366. Oteiza, P.I.; Erlejman, A.G.; Verstraeten, S.V.; Keen, C.L.; Fraga, C.G. Flavonoid-membrane interactions: A protective role of flavonoids at the membrane surface? Clin. Dev. Immunol. 2005, 12, 19-25. [CrossRef]

367. Verstraeten, S.V.; Jaggers, G.K.; Fraga, C.G.; Oteiza, P.I. Procyanidins can interact with Caco-2 cell membrane lipid rafts: Involvement of cholesterol. Biochim. Biophys. Acta Biomembr. 2013, 1828, 2646-2653. [CrossRef] 